\title{
Hanna Sjöholm
}

Assessments and Risk Factors for Falls in Persons with Acute Stroke
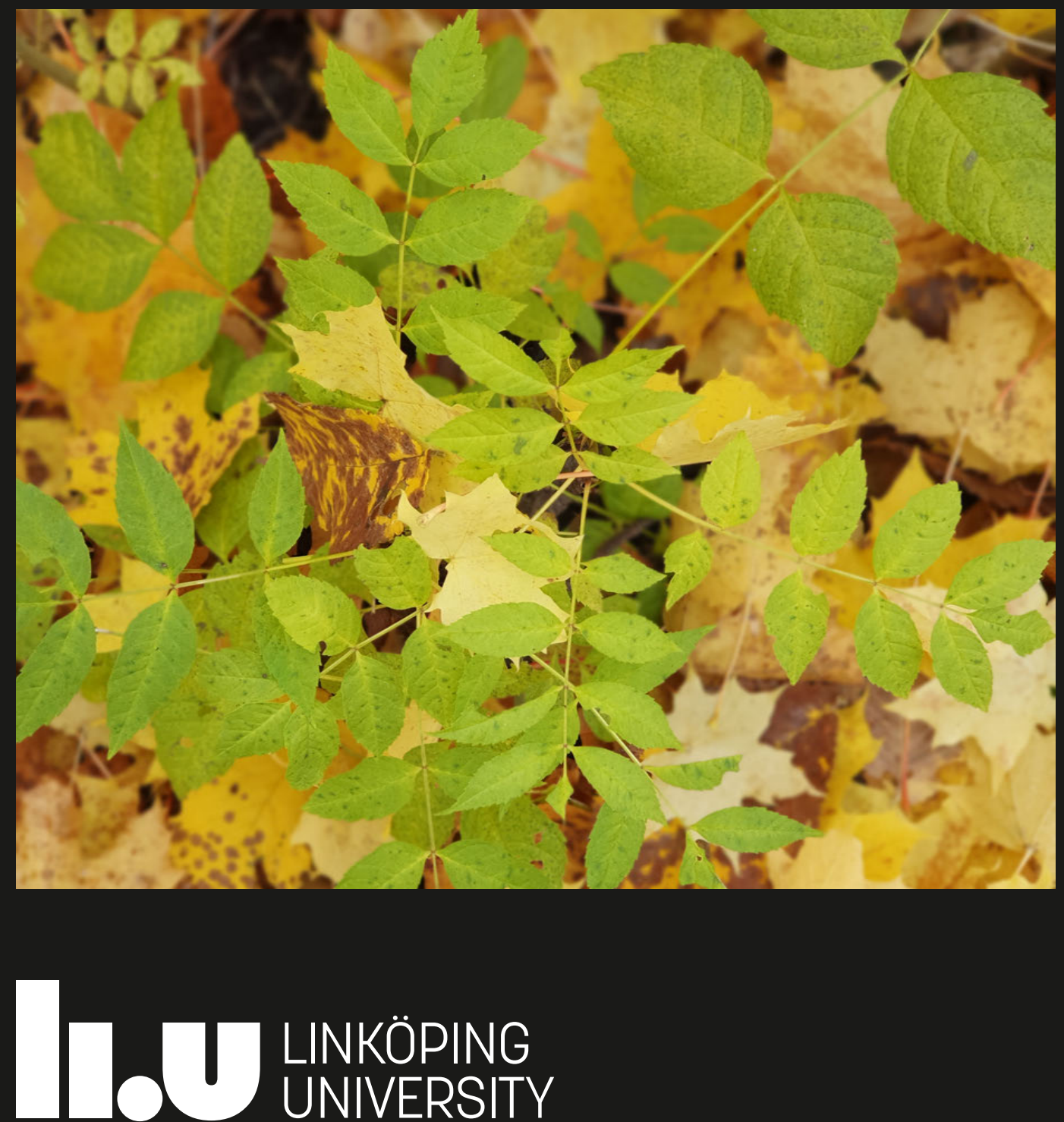

LINKÖPING UNIVERSITY 



\title{
Assessments and Risk Factors for Falls in Persons with Acute Stroke
}

\author{
Hanna Sjöholm
}

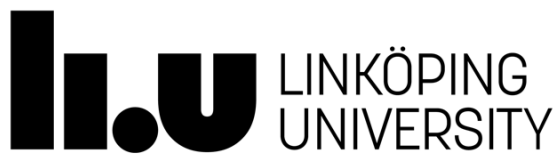

Department of Health, Medicine and Caring Sciences

Linköping University, Sweden

Linköping 2021 
(cc) EY-NC This work is licensed under a Creative Commons AttributionNonCommercial 4.0 International License.

https://creativecommons.org/licenses/by-nc/4.0/

(C) Hanna Sjöholm, 2021

Published papers have been reprinted with the permission of the copyright holder.

Printed in Sweden by LiU-Tryck, Linköping, Sweden, 2021

ISBN 978-91-7929-706-0

ISSN 0345-0082 
To Hilma, Tyra and Otto (I do really not expect you to read it)

Try to make someone happy every day, even if it's only yourself Unknown person 



\section{CONTENTS}

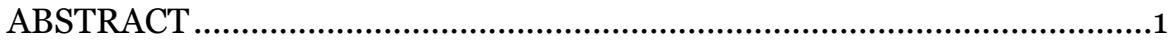

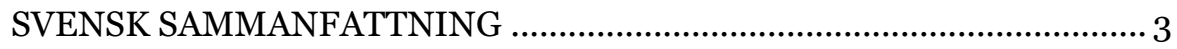

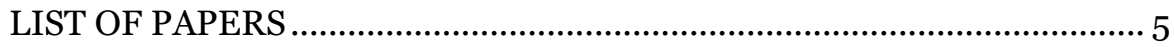

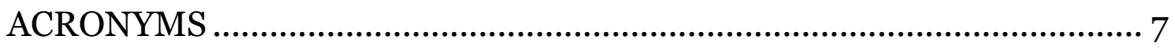

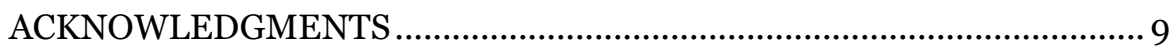

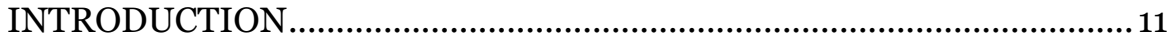

Stroke

Incidence and prevalence ..................................................................... 11

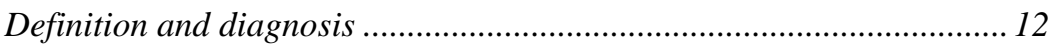

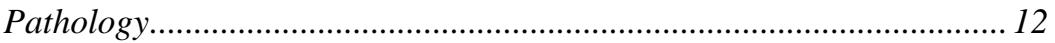

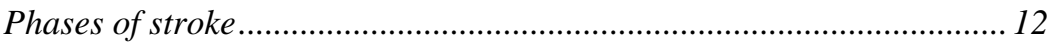

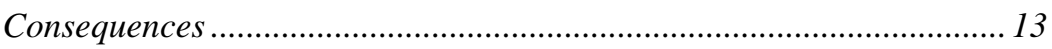

Falls..................................................................................................

Incidence and prevalence .................................................................... 13

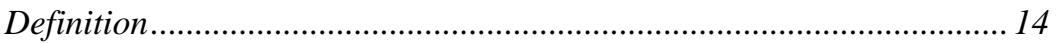

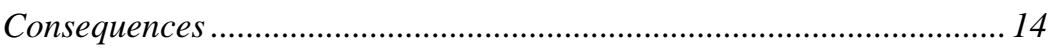

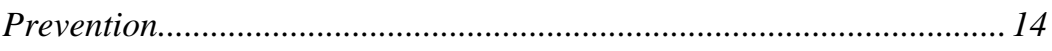

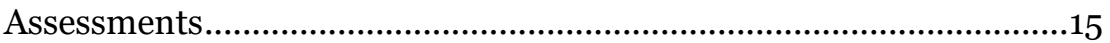

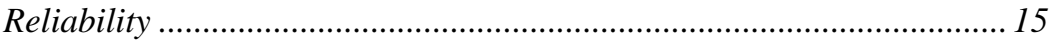

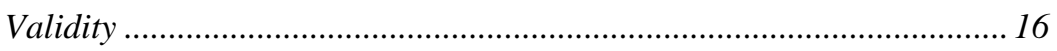

Risk factors for falls...............................................................................

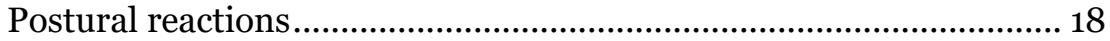

Obstacle avoidance and attention during gait activities .......................20

Sex differences in stroke and falls ....................................................... 21

Rationale of the thesis .......................................................................... 22

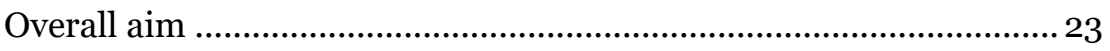

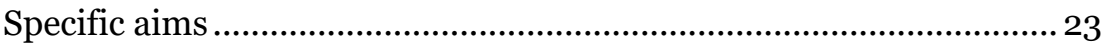

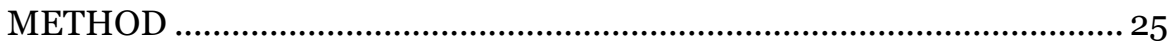


Overview of the studies ........................................................... 25

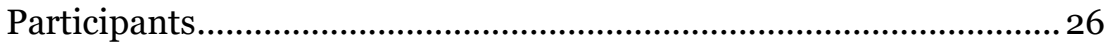

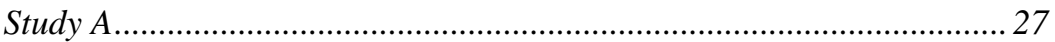

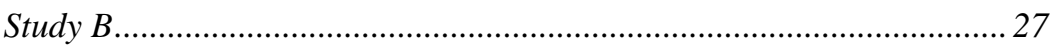

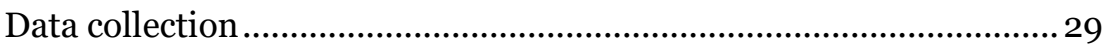

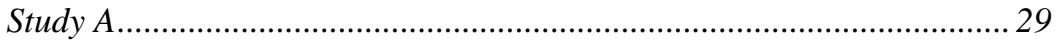

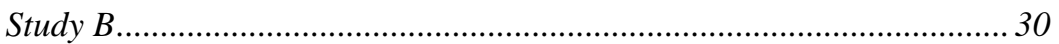

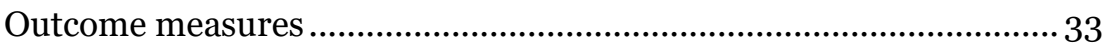

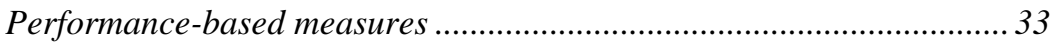

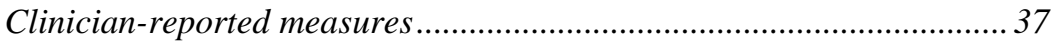

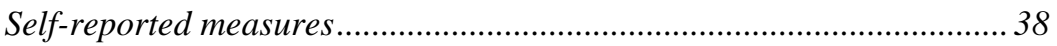

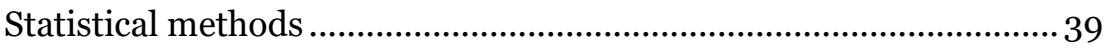

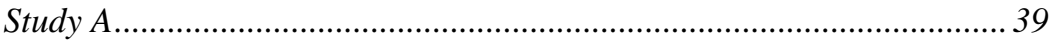

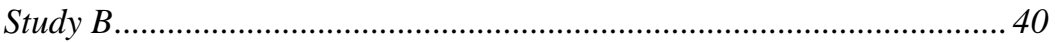

Ethical considerations ........................................................... 42

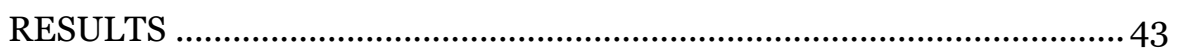

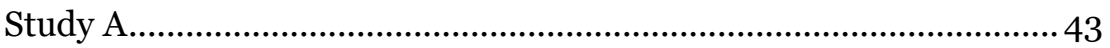

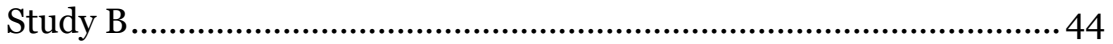

The Postural Reactions Test...................................................................... 44

The Cone Evasion Walk Test .................................................................... 46

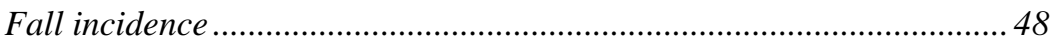

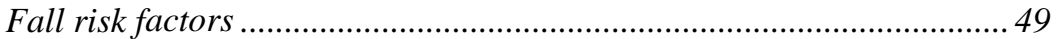

Falls during stroke unit stay.............................................................5 59

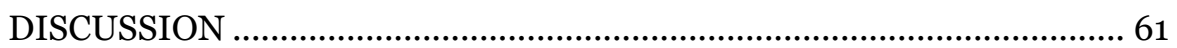

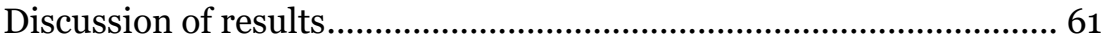

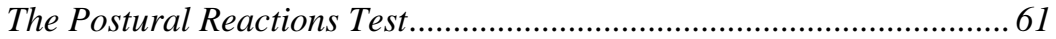

The Cone Evasion Walk Test .................................................................. 62

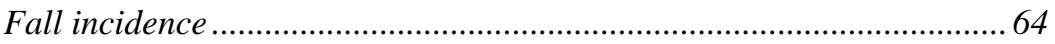

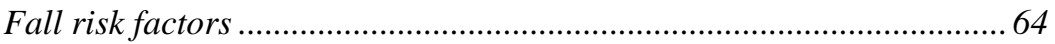

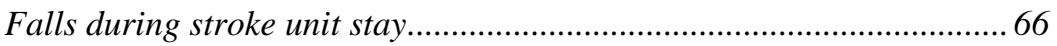

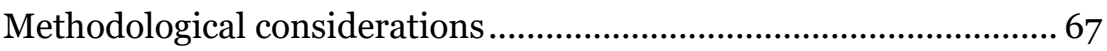

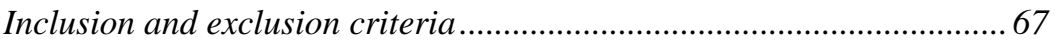


Development of the Postural Reactions Test......................................... 68

Development of the Cone Evasion Walk Test...................................... 68

Assessment of reliability in persons with acute stroke .......................... 69

Assessment of validity in persons with acute stroke............................. 69

Assessment of functions and activities in persons with acute stroke ...... 70

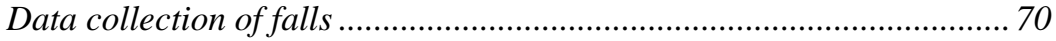

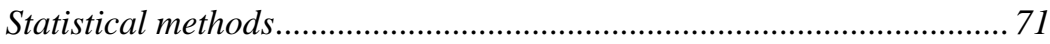

Clinical implications............................................................. 72

Future research ….................................................................... 74

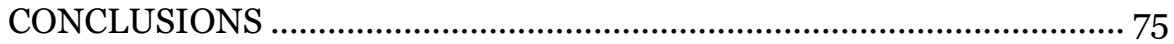

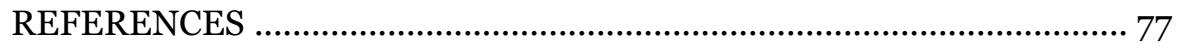





\section{ABSTRACT}

Background: Early identification of risk factors is crucial for reducing the high fall risk associated with stroke, and sex differences in relation to falls need to be further investigated. There is a lack of uniform, standardized, and reliable testing procedures for postural reactions, and existing tests assessing negotiating obstacles while walking cannot be performed when walking aids are used.

Aim: To investigate the predictive validity of fall risk in persons with acute stroke for easily administered data and assessments, as well as to investigate the psychometric properties of two new tests.

Methods: The Postural Rections Test (PRT) and the Cone Evasion Walk Test (CEW) were developed based on literature, and on input from an expert panel. To estimate the reliability of the PRT and CEW, videorecordings of 20 persons with acute stroke performing each item in the PRT and CEW were assessed by 10 physiotherapists on two occasions, at least two weeks apart. The construct validity of the CEW $(n=221)$, was examined in relation to selected corresponding tests, and predictive validity by correlating the CEW to falls within six months. In 124 women and 160 men the results from the PRT and CEW, along with other easily administered data and assessments on participant characteristics, functions, and activities were analyzed in relation to the number of days to the first fall by Cox regression, while fall incidence was analyzed by negative binomial regression, both for the total cohort, and for women and men separately. Sex differences in monthly fall incidence were analyzed with Poisson regression.

Results: For the intra-rater reliability of the PRT, the overall proportion of agreement was $87-92 \%$ for the different postural reactions, and in median 9-10 out of 10 physiotherapists scored the same value for interrater reliability. In the CEW the intra-class correlation coefficients for intra-rater and inter-rater reliability were $0.88-0.98$. The results showed expected poor to moderate correlations to the selected tests for construct validity, and to falls within six months. Participants touched significantly more cones on the side that was opposite to the side of their lesion. The Cox regression analysis showed that intake of more than eight medications, paresis in the arms, paresis in the legs, impaired protective reactions in sitting, and limitations in self-care activities were decisive risk factors for the time to the first fall, and according to the negative 
binomial regression, limitations in mobility activities was a decisive risk factor for high fall incidence in the total cohort $(\mathrm{p}<0.0005)$. The assessor's judgment of a person's six-month fall risk, was particularly well suited for identification of individuals with a high risk for multiple falls; however only in women when analyzed for each sex separately ( $\mathrm{p}<0.0005)$. Compared to men, a higher number of fall risk factors were identified in women, including impaired mental functions, paresis in the arms, and limitations in several activities of self-care and mobility $(\mathrm{p}<0.0005)$. In men, the most decisive fall risk factors were intake of a high number of medications, intake of antidepressants, and mobility limitations $(\mathrm{p}=0.001)$. Fall incidence during the first month from discharge was significantly higher in men compared to women.

Conclusions: The PRT and CEW can be reliably used in persons with acute stroke, and are valid for assessment of fall risk. A high quantity and wide range of rapid and easily collected data can be used for identification of persons at high risk for falls. The risk factors differed in part when analyzing the time to the first fall, and six-month fall incidence, and different fall risk factors were the most decisive when analyzed separately in women and men. Monthly fall incidence was higher in men during the first month.

Keywords: Postural reactions, attention, walking, reliability, reproducibility of results, patient outcome assessment, risk factors, accidental falls, stroke, cerebral infarction, sex differences. 


\section{SVENSK SAMMANFATTNING}

Bakgrund: Tidig identifiering av riskfaktorer för fall är av väsentlig betydelse för att minska den höga fallrisken hos personer med stroke, och kunskap om eventuella könsskillnader vad gäller riskfaktorer för fall behövs för att kunna individanpassa fallriskbedömningar och fallpreventiva insatser. Det har tidigare saknats ett enhetligt och standardiserat bedömningsförfarande för posturala reaktioner; dvs jämvikts-, upprätnings- och fallskyddsreaktioner. Det har även saknats ett bedömningsinstrument för förmågan att undvika föremål i samband med gång, som kan utföras av personer som går med gånghjälpmedel.

Syfte: Att hos personer med akut stroke undersöka prediktiv validitet av fallrisk för lättadministrerade patientdata och bedömningsinstrument, liksom att undersöka psykometriska egenskaper för två nyutvecklade tester.

Metod: Reliabilitetstestningen av Postural Reactions Test (PRT) och Cone Evasion Walk Test (CEW) utfördes genom att personer med akut stroke filmades då de utförde testerna. När alla delmoment i PRT samt CEW utförts av 20 personer vardera bedömdes testutförandena på filmerna av 10 sjukgymnaster vid två olika tillfällen, med minst två veckors mellanrum. Begreppsvaliditeten av CEW undersöktes genom att analysera samstämmigheten mellan CEW och ett antal utvalda, relaterade bedömningsinstrument. Deltagarna i studien noterade huruvida de fallit eller ej i falldagböcker och sedan samlades denna information in via månatliga telefonsamtal under sex månaders tid. Snabbt och enkelt insamlad patientdata och testresultat från lättadministrerade funktionsoch aktivitetstester analyserades i förhållande till fall både för samtliga deltagare i studien (284 stycken), men även för kvinnor och män separat. Könsskillnader i månatlig fallincidens analyserades också.

Resultat: Undersökningen av intrabedömarreliabilitet visade att samstämmigheten för de enskilda fysioterapeuterna i bedömningen av testutförandena mellan de två testtillfällena var 87-92\% för PRT och 7090\% för CEW. Undersökningen av interbedömarreliabiliteten visade att i median 9-10 av 10 fysioterapeuter gjorde samma bedömning av testutförandena av PRT, liksom av CEW. Resultaten av validitetstestingen visade ett signifikant men svagt samband mellan CEW och Timed Up and Go, Functional Ambulation Classification, Star Cancellation Test och uppmärksamhetsuppgiften "upprepa subtraktion av sju från 100" i 
Montreal Cognitive Assessment. I utförandet av CEW, gick deltagarna på signifikant fler koner på den sida som var motsatt deras hjärnskada. Ett signifikant svagt samband identifierades mellan CEW och antalet fall. I den totala kohorten var användande av fler än åtta läkemedel, armpares, benpares, nedsatta fallskyddsreaktioner i sittande, och nedsatt förmåga att utföra aktiviteter i det dagliga livet avgörande riskfaktorer för tidiga fall. En begränsad förflyttningsförmåga var en avgörande riskfaktorer för hög fallincidens. Testledarens bedömning av risken att falla de kommande 6 månaderna var särskilt väl lämpad för identifiering av personer med en hög risk för hög fallincidens, dock endast för kvinnorna när analysen utfördes för kvinnor och män separat. Fler riskfaktorer identifierades hos kvinnorna, däribland nedsatta psykiska funktioner, armpares och nedsättningar i flera olika aktiviteter rörande personlig vård och förflyttningar. Hos männen var de mest avgörande riskfaktorerna ett stort antal intagna läkemedel, användande av antidepressiva läkemedel samt en begränsad förflyttningsförmåga. Den månatliga fallincidensen var signifikant högre hos männen än hos kvinnorna den första månaden efter utskrivningen från någon av strokeavdelningarna.

Konklusion: PRT och CEW kompletterar befintliga bedömningsinstrument och är reliabla och valida för bedömning vid akut stroke. Både CEW och PRT-bedömningen av fallskyddsreaktioner i sittande kan användas för identifiering av personer med en förhöjd risk att falla. Ytterligare ett stort antal lättadministrerade bedömningsinstrument som kan användas för bedömning av fallrisk identifierades. Riskfaktorerna skiljde sig åt avseende risken att falla snart och risken att falla mycket och det var olika fallriskfaktorer som var de mest avgörande för kvinnorna jämfört med männen. Den första månaden efter utskrivning från strokeavdelning var den månatliga fallincidensen högre bland männen än bland kvinnorna. 


\section{LIST OF PAPERS}

I. Sjöholm H, Hägg S, Nyberg L, Kammerlind A-S. Reliability of test procedures for postural reactions in people with acute stroke. Int $\mathrm{J}$ Ther Rehabil. 2018;25(11):576-86.

II. Sjöholm H, Hägg S, Nyberg L, Rolander B, Kammerlind A-S. The Cone Evasion Walk Test: Reliability and validity in acute stroke. Physiother Res Int. 2019;24(1):e1744.

III. Sjöholm H, Hägg S, Nyberg L, Lind J, Kammerlind A-S. Exploring possible risk factors for time to first fall and six-month fall incidence in persons with acute stroke. Submitted 201208.

IV. Sjöholm H, Hägg S, Nyberg L, Lind J, Kammerlind A-S. Fall risk factors and monthly fall incidence in women and men with acute stroke. Manuscript. 


\section{ACRONYMS}

ADL Activities of daily living

ATC Anatomical Therapeutic Chemical Classification System

BBS Berg Balance Scale

CEW Cone Evasion Walk Test

CST $\quad 30$ s Chair Stand Test

DALY Disability-adjusted life years

EXIT Executive Interview

FAC Functional Ambulation Classification

HR Hazards Ratio

ICD International Classification of Disease

ICF International Classification of Functioning, Disability, and Health

IRR Incidence Rate Ratio

M-MAS Modified Motor Assessment Scale

MoCA Montreal Cognitive Assessment

MoCA-S7 Serial 7s attention task from the Montreal Cognitive Assessment

MoCA ATM Alternating Trail Making task from the Montreal Cognitive Assessment Scale

NIHSS National Institutes of Health Stroke Scale

Nbreg Negative binomial regression

PRT Postural Reactions Test

RaR Rate Ratio 
SCT Star Cancellation Test

S-FAC Self-Reported Functional Ambulation Classification

ST Step Test

SWWT Stops Walking When Talking

TUG Timed Up and Go

TUG ATM Timed Up \& Go with the Alternating Trail Making task from the Montreal Cognitive Assessment Scale added

TUG-cog Timed Up and Go-cognitive

TUG-S7 Timed Up \& Go with the Serial 7s attention task from the Montreal Cognitive Assessment added 


\section{ACKNOWLEDGMENTS}

I wish to express my whole-hearted gratitude to everyone who has supported me through the process of finishing my $\mathrm{PhD}$ studies and this thesis. I would like to thank you for sharing your knowledge, and expertise and for your warm cooperation. I would especially like to thank:

Ann-Sofi Kammerlind, main supervisor. Thank you for your never-ending support and help with little details and large questions.

Staffan Hägg, co-supervisor. Thank you for calm guidance, wise thoughts and sharing of your valuable experience in research.

Lars Nyberg, co-supervisor. Thank you for your enthusiasm, clear advice on methodological questions and for sharing your knowledge about stroke, falls, and physiotherapy.

Bo Rolander, co-author in paper 2. Thank you for your statistical and human advice during the work on all four papers, and for many nice lunches.

Jonas Lind, co-author in papers $3 \& 4$. Thank you for pointing out the value of this work when I needed to hear it, for sharing your thoughts about clinical values, and your expertise knowledge in neurology.

Sebastian Gustafsson, for coordinating the data collection at the University Hospital in Linköping.

Christina Sellin, for coordinating the data collection at Sunderby County Hospital in Luleå.

Mats Nilsson, for statistical support with papers $1 \& 2$.

Henrik Hedevik, for statistical support with papers 3 \& 4 . 
All colleagues that contributed to the data collection at Ryhov County Hospital, Jönköping, University Hospital, Linköping and Sunderby County Hospital, Luleå, and special thanks to all my great colleagues at the Rehabilitation center.

The staff at the Medical Library for your priceless help.

My fellow PhD students and colleagues at the Division of Prevention, Rehabilitation and Community Medicine for help, and interesting discussions throughout the PhD studies.

Everyone at Futurum, for support, nice conversations, and advice on tearcompatible mascara.

All participants, for being part of this massive data collection, and the contributing families and staff around the participants after discharge from the hospitals.

My family and friends for support; talks, hugs, runs, walks, laughter, tears, and practical help.

Fredrik, for coming into my life and making it so much more enjoyable, and rich. Thank you for your love and devotion, and help with figures and the cover page.

Hilma, Tyra, and Otto, for being such wonderful persons. It's a blessing to be your mother!

These studies were supported by grants from Futurum Region Jönköping County, the Medical Research Council of Southeast Sweden, and the Swedish Stroke Association. 


\section{INTRODUCTION}

Physical therapy aims to develop, maintain and restore optimal movement and functional ability in persons with health needs. This includes identification and maximization of movement potential and quality of life by for example, prevention, interventions and rehabilitation (1). In persons with stroke, several different functions and activities affecting mobility might be impaired (2) contributing to a high prevalence of falls (3) and an impact on quality of life (4). Therefore, assessment of disabilities in functions and activities interfering with safe mobility, and assessment of fall risk is essential (5). Also, in society there is an ambition to make health care more time- and cost-effective. The development and use of assessments that are easily administered, reliable and valid for their purposes, would help care givers to prioritize among duties, and to communicate knowledge objectively. The research presented in this thesis contributes knowledge that may help care givers to work sustainably and care recipients to have individualized and adequate care.

\section{Stroke}

\section{Incidence and prevalence}

A recent Global Burden of Diseases, Injuries, and Risk Factors Study, based on data from 195 countries, reported that stroke remains the second leading cause of disability and death (6). In 2017, there were 11.9 million stroke incidents, 104.2 million persons with stroke, and 132.1 million stroke-related disability-adjusted life years (DALYs) (DALY is a measure of overall disease burden, representing the number of years lost due to death, ill-health or disability). Stroke incidence, prevalence, mortality, and rate of DALYs have declined from 1990 to 2017, but the absolute numbers have almost doubled (6), and according to the analyses by Strong et al. (7) the number of first time strokes is expected to be 23 million in 2030.

Globally in 2017, approximately $65 \%$ of all strokes were cerebral infarctions, $26 \%$ primary intracerebral hemorrhage, and $9 \%$ subarachnoid hemorrhage, with a trend toward an increasing proportion of intracerebral hemorrhage in high income countries, and increasing stroke burden in persons aged 45-59 (6). 


\section{Definition and diagnosis}

The World Health Organization defines a stroke as: "rapidly developed clinical signs of focal or global disturbance of cerebral function, lasting more than 24 hours or until death, with no apparent non-vascular cause" (8, p. 108), a definition that originates from a report by Hatano in 1976 (9). Lately it has been proposed that the diagnosis of stroke should instead be determined by neuroimaging results alone. However medical imaging does not always correlate with clinical status or the presence of infarction, and since clinical status matters most for the patients and is the basis for assessments and treatment, diagnosing based on clinical signs remains adequate, despite advances in technology (10).

The stroke diagnosis is heterogeneous including subarachnoid hemorrhage (International Classification of Diseases (ICD) code I6o (11)), intracerebral hemorrhage (code I61), and cerebral infarction (code I63). The ICD-code I64, cerebrovascular accident/stroke, not specified as hemorrhage or infarction, can be used when the diagnosis is made only by clinical signs (10), something that is possible to perform accurately (12).

\section{Pathology}

Subarachnoid hemorrhage is a rupture of a vessel in the subarachnoid space between the arachnoid membrane and the pia mater, and is not included in this thesis due to the different pathology and epidemiology (13). Intracerebral hemorrhage is caused by a rupture of a cerebral blood vessel, and causes distortion and compression of the brain tissue leading to edema, inflammatory cells, apoptosis, and necrosis in the surrounding regions (14). Cerebral infarction is most commonly caused by cerebral small-vessel disease, embolic or thrombotic events, resulting in interruptions to cerebral blood vessels. The temporary or permanent reduction of blood flow to the brain territories provided, results in the dysfunction or death of brain cells (15).

\section{Phases of stroke}

The symptoms and condition of the stroke change over time. The first 24 hours from stroke onset are defined as stroke in the hyper-acute phase and during this first day, cell death occurs and hematoma expands. In the first seven days from stroke onset, the acute phase, inflammation and scarring occur. Most recovery takes place during the acute and early subacute phases (seven days to three months), and the first month is particularly critical for neural plasticity. Recovery happens both through 
behavioral restitution (true recovery which requires neural repair) and compensation, and is present even during the late subacute phase (three to six months) and the chronic phase (after six months) (16).

In Sweden in 2019, persons who had just had a stroke were given regional hospital care in median for seven days (17). This means that also persons in the early subacute phase are among those receiving acute stroke care in Sweden. In this thesis, studies reporting data collection within 14 days from stroke onset, or data collection within 14 days from admission to an acute stroke unit, are considered as studies of persons with acute stroke.

\section{Consequences}

Stroke can cause a variety of dysfunctions. Mental functions, (according to the International Classification of Functioning, Disability, and Health (ICF) coding (18), (code b1)), sensory functions and pain (code b2), and neuromusculoskeletal and movement-related functions (code b7) are commonly affected (2). For example impaired cognition (19) attention deficits (20), impaired comprehension and expression of language (21), depressive symptoms, anxiety, pain (3), somatosensory dysfunctions (22), paresis in the arms and legs (23), and postural instability (24) are commonly present in persons with stroke. Limitations in activities of selfcare (code d5) are common (2), as well as decreased mobility (code d4), including impaired gait (25), and impaired ability to avoid objects while walking (26). Since a stroke may impair so many different functions and may result in limitations in such a large number of activities, the risk for falls is high (3).

\section{Falls}

\section{Incidence and prevalence}

Compared to approximately 0.65 falls each person-year in the general population of elderly persons, fall incidence rates of 1.3-6.5 falls each person-year have been reported in persons with stroke, and persons with stroke are more likely to experience recurrent falls compared to elderly persons in general (27). Compared to controls $\geq 65$ years old, injurious falls are more common in persons with stroke (28), for whom injuries have been reported in 8-69\% of the falls, including bruises and grazes (27) and the risk of hip-fracture has been found to be almost double (HR, 1,69 [95\% CI, 1.46-1.96] $\mathrm{p}<0.05$ ) among persons with stroke compared to controls (29). 


\section{Definition}

When these studies were conducted, we used the definition of a fall that was recommended at the time: "an unexpected event in which the participants come to rest on the ground, floor or lower level" (30, p. 1619). The World Health Organization now defines a fall as "an event which results in a person coming to rest inadvertently on the ground or floor or other lower level" (31).

\section{Consequences}

In Sweden in 2017, approximately 300 ooo persons sought specialist care, 70 ooo persons needed inpatient hospital care, and approximately 1000 persons died as a consequence of a fall (32). During 2018, almost 20 ooo fall-related hospital inpatient episodes of care were registered in persons $\geq 65$ years of age, resulting in an average of approximately two months of home help services after hospital stay (33). In Sweden, the direct costs of accidental falls in 2006 were calculated as almost five billion SEK (fatal injuries 4600, non-fatal-injuries 200, and deaths 50 million SEK), and costs related to deterioration in quality of life were calculated as nine billion SEK (fatal injuries 4600 , and deaths 4200 million SEK). If the development continues as now the total cost for falls is calculated to be approximately 22 billion SEK in 2050 (34).

In addition to the economic consequences, and previously mentioned physical injuries, consequences of falls in persons with stroke also include reduced mobility and activity, fear of falling, reduced social activity, depressed mood, and a higher level of stress among those caring for the fallers $(27,35,36)$.

\section{Prevention}

A Cochrane review of interventions for preventing falls in communitydwelling elderly persons stated that multifactorial interventions, including individual risk assessment, reduce the rate of falls (RaR, o.76 [95\% CI, o.67-0.86] 19 trials). Also, interventions with multi-component exercise, both when delivered as group classes or individually prescribed at home, gradual withdrawal of psychotropic medications, use of anti-slip shoe devices in icy conditions, home safety assessments and modified interventions have been found to reduce the fall rate (37). Regarding interventions for preventing falls in persons with stroke, the authors of another Cochrane review concluded that very little evidence about 
interventions, other than exercises, to reduce falling post stroke exists, and that stronger evidence is needed (38).

\section{Assessments}

In order to identify high fall risk individuals and areas for prevention, further knowledge of clinical assessments and their predictive abilities is needed. In Sweden, assessment of fall risk is mandatory in persons $\geq 65$ years of age, and for adults with neurological or cognitive diseases (32). The recommended first choice is the Downton Fall Risk Index (39), since this is part of the National Quality Registry for Preventative Care (40). In persons with stroke the sensitivity of the Downton Fall Risk Index has been shown to be $91 \%$; however, the specificity is only $27 \%$ (41). For the following extended investigation of fall risk a wide range of assessments is needed to address the multifactorial risk for falls in the heterogeneous acute stroke population. Not only do activities of mobility or activities contributing to an increased risk for falls need to be assessed, but also functions possibly interfering with such activities in order to target areas for prevention $(2,5)$.

Risk factors for falls are different to some extent in persons with stroke compared to elderly persons in general (42), and the condition of persons with stroke varies in the different phases of stroke (16). Therefore, fall risk assessments used during the first days from stroke onset need to be validated in patients receiving acute stroke care. In our experience it is also valuable if the different components of the fall risk are stated in objective assessments when communicating the fall risk to patients, their families, or other care givers, instead of communicating only the care givers' judgment of risk for falls. However, the care givers' judgment can be used to identify fallers (43). Assessments can also be used for measurement of individual change over time as well as for group comparisons, and in order to meet these needs, it is essential that assessments are reliable and valid (44).

\section{Reliability}

Reliability can be described as the degree to which a measurement is free from both random and systematic error, and is an expression of the proportion of the total variance in the measurement that is due to "true" variations between subjects. A high reliability score provides the information that the error of the measurement is a relatively small fraction of the range in the observations. A measurement can be reliable 
in a highly heterogeneous population, but not in a homogeneous population with small natural changes. Therefore, the measurement error must be contrasted with the expected variation among the persons being assessed and a measurement can never be reliable in itself, but is a reflection of the extent to which it can differentiate among individuals in a specific population, for example persons with acute stroke. The assessment of reliability can be performed under several conditions: over time (test-retest reliability), by different persons on the same occasion (inter-rater reliability), or by the same assessor on different occasions (intra-rater reliability) (44).

\section{Validity}

Validity can be described as the degree to which an assessment measures the construct(s) it was aimed to measure, and it comprises content validity, construct validity, and criterion validity. As for reliability the validity can never be determined for an assessment alone, but for the use of an assessment in a specific population as described below.

Content validity measures the degree to which the content of an assessment adequately reflects the construct it was intended to measure, and determines if all aspects of the content are included, and irrelevant aspects are not. For example in the assessment of grip strength by a dynamometer, the psychometric properties might not be identical in healthy persons compared to persons with rheumatoid arthritis affected by pain. A measure that contains representable items of the target to be measured provides more accurate inferences, that remain true under a broad variety of conditions and circumstances. The simplest form of content validity, face validity, measures the degree to which an assessment looks as though it is an adequate reflection of the construct intended to be measured.

Construct validity measures the degree to which the scores of an assessment are consistent with a hypothesis, based on the assumption that the assessment validly measures the intended construct in a specific group of persons. For example, the ability to avoid objects while walking is an activity where one might have a hypothesis that specific impairments in a specific group of persons may contribute to the performance.

Designing measurements of a hypothetical construct is relevant when the construct is new, or when we are dissatisfied with the existing assessments. The underlying theory helps us to develop better 
assessments, by explaining a broader range of findings or providing more accurate predictions.

Criterion validity measures the degree to which an assessment is an adequate reflection of a gold standard in a specific population. Criterion validity contains concurrent validity and predictive validity. Concurrent validity measures the correlation between the new assessment and the criterion measure (gold standard), both performed at the same time. This can be relevant for example if the gold standard is time-consuming (44) as is the case with Berg's Balance scale (BBS) (45), which is considered a gold standard for assessment of functional balance and takes approximately 15-20 minutes to perform. In predictive validity the criterion is available in the future (44). An example of this is that scores from a clinical assessment can be analyzed in relation to falls in order to examine the assessment's potential to identify persons at risk for future falls.

\section{Risk factors for falls}

Potential risk factors for falls have been studied for decades. A review from 1985 on risk factors for falls in elderly persons states that females, persons with cognitive impairments, and persons who use diuretics, tranquilizers, and hypnotics seems to be at highest risk of falls (46). Since then, several studies of falls have been conducted, and according to a review from 2013, consistently identified risk factors for falls in elderly community-dwelling persons are: a history of falls, impaired balance, impaired gait, use of walking aids, muscle weakness, visual and cognitive impairments, impaired functional activity, depression, fear of falling, polypharmacy, use of culprit medications, incontinence, Parkinson's disease, peripheral neuropathy, cardiovascular diseases, stroke, and age over 80 years (47).

In persons with stroke, recent reviews suggest that a history of falls, impaired balance, impaired mobility, disability in self-care, depression, cognitive impairment, hemineglect, and use of sedative and psychotropic medications are risk factors for falls $(48,49)$. Campbell et al. (49) found that during post-stroke rehabilitation, impaired balance, hemineglect and self-care deficits had the strongest empirical support as risk factors for falls.

It has been shown that the risk for falls is high during all stages post stroke (27). However, most falls occur during the first months after stroke 
onset (50). In order to reduce the number of falls, it is important to identify persons at risk as early as possible after stroke onset. There are a number of studies collecting data in the acute phase of stroke with a prospective follow-up of post-discharge falls (50-59) (Table 1). Also, in these studies, impairments of postural control are commonly reported as related to fallers and falls.

\section{Postural reactions}

Postural control includes components of steady state balance, proactive balance and reactive balance (60). In the reactive balance control the postural reactions (ICF code b755) automatically assist in maintaining balance by changing muscle tone or moving parts of the body, including equilibrium reactions, righting reactions and protective reactions $(61,62)$. When the center of gravity is disturbed the equilibrium reactions provide balance by counter-movements of the head, trunk, and extremities away from the direction of displacement. The righting reactions support the head and trunk positioning vertically in space and align the eyes with the horizon. The righting reactions involve movements of the head, trunk, and extremities, and thus in adults the equilibrium reactions and righting reactions co-exist. If balance cannot be restored by the equilibrium and righting reactions, protective reactions are needed either by using the arms, or by an executive step to protect the body from injury or prevent a fall (61-63). In persons with stroke the reactive balance control might be impaired (64-66), and latencies in muscle onset after exposure to balance perturbations are significantly longer compared to controls (67), which results in an increased risk of falling (68).

It has been shown that there is only a moderate correlation between proactive and reactive balance control in persons with stroke, indicating recruitment of different neural mechanisms (69), and a need for development of separate assessments of proactive and reactive balance. Specific tests for assessment of reactive balance by the postural reactions may be important for identifying persons at risk for falls and for directing appropriate intervention strategies $(62,66)$.

Assessment of postural reactions has been part of clinical practice for decades (70); however, there is a lack of assessments specifically revealing the capacity of reactive balance control at a functional level, since most clinical measures are based on task performances (2). 


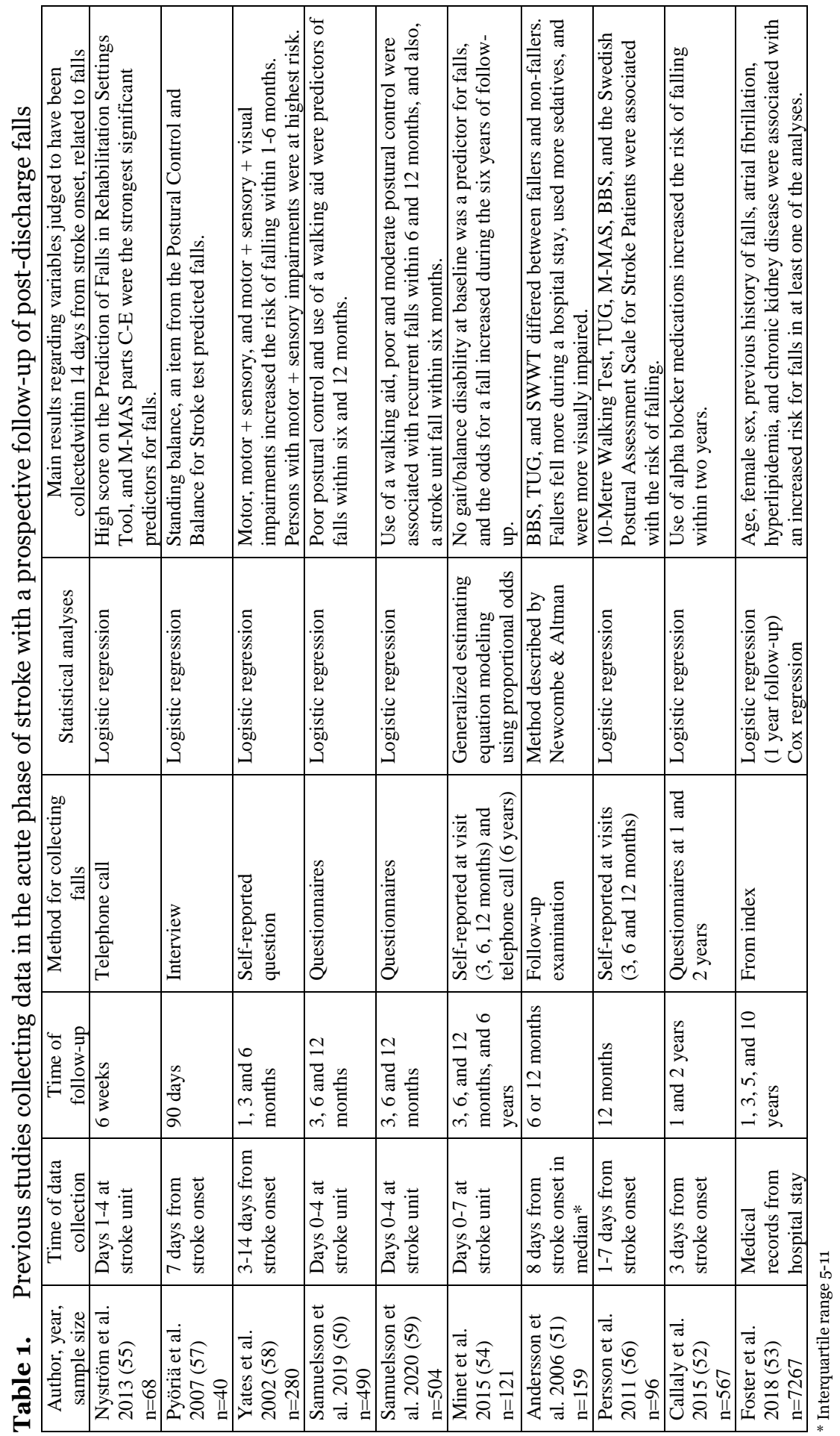


Protective reactions while sitting are assessed in the Fugl-Meyer Assessment of Motor Recovery after Stroke (71), and in the Birgitta Lindmark assessment (72). Protective reactions while standing are assessed in the Balance Evaluation Systems Test (BESTest) (73) using the instructions to lean toward the assessor's hand that the tested person needs to understand and follow. These tests take approximately 30 minutes to perform. To fill the gaps in previous tests assessing postural reactions, Hanna Sjöholm (HS) and colleagues developed the Postural Reactions Test (PRT) (74). In contrast to the previously mentioned assessments, the PRT only includes assessments of the postural reactions at a functional level, and is the only test assessing all the postural reactions (equilibrium reactions, righting reactions, and protective reactions) in a standardized and uniform way in the same test. Compared to the Fugl-Myer and Birgitta Lindmark assessment the PRT has an added clarification of what reactions to assess as 'impaired' or 'normal', and compared to the BESTest, the protective reaction in standing in the PRT can also be assessed in persons with limited abilities to follow instructions. The PRT takes less than five minutes to perform, and can also be used to guide treatment and for identification of persons at high risk of falling. Intact postural reactions are essential during gait activities (60), and fall accidents most commonly happen during walking or transfer in community-dwelling persons with stroke (27). The demands on a person's postural control are even greater when an attentiondemanding task, such as avoiding objects, is added.

\section{Obstacle avoidance and attention during gait activities}

Significant reductions in motor performance during gait activities with an added attention-demanding task, and in attention-demanding environments have been found in persons with stroke (75-78), due to cognitive-motor interference. Cognitive-motor interference is evident when cognitive and motor tasks are performed simultaneously, with a deterioration in both or one of the tasks as a result (75). This is even more common in persons with stroke compared to the elderly in general. In a previous study of obstacle avoidance during walking the healthy controls were successful in $97 \%$ of the trials and the persons with stroke in $30 \%$ (79). Walking and simultaneously avoiding obstacles (ICF-code d455), requires both attentional (ICF-code b140), perceptual (ICF-code b156), seeing (ICF-code b210), and several neuromusculoskeletal and 
movement-related functions (ICF-codes b710-799), which are functions that might be impaired in a person with stroke (2).

There are a few tests that assess the cognitive load on gait control by a dual task; the Stops Walking When Talking observation (SWWT) (80) by answering a question while walking, and the Timed Up and Go cognitive (TUG-cog) (81), by walking and performing an added cognitive task. Both these tests can be used to identify fallers $(82,83)$. Other tests assess the attentional and proactive gait control-demanding task of negotiating and crossing obstacles while walking $(79,84-86)$, but these tests cannot be performed when walking aids are used. Since persons with stroke commonly use walking aids (50), it is important to develop reliable and valid assessments of obstacle avoidance for persons with stroke (87) and to assess the predictive value for future falls of such tests. To fill this gap, HS and colleagues developed the Cone Evasion Walk test (CEW) (88). The CEW assesses the ability to evade objects while walking and can be performed with or without walking aids. Such assessment can be used to guide treatment, to identify improvements over time, and to assess the risk for falls.

\section{Sex differences in stroke and falls}

In the exploration of fall risk factors and fall incidence in persons with stroke, sex differences also need to be studied, since several underlying components differ between women and men. Compared to men, women have an increased prevalence of many stroke risk factors, including hypertension, atrial fibrillation, metabolic syndrome, and abdominal obesity (89). Females over the age of 80 , as a group, have been reported to have more stroke incidents, more stroke-related disability-adjusted life years, and more deaths compared to men (6), and women overall suffer from more stroke-related disability, non-classical stroke symptoms and institutionalization due to the stroke than men do (90). Also, approximately two-thirds of all falls and fractures within 10 years from stroke onset occur in women (53). However, an almost doubled risk for falls during hospital stay (91), and a more than doubled risk for repeated falls six weeks from stroke onset have been found in men compared to women (55). Fear of falling and depression have been shown to be predictors for falls (47) and are associated with female sex in persons with acute stroke $(92,93)$. Risk-taking behavior (94) and greater muscle strength (95) are associated with male sex. 


\section{Rationale of the thesis}

Fall incidence rates are higher in persons with stroke (27), and injurious falls are more common (28) compared to the general elderly population. Also, risk factors for falls are different for persons with stroke compared to age and sex-matched controls (42). Therefore, studies of risk factors for falls are needed for persons with stroke exclusively. It has been shown that multifactorial interventions including individual risk assessments can reduce the rate of falls in community-dwelling older persons (37). However, little is known about the effect on falls of individual fall risk assessments in persons with stroke (38). Moreover, there is a lack of assessments suitable for assessment of fall risk in persons with acute stroke. In order to identify high fall risk individuals and areas for prevention, more detailed knowledge of clinical assessments is needed.

Impairments in reactive postural control are common after stroke (6466), and contribute to an increased risk for falls (68). Existing tests including assessments of postural reactions (71-73), do not contain all postural reactions (equilibrium, righting, and protective reactions), do not enable separate use of specific items, and take approximately 30 minutes to perform. In persons with acute stroke, there is a need for standardized testing procedures for all postural reactions at a functional level. It would be advantageous if the specific items could be reliably used both separately or together in a rapid and easily administered test. Such a test needs to be developed and assessed for reliability and predictive validity of falls in persons with acute stroke.

Impairments in the ability to walk and simultaneously perform attentiondemanding tasks are common after stroke (75) and assessments of this ability can be used to identify fallers $(82,83)$. Other tests assess the attentional and proactive gait control-demanding task of negotiating and crossing obstacles while walking $(79,84-86)$, but these tests cannot be performed when walking aids are used. Such a test needed to be developed and assessed for reliability and predictive validity of falls for persons with acute stroke.

In order to reduce the number and consequences of falls, early identification of potential fallers is important. In collecting falls, daily recording and monthly reporting are recommended, since short intervals in data collection of falls are considered to increase the internal validity of a study $(30,96)$. It is also recommended to analyze falls with negative binomial regression (nbreg) (97), including both time and number of falls 
in the analyses. Including both is relevant due to the decisive impact on the total risk for falls of these components. In previous studies investigating how factors collected in the acute phase of stroke can predict falls after discharge (Table 1) (50-59) this was not done. Moreover, it is valuable if assessments used for screening of fall risk are rapid and easy to administer in clinical practice (47). The predictive validity of falls for such assessments needs to be established in persons with acute stroke. Also, in the multifactorial phenomenon of falls in the heterogeneous acute stroke population, it is valuable if the factors are analyzed univariately to obtain generalizable results of the fall risk connected to all single variables studied, including all participants in the analyses. Such results are important both for individualized assessment of fall risk in clinical practice and for development of multivariate risk models in different strata of the population.

Sex differences both regarding stroke $(6,89,90)$ and falls $(53,55,91,98)$ are already known, and sex differences in relation to falls must be further investigated in order to identify possible needs for adaptation of fall risk assessment and prevention strategies with respect to sex. In persons with acute stroke (Table 1) (50-59) this has not yet been done.

\section{Overall aim}

To investigate the predictive validity of fall risk in persons with acute stroke for easily administered data and assessments, as well as to investigate the psychometric properties of two new tests.

\section{Specific aims}

Paper 1 To examine the intra- and inter-rater reliability of the newly developed PRT for use in persons with acute stroke.

Paper 2 To examine the reliability and validity of the CEW, a new test assessing the ability to evade obstacles, in persons with acute stroke.

Paper 3 To explore how the time to the first fall, and the six-month fall incidence, relate to rapidly and easily collected data in persons with acute stroke.

Paper 4 To explore possible fall risk factors and monthly fall incidence in women and men with acute stroke. 


\section{METHOD}

\section{Overview of the studies}

This thesis consists of two studies which resulted in four papers. An overview of the studies is presented in Table 2.

Table 2. Overview of studies and papers included in the thesis

\begin{tabular}{|c|c|c|c|c|}
\hline & Paper 1 & Paper 2 & Paper 3 & Paper 4 \\
\hline & \multicolumn{2}{|c|}{ Study A } & & \\
\hline & & \multicolumn{3}{|c|}{ Study B } \\
\hline Design & $\begin{array}{l}\text { Cross-sectional } \\
\text { study }\end{array}$ & $\begin{array}{l}\text { Cross-sectional } \\
\text { study and cohort } \\
\text { study }\end{array}$ & Cohort study & Cohort study \\
\hline Aim & $\begin{array}{l}\text { To examine the } \\
\text { intra- and inter- } \\
\text { rater reliability of } \\
\text { the newly } \\
\text { developed PRT for } \\
\text { use in persons with } \\
\text { acute stroke. }\end{array}$ & $\begin{array}{l}\text { To examine the } \\
\text { reliability and } \\
\text { validity of the } \\
\text { CEW, a new test } \\
\text { assessing the } \\
\text { ability to evade } \\
\text { obstacles, in } \\
\text { persons with acute } \\
\text { stroke. }\end{array}$ & $\begin{array}{l}\text { To explore how } \\
\text { the time to the } \\
\text { first fall, and the } \\
\text { six-month fall } \\
\text { incidence, relate } \\
\text { to rapidly and } \\
\text { easily collected } \\
\text { data in persons } \\
\text { with acute stroke. }\end{array}$ & $\begin{array}{l}\text { To explore } \\
\text { possible fall risk } \\
\text { factors and } \\
\text { monthly fall } \\
\text { incidence in } \\
\text { women and men } \\
\text { with acute stroke. }\end{array}$ \\
\hline Participants & $\begin{array}{l}36 \text { consecutively } \\
\text { recruited persons } \\
\text { with acute stroke. }\end{array}$ & $\begin{array}{l}20+221 \text { (study A } \\
+ \text { study B) } \\
\text { consecutively } \\
\text { recruited persons } \\
\text { with acute stroke. }\end{array}$ & $\begin{array}{l}284 \\
\text { consecutively } \\
\text { recruited persons } \\
\text { with acute stroke. }\end{array}$ & $\begin{array}{l}284 \\
\text { consecutively } \\
\text { recruited persons } \\
\text { with acute stroke. }\end{array}$ \\
\hline Data collection & $\begin{array}{l}\text { Video-recorded } \\
\text { clinical } \\
\text { assessment. Two } \\
\text { group meetings for } \\
\text { physiotherapists } \\
\text { assessing the } \\
\text { video-recorded } \\
\text { performances. }\end{array}$ & $\begin{array}{l}\text { Video-recorded } \\
\text { clinical } \\
\text { assessment. Two } \\
\text { group meetings for } \\
\text { physiotherapists } \\
\text { assessing the } \\
\text { video-recorded } \\
\text { performances. } \\
\text { Data collection } \\
\text { during hospital } \\
\text { stay and six } \\
\text { months prospective } \\
\text { follow-up on falls. }\end{array}$ & $\begin{array}{l}\text { Data collection } \\
\text { during hospital } \\
\text { stay and six } \\
\text { months } \\
\text { prospective } \\
\text { follow-up on } \\
\text { falls. }\end{array}$ & $\begin{array}{l}\text { Data collection } \\
\text { during hospital } \\
\text { stay and six } \\
\text { months } \\
\text { prospective } \\
\text { follow-up on } \\
\text { falls. }\end{array}$ \\
\hline Data analysis & $\begin{array}{l}\text { Percentage of } \\
\text { agreement, } \\
\text { medians. }\end{array}$ & $\begin{array}{l}\text { Percentage of } \\
\text { agreement, } \\
\text { medians, ICC, } \\
\text { Spearman's rank } \\
\text { correlation, linear } \\
\text { correlation and } \\
\text { Cox regression. }\end{array}$ & $\begin{array}{l}\text { Cox regression } \\
\text { and negative } \\
\text { binominal } \\
\text { regression. }\end{array}$ & $\begin{array}{l}\text { Cox regression } \\
\text { and negative } \\
\text { binominal } \\
\text { regression. }\end{array}$ \\
\hline
\end{tabular}




\section{Participants}

\section{Background characteristics of the study participants and the general stroke population in Sweden are presented in Table 3.}

Table 3. Background characteristics of study participants and the general stroke population in Sweden

\begin{tabular}{|c|c|c|c|c|c|}
\hline & $\begin{array}{c}\text { Participants } \\
\text { Study A, } \\
\text { Paper 1 }(n=36)\end{array}$ & $\begin{array}{c}\text { Participants } \\
\text { Study A, } \\
\text { Paper } 2(n=20)\end{array}$ & $\begin{array}{l}\text { Participants } \\
\text { Study B, } \\
\text { Paper 2 } \\
(\mathrm{n}=221)\end{array}$ & $\begin{array}{c}\text { Participants } \\
\text { Study B, } \\
\text { Paper 3\&4 } \\
(\mathrm{n}=284)\end{array}$ & $\begin{array}{c}\text { General } \\
\text { stroke } \\
\text { population } \\
*\end{array}$ \\
\hline $\begin{array}{l}\text { Age, years, } \\
\text { mean (SD) } \\
\text { (min-max) }\end{array}$ & 75 (11) (51-91) & 74 (14) (51-91) & $73(11)(36-95)$ & 74 (11) (36-95) & 75 \\
\hline $\begin{array}{l}\text { Sex, women/men, } \\
\%(\mathrm{n})\end{array}$ & $42 / 58(15 / 21)$ & $35 / 65(7 / 13)$ & $43 / 57(94 / 127)$ & $44 / 56(124 / 160)$ & $47 / 53$ \\
\hline $\begin{array}{l}\text { ADL dependent } \\
\text { before stroke onset, } \\
\text { yes } / \text { no, } \%(\mathrm{n})\end{array}$ & $12 / 88(4 / 29) \dagger$ & $5 / 95(1 / 18) \ddagger$ & $15 / 85(31 / 169) \S$ & $14 / 86(37 / 220) \|$ & $13 / 87$ \\
\hline $\begin{array}{l}\text { First stroke, } \\
\text { yes/no, } \%(\mathrm{n})\end{array}$ & $73 / 27(24 / 9) \dagger$ & $74 / 26(14 / 5) \ddagger$ & $78 / 22(169 / 47) \S$ & $76 / 24(213 / 66)||$ & $78 / 22$ \\
\hline $\begin{array}{l}\text { Days since stroke } \\
\text { onset, mean (SD) } \\
(\min -\max )\end{array}$ & $4(3)(0-13)$ & $5(3)(1-13)$ & $5(3)(0-14)$ & $5(3)(0-14)$ & - \\
\hline $\begin{array}{l}\text { NIHSS at } \\
\text { admission, median } \\
(\min -\max )\end{array}$ & $3(0-15) \dagger$ & $2(0-11)+$ & $3(0-21) \S$ & $3(0-21)||$ & $3(0-42)$ \\
\hline $\begin{array}{l}\text { Walking aid, } \\
\text { yes/no, \% (n) }\end{array}$ & $56 / 44(20 / 16)$ & $40 / 60(8 / 12)$ & $40 / 60(89 / 132)$ & $42 / 58(120 / 164)$ & - \\
\hline \multicolumn{6}{|l|}{ Stroke type \% (n) } \\
\hline $\begin{array}{l}\text { Intracerebral } \\
\text { hemorrhage }\end{array}$ & $14(5)$ & $15(3)$ & $8(18)$ & $10(29)$ & 13 \\
\hline Cerebral infarction & $64(23)$ & $70(14)$ & $69(153)$ & $65(184)$ & 86 \\
\hline Not specified & $22(8)$ & $15(3)$ & $20(44)$ & $21(59)$ & 1 \\
\hline Both & $0(0)$ & $0(0)$ & $3(6)$ & $4(12)$ & - \\
\hline \multicolumn{6}{|l|}{ Stroke location $\mathrm{n} \#$} \\
\hline Right & 15 & 12 & 87 & 115 & - \\
\hline Left & 3 & 1 & 72 & 87 & - \\
\hline Brainstem & 6 & 3 & 12 & 12 & - \\
\hline Cerebellum & 5 & 2 & 22 & 30 & - \\
\hline Not specified & 8 & 3 & 44 & 59 & - \\
\hline \multicolumn{6}{|l|}{ Paresis $\%(\mathrm{n}) * * \S \|$} \\
\hline Right side only & $22(8)$ & $20(4)$ & $8(17)$ & $9(25)$ & - \\
\hline Left side only & $61(22)$ & $65(13)$ & $14(30)$ & $19(51)$ & - \\
\hline No paresis & $17(6)$ & $15(3)$ & $74(161)$ & $64(173)$ & - \\
\hline Both sides & $0(0)$ & $0(0)$ & $5(11)$ & $8(22)$ & - \\
\hline \multicolumn{6}{|c|}{ Cognitive impairment $\%(\mathrm{n}) * * \S\rfloor$} \\
\hline $\begin{array}{l}\text { Collected from } \\
\text { journal, yes/no }\end{array}$ & $61 / 39(22 / 14)$ & $50 / 50(10 / 10)$ & - & - & - \\
\hline $\begin{array}{l}\text { MoCA total score } \leq \\
21, \text { yes/no }\end{array}$ & - & - & $42 / 58(86 / 117) \S$ & $49 / 51(118 / 122) \S$ & - \\
\hline
\end{tabular}

* Data collected from Riksstrokes Årsrapport 2016 (99)

t Data was available for 33 participants

₹ Data was available for 19 participants

$\S$ Data was available for 200 participants regarding ADL, 215 participants regarding first stroke, 156 participants regarding NIHSS, 219 participants regarding paresis, and 203 participants regarding the MoCA

| | Data was available for 257 participants regarding ADL, 279 participants regarding first stroke, 198 participants regarding NIHSS, 271 participants regarding paresis, and 240 participants regarding the MoCA

\# Some participants had more than one stroke location

** In the reliability study, data about paresis, and cognitive impairment was collected from the journals. In the validity study paresis was determined from NIHSS, and cognitive impairment was determined from the results $\leq 21$ scores in the MoCA. 


\section{Study A}

The inclusion criteria were a diagnosis of stroke (ICF codes I61, I63, or I64) and symptom onset within 14 days before testing.

The exclusion criteria were traumatic brain injury, major orthopedic problems, neurological problems other than stroke, no evident residual symptoms due to the current stroke onset at the time of the testing, medical reasons for being unable to participate, need of professional interpreter to obtain informed consent, or not being able to follow instructions considerably simpler than the test instructions.

Thirty-six participants were recruited consecutively from the stroke unit at Ryhov County Hospital, Jönköping between April 9 - May 18, and August 26 - September 23, 2013, until 20 participants had completed each PRT item and CEW. Reasons for missing out were: did not want to perform the item/test, films could not be analyzed, no study-personal available before discharge, or no need since 20 participants were already included in that particular PRT item or CEW (Figure 1). For a detailed description of how the 36 participants were distributed in the different items in PRT please see paper 1.

No significant differences were found between the participants and the non-participants with respect to age, or time since stroke onset. In the 36 participants included in paper 1 there were no differences regarding sex. However, in paper 2, there was a greater proportion of women among the non-participants compared to the 20 participants ( $80 \%$ compared to $35 \%)$.

\section{Study B}

The inclusion criteria were a diagnosis of stroke (ICD codes I61, I63, or I64), onset of symptoms within 14 days prior to testing, being resident in the catchment area, and staying at the stroke units of one of the three included hospitals.

The exclusion criteria were risk of impaired health from being asked to participate, or a professional interpreter needed to obtain informed consent. 
Three hundred participants were recruited consecutively from the stroke units at Ryhov County Hospital, Jönköping, University Hospital, Linköping and Sunderby County Hospital, Luleå, Sweden between January 25, 2016 and February 10, 2017. Of the 300 included participants, 221 were able to perform the CEW and were included in the analysis in paper 2. Also, out of the 300 included participants, 284 (124 women and 160 men) were part of at least one follow-up and were included in the analyses in papers 3 \& 4 (Figure 1).

The non-participants were older (mean 76 years (32-95)) than the 221 participants (mean 73 (36-95)) included in paper 2, but sex and the number of days from stroke onset until being asked about participation did not differ. For the 284 participants included in papers $3 \& 4$ there were no significant differences between the participants and nonparticipants with respect to age, sex, or the number of days from stroke onset until being asked about participation. Due to the limited capacity of acute stroke units, 61 persons diagnosed with stroke in Jönköping, 69 in Luleå and 37 in Linköping were never admitted to the stroke units and were therefore not available for inclusion.

\begin{tabular}{|c|c|c|c|}
\hline \multicolumn{2}{|c|}{ Study A } & \multicolumn{2}{|c|}{ Study B } \\
\hline $\begin{array}{l}50 \text { persons met the } \\
\text { inclusion criteria }\end{array}$ & $\begin{array}{l}14 \text { persons were excluded } \\
\text { for the following } \\
\text { reasons: }\end{array}$ & $\begin{array}{l}478 \text { persons met the } \\
\text { inclusion criteria }\end{array}$ & $\begin{array}{l}178 \text { persons were } \\
\text { excluded for the } \\
\text { following reasons: }\end{array}$ \\
\hline \multirow{2}{*}{$\begin{array}{l}36 \text { persons were } \\
\text { included in the study, } \\
\text { until all the tests below } \\
\text { had been performed by } \\
20 \text { participants each }\end{array}$} & \multirow{2}{*}{$\begin{array}{l}\text { - } 12 \text { did not give } \\
\text { consent } \\
2 \text { could not perform } \\
\text { assessments before } \\
\text { discharge }\end{array}$} & $\begin{array}{l}300 \text { persons were } \\
\text { included in the study }\end{array}$ & \multirow{3}{*}{$\begin{array}{l}\text { - } 146 \text { did not give } \\
\text { consent } \\
\text { For } 31 \text { persons, } \\
\text { no assessors were } \\
\text { available } \\
1 \text { person was asked } \\
\text { to participate after } \\
14 \text { days }\end{array}$} \\
\hline & & & \\
\hline & & & \\
\hline & Paper 1 & & \\
\hline & \multirow{2}{*}{$\begin{array}{l}\mathrm{n}=20 \text { assessed eqilibrium } \\
\text { and righting reactions }\end{array}$} & & \multirow{2}{*}{$\begin{array}{l}15 \text { persons did not } \\
\text { participate in any } \\
\text { follow-ups }\end{array}$} \\
\hline & & & \\
\hline & $\begin{array}{l}\mathrm{n}=20 \text { assessed postural } \\
\text { reactions in sitting }\end{array}$ & & \\
\hline & $\begin{array}{l}\mathrm{n}=2 \mathrm{O} \text { assessed postural } \\
\text { reactions in standing }\end{array}$ & & $\begin{array}{l}1 \text { person was excluded } \\
\text { since the diagnosis was } \\
\text { changed }\end{array}$ \\
\hline & \multicolumn{2}{|l|}{ Paper 2} & Paper $3 \& 4$ \\
\hline & $\begin{array}{l}n=20 \text { performed CEW } \\
\text { and were part of the } \\
\text { reliability analysis }\end{array}$ & $\begin{array}{l}n=221 \text { performed CEW } \\
\text { and were part of the } \\
\text { validity analysis }\end{array}$ & $\begin{array}{l}n=284 \text { were part of } \\
\text { the analyses }\end{array}$ \\
\hline
\end{tabular}

Figure 1. Flow chart of the recruitment process 


\section{Data collection}

\section{Study A}

\section{Development of the Postural Reactions Test and the Cone Evasion Walk Test}

The development of the PRT and CEW was initiated by Hanna Sjöholm (HS) because of a clinical need to assess postural reactions (including equilibrium, righting and protective reactions), and the ability to walk without walking into furnishings and other persons, in a standardized, rapid, and easily administered way. The test procedures were developed based on the literature, on other tests (71-73), and on clinical experience, and in collaboration with patients and physiotherapists at the stroke unit at Ryhov County Hospital, Jönköping, Sweden. At the start, different approaches to assessing postural reactions and ability to walk and avoid objects were used by HS in the clinical work. When a clinically appropriate version was identified for each test, it was documented and pilot-tested in two phases. The first phase consisted of three meetings where face validity was evaluated through systematic feedback from nine clinically active physiotherapists within the field of neurology disorders (HS received the feedback and was not one of the nine). The procedures and instructions for the assessments were discussed based on the manuals and video-recorded performances, different interpretations were documented, and clarifications were implemented.

In the second phase, the assessments were used over a one-year period by four physiotherapists in their clinical work at the stroke unit, resulting in further revisions of the test instructions (three of the nine previously mentioned physiotherapists and HS). Following revisions of the pilot testing, standardizations that were not necessary to distinguish scores of the tests were discarded. Also, the instructions were complemented with clarifications regarding administration, safety and scoring.

\section{Assessment of reliability}

One of the physiotherapists working at the stroke unit (HS) conducted the tests when participants performed PRT $(\mathrm{n}=20$ for each item) and/or CEW $(n=20)$. The participants performed each item/test once, and the performances were video-recorded. For each item/test, ten 
physiotherapists assessed the 20 video-recorded performances. Two weeks later the ten physiotherapists assessed the video-recorded performances a second time. Thus, the study included 400 ratings for each item/test. The assessment sessions were conducted by HS, who did not assess the video-recorded performances. Two of the ten physiotherapists had previously been involved in the pilot testing of the second phase. All the physiotherapists had work experience in the field of neurology, median work experience 16 years (range 6-43 years), and limited or no experience in using the tests.

The assessment sessions were carried out in a controlled and standardized situation. The physiotherapists received and read the manual and HS gave the instructions orally at the beginning of each session. The assessments were simultaneously carried out, the physiotherapists could choose to watch the videos once or twice during each session, and they were not allowed to discuss their scores. The videos were observed in a randomly determined order that differed between the two assessment sessions, and at the second session the physiotherapists did not have access to their previous scores. If a physiotherapist was unable to attend an assessment session the assessment was allowed to be performed at a later date.

\section{Study B}

\section{Participant characteristics, functions, and activities}

Data regarding participant characteristics was collected, and assessments of participant functions and activities were conducted by trained physiotherapists, including HS, and occupational therapists working at the three stroke units as soon as possible within 14 days from stroke onset. A five day span was allowed for data collection, and participants were asked to perform the tests as long as they had not failed in tasks with simpler instructions.

Stroke location (right or left hemisphere, brainstem, cerebellar), type (intracerebral hemorrhage, ischemic), whether the stroke was verified only by clinical signs or medical imaging (12), and consciousness (first item of National Institutes of Health Stroke Scale (NIHSS) (100) were registered. Medications at discharge were registered by the Anatomical Therapeutic Chemical Classification (ATC) code. Data collected by participant interview (Table 4), was obtained from family, care givers or 
medical reports when needed and analyzed as yes/no. After collecting all the data, the assessor judged whether the participant was at high or low risk of falling within a week and within six months.

Table 4. Participant characteristics analyzed in relation to falls (study B)

\begin{tabular}{|c|c|}
\hline Collected from medical reports & Collected from participant interview \\
\hline Age & General dizziness \\
\hline Sex & Dizziness when rising \\
\hline Body Mass Index & Depression during previous year \\
\hline Days from stroke onset to admission at stroke unit & Previous stroke \\
\hline Length of stroke unit stay (days) & Joint problems \\
\hline Discharged to home or elsewhere & Decreased sensibility in hands or feet \\
\hline Number of medications & Living permanently alone \\
\hline Number of medications >8 (101) & Length of education* \\
\hline $\begin{array}{l}\text { Number of medications } \geq 5 \text { with N05BA, } \\
\text { N05CD, N05CF or N06A included (102) }\end{array}$ & Falls during the previous year \\
\hline Antidepressants (N06A) & Falls during stroke unit stay \\
\hline \multicolumn{2}{|l|}{$\begin{array}{l}\text { Sedatives (N05A (but not N05AN), N05B, } \\
\text { N05BA, N05CD, N05C (but not N05CF)) }\end{array}$} \\
\hline \multicolumn{2}{|l|}{ Anti-hypertensives (C07, C08, and C09) } \\
\hline \multicolumn{2}{|l|}{ Benzodiazepine-related drugs (N05CF) } \\
\hline \multicolumn{2}{|l|}{ Beta receptor blockers (C07) } \\
\hline Narcotics (N02A) & \\
\hline
\end{tabular}

* Length of education $>12$ years (collected together with the MoCA)

The construct validity of the CEW (paper 2) was evaluated in relation to the following assessments that measure aspects of mobility, mental functions and sensory functions and that were expected to be related to CEW performance: The Functional Ambulation Classification (FAC) (103), Timed Up and Go (TUG) (104), the Serial 7s attention task from the Montreal Cognitive Assessment (MoCA) (105) (MoCA S7), the TUG with MoCA S7 added (TUG S7), and the Star Cancellation Test (SCT) (106). The side of the lesion (right/left) was also analyzed in relation to CEW.

The assessor-judged risk of falling, the participant characteristics presented in Table 4, and the functions and activities presented in Table 5 , were analyzed in relation to falls since they have been identified as potential fall risk factors in previous studies, or in our clinical experience. 
Table 5. Function and activity factors analyzed in relation to falls (study B)

\begin{tabular}{|c|c|}
\hline Functions & Activities \\
\hline $\begin{array}{l}\text { Global and specific mental functions (ICF code } \\
\text { b110-b189) }\end{array}$ & Self-care (ICF code d5) \\
\hline Cognition (by MoCA) & The Barthel index \\
\hline Impulse control (by EXIT) & Mobility (ICF code d4) \\
\hline Visual neglect (by SCT) & The Barthel items Transfers, Mobility, and Stairs \\
\hline Motor neglect & CST \\
\hline Sensory neglect in hands & ST \\
\hline Sensory neglect in feet & FAC \\
\hline Motor restlessness & CEW \\
\hline Fear of falling & TUG \\
\hline Participants' insights about their gait (by S-FAC) & TUG ATM \\
\hline $\begin{array}{l}\text { Participants' insights about their visuospatial } \\
\text { abilities }\end{array}$ & TUG S7 \\
\hline Latency in answers & $\begin{array}{l}\text { Walking with no aid, walking aid or transfer with } \\
\text { wheelchair }\end{array}$ \\
\hline Touch function (ICF code b265) & Ability to stand without support for 10 seconds \\
\hline \multicolumn{2}{|l|}{ Touch in the hands } \\
\hline \multicolumn{2}{|l|}{ Touch in the feet } \\
\hline \multicolumn{2}{|l|}{ Muscle power functions (ICF code b730) } \\
\hline \multicolumn{2}{|l|}{ Handgrip strength (by the Jamar dynamometer) } \\
\hline \multicolumn{2}{|l|}{$\begin{array}{l}\text { Motor function in arms (by fifth item in the } \\
\text { NIHSS) }\end{array}$} \\
\hline \multicolumn{2}{|l|}{$\begin{array}{l}\text { Motor function in legs (by sixth item in the } \\
\text { NIHSS) }\end{array}$} \\
\hline \multicolumn{2}{|l|}{ Movement functions (ICF code b750-b789) } \\
\hline \multicolumn{2}{|l|}{ Protective reactions while sitting (by PRT) } \\
\hline Protective reactions while standing (by PRT) & \\
\hline
\end{tabular}

Sex, CEW (two variables), protective reactions while sitting (two variables), and protective reactions while standing (two variables) were evaluated in relation to falls during the stroke unit stay.

\section{Data on falls}

The fall definition was given in oral and written form to all care givers at the three stroke units, to the participants, and when involved in the reports on post discharge falls, also family or care givers. A fall diary was distributed for daily reporting, as a memory support, and falls during six 
months from discharge were noted by monthly telephone calls to the participants or, when needed, the family or care giver.

To record falls during the stroke unit stay a study routine was implemented at the three stroke units, where falls were registered as written reports. Falls were also reported by the care givers as part of the clinical routine in daily reporting, and by the participants at discharge. The place (participant's room/bathroom/elsewhere), staff presence (yes/no), and whether the recommendations regarding use of walking aids and supervision were followed while transferring (yes/no) when falls occurred during the hospital stay were also noted.

For papers $3 \& 4$, falls were complemented by incidents registered in the National Quality Registry for Preventative Care.

\section{Outcome measures}

Addressing the multifactorial phenomenon of falls, several outcome measures were selected for this thesis, all of which are easy to use in clinical practice, and all except the MoCA (the complete test) taking less than five minutes to complete. Primarily, performance-based measures with established psychometric values were selected. For functions and activities lacking established assessments, those were developed (PRT, CEW) and tested for reliability (Study A). When supported by the literature several cut-offs were sometimes used due to the different aims of the papers. References to such cut-offs are presented in the text below.

\section{Performance-based measures}

\section{Global and specific mental functions (ICF code b110-b189)}

The Montreal Cognitive Assessment Scale (MoCA) (105) was developed for screening of mild cognitive impairment and takes approximately 1015 minutes to complete. The test assesses several cognitive domains: visuospatial, executive, attentional, concentration, language, abstraction, memory functions, and orientation to time and place, scored in 12 different items. The maximum score of 30 indicates the highest level of cognitive function. Also, one additional score for education $\leq 12$ years is added. High test-retest reliability and good internal consistency have been shown in a mixed group of persons with Alzheimer's disease, with mild cognitive impairments, and in elderly persons (105). The predictive validity of post-stroke cognitive impairments has been demonstrated at a 
total score of $\leq 21$ in persons with acute stroke $(107,108)$. In univariate analyses in persons with acute stroke, low MoCA scores were significantly associated with risk of falling $(50,59)$.

Impulse control was assessed by item 15 (Go/No-Go task) in the Executive interview (EXIT) (109). EXIT is a 25-item interview developed to assess executive cognitive function at the bedside. It takes approximately 10 minutes to perform and has been shown to be a reliable and valid assessment in elderly persons. In the Go/No-Go task the assessor performs a sequence of five alternating movements and notes whether the participant can follow the instructions correctly. When the assessor raises a finger the participant is told to touch their nose, and when the assessor touches their nose the participants should raise their finger (109).

The Star Cancellation Test (SCT) (106) was developed for screening of spatial neglect in persons with cerebrovascular accidents and usually takes less than five minutes to complete. The test is performed by marking 54 small stars on a paper containing large stars, small stars, and words. In papers $3 \& 4$, the SCT total score, SCT total score $\leq 44$ (110), SCT total score $\leq 50$ (111) and, SCT unilateral spatial neglect (110, 111) were analyzed in relation to falls. The SCT has been shown to be valid (111), and reliable (112) in persons with stroke, and tardiness in the SCT was related to an increased risk for falls in persons with stroke (113).

\section{Muscle power functions (ICF code b730)}

Handgrip strength was measured by using a Jamar dynamometer (114), which has been shown to be a reliable and valid assessment in several different populations including persons with stroke (reliability) (115) and elderly persons in general (validity) (116). The assessment is performed while sitting, with the dynamometer vertically presented, the shoulder adducted and neutrally rotated, the elbow flexed at 90 degrees, the forearm in a neutral position, and the wrist between 0 and 30 degrees extension, and o to 15 degrees ulnar deviation. The arm should not be supported. The assessment takes less than five minutes to complete. In papers $3 \& 4$ we present the results for handgrip strength in the weakest hand, the mean of three trials $(\mathrm{kg})(114)$, the mean of the weakest hand/mean of the strongest hand (\%), and the handgrip strength over the reference value for age and sex (117) in both, one or no hands. Reduced handgrip strength has been found to be a risk factor for falls in persons with stroke (113). 
Motor function in the arms was assessed by the fifth item in the National Institutes of Health Stroke Scale (NIHSS) (100). The NIHSS was developed for neurological examination of persons with acute stroke. It is a reliable and valid measure in persons with stroke, consisting of 15 items. For assessment of motor arm function the arm is lifted, with palms down, to 90 degrees (if sitting) or 45 degrees (if lying down). If the arm falls before 10 seconds the drift is scored. Both arms are assessed, with the non-paretic arm tested first. In papers $3 \& 4$ the fifth item was analyzed as paresis in $\geq$ one arm when the full score was not given for both arms.

Motor function in the legs was assessed by the sixth NIHSS item. The leg is raised to 30 degrees (when lying down), and drift is scored if the leg falls within five seconds. Both legs are assessed, with the non-paretic leg tested first (100). The NIHSS takes less than 10 minutes to complete. In papers $3 \& 4$ the fifth item was analyzed as paresis in $\geq$ one leg when the full score was not given for both legs.

\section{Movement functions (ICF code b75o-b789)}

The Postural Reactions Test (PRT) (74) (appendix to paper 1) was developed for assessment of postural reactions in persons with acute stroke. The PRT assesses equilibrium reactions, righting reactions, protective reactions while sitting, and protective reactions while standing. The four reactions can be reliably assessed and scored independently of each other. Equilibrium reactions and righting reactions are scored as: No/uncertain reaction (score $=0$ ), or a definite reaction (score $=1$ ). Protective reactions while sitting and standing are scored 0-2, with a high score indicating an intact protective reaction. PRT takes less than five minutes to complete and protective reactions in sitting can be used to identify persons with acute stroke at high risk for falls (papers $3 \& 4$ ).

\section{Mobility (ICF code d4)}

The 30 s Chair Stand Test (CST) (118) was developed for measuring lower body strength in elderly persons. The test begins with the person seated on a chair. With the arms crossed, the participant is encouraged to complete as many full stands as possible within 30 seconds. In the Swedish version used in papers $3 \& 4$, participants were allowed to use the hands if necessary, and in these cases this was noted. The CST is reliable in persons with acute stroke (119) and its validity has been confirmed in elderly persons (118). 
The Step Test (ST) (120) was developed for assessment of dynamic standing balance in persons with stroke and has been found to be reliable and valid for this population. The ST assesses a person's ability to repeatedly place a foot on a $7.5 \mathrm{~cm}$ high step and back to the floor as fast as possible in a period of 15 seconds. The score is counted for each leg separately and is equal to the number of completed steps within the 15 seconds. It has been shown that a cut-off score of $<7$ can be used for prediction of falls in persons with stroke (121).

The Functional Ambulation Classification (FAC) (103) was developed for distinguishing functional walking ability in persons with neurological impairments. It categorizes a person's walking ability into one of six categories, based on their level of human assistance needed and takes approximately one to five minutes to complete. It has been shown that persons with stroke categorized as FAC 4 have a higher risk for falls compared to FAC 5-6 (113) (category 6 being the most functional level of walking). FAC has been found to be reliable and valid in persons with stroke (122).

The Cone Evasion Walk Test (CEW) (88) (appendix to paper 2) was developed for assessment of the ability to avoid objects while walking in persons with acute stroke, by twice walking a distance of three meters between four cones without touching them. The cones are placed in relation to a temporary center line; at a $5 \mathrm{~cm}$ distance if no walking aid, crutches, or a cane is used, at a $25 \mathrm{~cm}$ distance for walkers, and a $30 \mathrm{~cm}$ distance for walking tables. The subjects perform the test with their ordinary walking aid at a self-chosen speed. The assessor records the total number of cones touched on each side (maximum four), summarizes the total score (maximum eight), and notes how many of the touches were made by the front or back of the walking aid, if one was used. The CEW takes less than five minutes to complete and is a reliable and valid assessment in persons with acute stroke. The number of cones touched in the CEW has been shown to be related to an increased risk for falls (88).

The Timed Up and Go (TUG) test (104) was developed to assess basic functional mobility in frail elderly persons by assessing the time it takes to rise from a chair, walk three meters at a safe and self-chosen speed, turn around, walk back, and sit down on the chair. Use of walking aids is allowed and the test takes less than two minutes to perform. The cut-off score of 13.5 recommended for prediction of falls by Shumway et al. (81) has also been shown to differentiate between fallers and non-fallers in 
persons with acute stroke (51). The TUG has been found to be a reliable and valid assessment in persons with stroke (123). TUG-cog tests are TUG tests performed with an additional cognitive task. In the original TUG-cog, individuals were asked to count backward while completing the TUG, and both the TUG-cog time and the time difference between TUG and TUG-cog were shown to differentiate between fallers and non-fallers (81). In papers $3 \& 4$ the TUG was performed with the Alternating Trail Making task from the MoCA (MoCA ATM) added (TUG ATM), which involved alternating naming numbers and letters $\left(1 \mathrm{~A}, 2 \mathrm{~B}, 3 \mathrm{C}, 4 \mathrm{D},{ }_{5} \mathrm{E}\right)$. In papers 2-4, the TUG 57 was also performed, which involved counting backward from one hundred in steps of seven, five times (93, 86, 79, 72, 65) while performing the TUG.

\section{Self-care (ICF code d5)}

The Barthel index (124) was developed for scoring independency in chronically ill persons by 10 items: Feeding, Bathing, Grooming, Dressing, Bowels, Bladder, Toilet use, Transfers, Mobility, and Stairs. The Barthel index is scored 0-100, with a score of 100 indicating the highest level of independency. The Barthel index takes less than five minutes to complete for staff members knowing the person, or approximately 20 minutes of direct observation. The index is reliable and valid in persons with stroke $(125,126)$. A cut-off of 95 has been recommended in persons with acute stroke to differentiate between favorable and unfavorable outcomes (127), and a cut-off of 20 is recommended for identification of persons with total dependency in self-care and mobility (128). Low Barthel scores (0-49) have been found to be significantly more common among fallers than non-fallers in persons with acute stroke (54).

\section{Clinician-reported measures}

\section{Global and specific mental functions (ICF code b110-b189)}

Sensory neglect was assessed by noting whether the participants were able to recognize touch (tested as described below) on two hands/feet at the same time. If not, that was interpreted as sensory neglect.

Motor neglect was considered present if no attempt to move was seen in one of the arms when participants were asked to raise both arms.

Motor restlessness was noted by the assessor telling the participant to sit/lie down, and then, for a period of one minute, judging whether the participant stayed in position calmly (judged as being motor calm), 
moved parts of the body but stayed in position (partly restless), or rose (restless).

Latency in answers (yes/no) was judged by the assessors when questions about participant characteristics were asked.

\section{Touch function (ICF code b265)}

Touch function in the hands was assessed by touching the dorsal side of the hands, one side at a time and asking the participant to state the location of the touch.

Touch function in the feet was assessed by the same procedure.

\section{Mobility (ICF code d4)}

Use of a walking aid was documented by noting how the participant transported themselves; whether a wheelchair or walking aids were used, or whether the participant could walk without support.

Ability to stand without support for 10 seconds, with a self-selected stance was noted (yes/no).

\section{Self-reported measures}

\section{Global and specific mental functions (ICF code b1)}

The participants' views on their visuospatial ability were assessed by asking them whether they believed they had marked all stars in the SCT (yes/no/unsure). The actual number of marked stars was compared to the participants' judgment of their SCT performance and analyzed as participant overestimation (yes/no).

The participants' views on their gait were assessed by asking them for a Self-Reported Functional Ambulation Classification (S-FAC). The functional ambulation category judged by the assessor was compared to the participants' judgment and analyzed as participant overestimation (yes/no).

Fear of falling was noted by asking the participant whether they had no, minor, moderate, or a major fear of falling. 


\section{Statistical methods}

\section{Study A}

For inter-rater reliability, we noted the most common score for each participant and the number of physiotherapists who gave that score. Next, the median and quartiles were calculated for how many physiotherapists had scored the most common value for all participants (Table 6). For continuous data (CEW), consistency in scoring between the ten physiotherapists, was also examined by the intra-class correlation coefficient (ICC 2,1) (two-way random effect model, absolute agreement definition, single measure) with a 95\% confidence interval (CI) (129).

The medians and quartiles of the two test sessions were calculated for intra-rater reliability, and the overall proportions of agreement (in percentage) between the two test sessions were determined. In addition to this, the scoring consistency between the two sessions was examined using ICC 2,1 for continuous data.

The non-participants were compared to the participants using the MannWhitney U-test (age and days since stroke onset) and Fischer's exact test (sex). A p-value < 0.05 was considered significant.

Table 6. Example of how the number of PTs scoring the most common value was calculated to assess the inter-rater reliability $(n=20)$ for each test.

Ex. Equilibrium reaction, leaning to the right side, 10 PTs scoring videos of 20 participants

\begin{tabular}{|c|c|c|c|c|c|c|c|c|c|c|c|}
\hline Participant & PT1 & PT2 & PT3 & PT4 & PT5 & PT6 & PT7 & PT8 & РT9 & PT10 & $\begin{array}{l}\text { Number of PTs } \\
\text { scoring the most } \\
\text { common value }\end{array}$ \\
\hline 1 & 1 & 1 & 1 & 1 & 1 & 1 & 1 & 1 & 1 & 1 & 10 \\
\hline 2 & 1 & 1 & 1 & 1 & 0 & 1 & 1 & 1 & 1 & 1 & 9 \\
\hline 3 & 0 & 0 & 0 & 0 & 0 & 0 & 0 & 1 & 0 & 0 & 9 \\
\hline • & - & • & • & • & - & • & - & - & • & • & • \\
\hline 20 & • & • & • & • & • & • & • & • & • & • & $\begin{array}{l}\cdot \\
\text { Median (q1-q3): } \\
10(9-10)\end{array}$ \\
\hline
\end{tabular}




\section{Study B}

In paper 2, pairwise comparisons with the Wilcoxon's test were used for analyzing touches made by the front/back wheels of walking aids used while performing the CEW. Construct validity was investigated using Spearman's rank correlation coefficient and Fisher's exact test. A correlation coefficient between $\mathrm{O}$ and 0.50 was considered as poor correlation, $0.50-0.75$ as moderate correlation, $0.75-0.90$ as good correlation, and $0.90-1$ as excellent correlation (129). In each analysis of construct validity, participants who did not perform the CEW and the other test on the same day were excluded. The relationship between the CEW and the number of falls was analyzed by linear regression, and the number of days to the first fall incident was analyzed by Cox regression. Only participants who took part of all the six-month follow-ups were included in the analyses of the CEW in relation to falls $(n=203)$. A $p$-value of $<0.05$ was considered significant.

In papers $3 \& 4$ the independent variables were analyzed by Cox regression (number of days to the first fall incident) and by nbreg (fall incidence), and the results are presented as risk of early falls and risk of multiple falls/high fall incidence respectively. In both Cox regression and nbreg, both the time and the falls are taken into account, which is recommended in studies of falls (97). The proportional hazard assumption in Cox regression was tested and when assumptions were not met, analyses with o-3 month and 4-6 month follow-ups were performed and found to be different.

The aim of the explorative study B was to present generalizable results of the fall risk connected to all single variables studied. Therefore, analyses were performed univariately, factor for factor, including all participants. The analyses were performed for all the recruited participants, but also for men and women separately. The Bonferroni correction suggests that variables with $\mathrm{p}<0.0005$ should be considered significant in this study ( $\mathrm{p}$ $<0.05 / 95$ variables in paper $3, \mathrm{p}<0.05 / 94$ in paper 4).

For sex, PRT, and the CEW, logistic regression was used for analysis of differences between fallers and non-fallers during the stroke unit stay, and nbreg was used for analysis of fall incidence during the stroke unit stay. Differences between women and men in monthly fall incidence were analyzed with Poisson regression, and a p-value of $<0.05$ was considered significant. 
The non-participants were compared with the participants using an Independent Samples T-Test (age and days since stroke onset) and Chisquare (sex). A $p$-value of $<0.05$ was considered significant.

Partly because of our ambition to identify rapid and easily administered assessments and data that could be used for identification of persons at high risk of falls, in papers $3 \& 4$ the Barthel index and the MoCA were analyzed both as total scores, and all items separately. In the MoCA, the three visuospatial/executive items ATM, Cube, and Clock were also analyzed together, as well as the three attention items Digit Span, Vigilance, and S7, and the two language items Sentence Repetition and Verbal Fluency.

Data collected for the left and right side separately were recoded into new variables. A variable with three categories; well-functioning on both sides, one side or no side was created, and when scores were used, scores on the worst side were analyzed. The continuous variables were analyzed as continuous variables, and when established cut-offs were identified analyses of those were added. The cut-offs for the CEW were based on the results of this study. For some variables (CEW, FAC, and several of the MoCA items) the fall risk outcome did not correlate with the order of test categories in a logical way, and for some variables (sensibility decreased in $\geq$ one hand, sensibility decreased in $\geq$ one foot, paresis in $\geq$ one arm, paresis in $\geq$ one arm leg (yes/no), and some of the MoCA items) fewer than $5 \%$ of the participants were in a category. Therefore, these variables were not presented with their original number of categories, and MoCA Delayed recall and MoCA Attention 3 tasks do not have the full score as the reference category in the analyses. All the MoCA items were dichotomized to be equivalent to each other. Lateralized neglect was assessed by measuring asymmetry in detected targets in the SCT. The number of marked stars on the left side was divided by the total number of marked stars (110) and unilateral spatial neglect was defined as star ratio 0-0.46 (left neglect) and 0.54-1 (right neglect) (111). The variable length of stroke unit stay was logarithmized due to a positive skewness in the variable.

Participants who had failed in tasks with simpler instructions due to cognitive impairments were not always asked to perform specific items in the MoCA for ethical reasons. In these cases, a score of o was given on that item $(n=8-10)$. The same course of action was taken for aphasia in the language tasks in the MoCA $(n=6-7)$, motor impairment $(n=45)$ or 
impaired vision $(\mathrm{n}=2)$ in the variable " $\mathrm{CEW}>2$ touches on the worst side or unable", and motor impairments for ST, CST, hand grip strength, standing with no support, and FAC ( $n=64 / 27 / 13 / 13 / 8)$. If someone had not completed the TUG after 60 seconds, that performance was analyzed as taking 60 seconds $(n=6)$. For participants who performed the TUG ATM or TUG S7 quicker than the TUG $(n=0 / 6)$, the time difference was set to 0 .

\section{Ethical considerations}

Both studies were conducted in accordance with the Declaration of Helsinki, and approved by the Regional Ethical Review Board in Linköping (study A: dnr; 2013/14-31 (original), dnr ; 2013/132-32, dnr ; 2013/291-32, dnr ; 2017/578-32), (study B: dnr ; 2015/353-31 (original), dnr ; 2017/577-32, dnr ; 2018/199-32). All participants in study A gave written informed consent. In study B, all participants with the ability to give written informed consent did so. Persons in a palliative state were not included due to the exclusion criteria "risk of impaired health from being asked about participation". When the exclusion criteria were not violated, participants not able to give informed consent were included as permitted in the ethical approval.

We paid close attention to what the participants had energy to do and the assessments were performed on different occasions with rest in between when needed. The participants were informed that they could decline to perform any test, and could interrupt their participation in the study whenever they wanted without further explanation. We did not judge the fall risk to be increased when performing the tests under the supervision of a physiotherapist.

If the research described in this paper had not been conducted the knowledge gaps described in the rational of this thesis would still remain. 


\section{RESULTS}

\section{Study A}

For inter-rater reliability of the four items in the PRT, nine to ten out of ten physiotherapists scored the same value (Table 7). For intra-rater reliability the overall proportion of agreement was $91 \%$ for the equilibrium reactions, $87 \%$ for the righting reactions and $92 \%$ for protective reactions while sitting and standing (Table 8). The ICC analysis shows that inter-rater reliability was excellent for the CEW total score, and touches made by the front of a walking aid. Also, 10 of 10 physiotherapists scored the same value in median. For touches made by the back of a walking aid, the ICC analysis indicated that inter-rater reliability was good, and nine out of ten physiotherapists scored the same value in median (Table 7). Intra-rater reliability was excellent for both the CEW total score, touches with the front, and the back based on the ICC analysis. The overall proportion of agreement was $90 \%, 83 \%$, and $70 \%$ for the total score, the front touches, and the back touches (Table 8).

Table 7. Inter-rater reliability for the Cone Evasion Walk Test and the Postural Reactions Test

\begin{tabular}{|l|l|l|}
\hline \multicolumn{1}{|c|}{ Inter-rater reliability } & $\begin{array}{c}\text { Number of PTs scoring the most } \\
\text { common value, median (q1-q3) }\end{array}$ & \multicolumn{1}{c|}{ ICC (95\% CI) } \\
\hline CEW total score & $10(10-10)$ & $0.96(0.94-0.98)$ \\
\hline CEW front* & $10(7-10)$ & $0.93(0.85-0.98)$ \\
\hline CEW back* & $9(6-10)$ & $0.88(0.74-0.97)$ \\
\hline Equilibrium reactions & $10(9-10)$ & \\
\hline Righting reactions & $9(8-10)$ & \\
\hline Protective reactions in sitting & $10(9-10)$ & \\
\hline Protective reactions in standing & $10(9-10)$ & \\
\hline
\end{tabular}

* Touches with the front respectively back of a walking aid

$\mathrm{PT}=$ physiotherapist 
Table 8. Intra-rater reliability for the Cone Evasion Walk Test and the Postural Reactions Test

\begin{tabular}{|l|l|l|l|l|}
\hline \multicolumn{1}{|c|}{ Intra-rater reliability } & \multicolumn{1}{|c|}{$\begin{array}{c}\text { First test } \\
\text { session, } \\
\text { median (q1-q3) }\end{array}$} & $\begin{array}{c}\text { Second test } \\
\text { session, } \\
\text { median (q1-q3) }\end{array}$ & $\begin{array}{c}\text { Overall } \\
\text { Proportion of } \\
\text { agreement (\%) }\end{array}$ & ICC (95\% CI) \\
\hline CEW total score & $0(0-2)$ & $0(0-2)$ & 90 & $0.98(0.97-0.98)$ \\
\hline CEW front* & $0(0-3)$ & $1(0-3)$ & 83 & $0.94(0.91-0.96)$ \\
\hline CEW back* & $2(0-2)$ & $2(0-2)$ & 70 & $0.91(0.86-0.94)$ \\
\hline Equilibrium reactions & $1(1-1)$ & $1(1-1)$ & 91 & \\
\hline Righting reactions & $1(1-1)$ & $1(1-1)$ & 87 & \\
\hline $\begin{array}{l}\text { Protective reactions in } \\
\text { sitting }\end{array}$ & $2(1-2)$ & $2(1-2)$ & 92 & \\
\hline $\begin{array}{l}\text { Protective reactions in } \\
\text { standing }\end{array}$ & $1(1-1)$ & $1(1-1)$ & 92 & \\
\hline
\end{tabular}

* Touches with the front or back respectively of a walking aid

\section{Study B}

In mean, participants were assessed five days from stroke onset.

\section{The Postural Reactions Test}

Impaired protective reactions while sitting was a decisive risk factor for early falls $(\mathrm{p}<0.0005)$ and a possible risk factor for multiple falls. When the analyses were performed for women and men separately it was a possible risk factor for both sexes, with a particularly high impact in the women (Table 9). The variable protective reactions while standing, scores on the worst side, was not significantly associated with a high risk for falls in any of the analyses ( $>0.05)$. Men having no intact protective reactions while standing at either side had an increased risk for early falls (HR, 2.25 [95\% CI, 1.22-4.17] $\mathrm{p}=$ =.010) (Supplemental material for paper 4). 


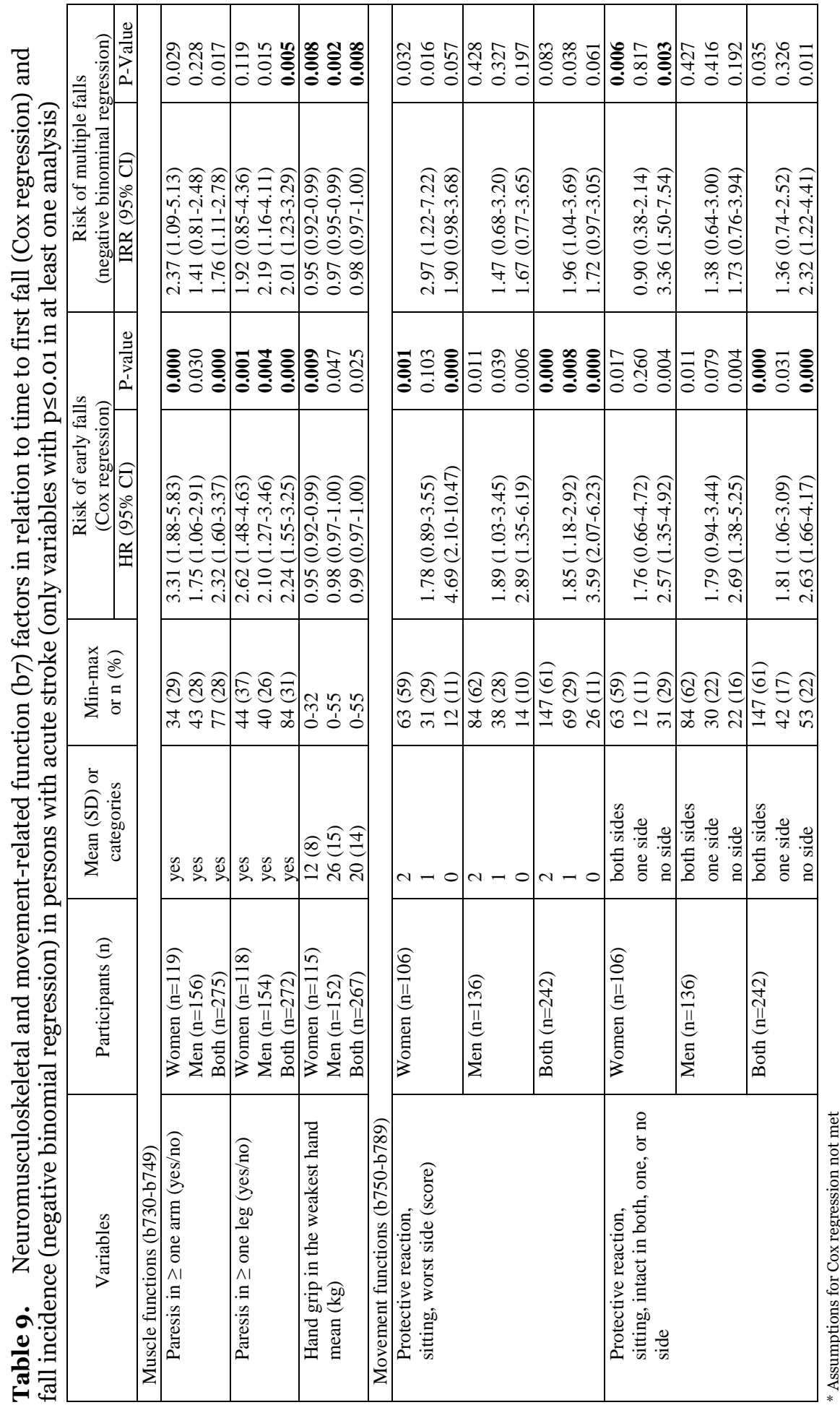




\section{The Cone Evasion Walk Test}

Of the 221 persons performing the CEW in paper 2, 62\% did not use a walking aid and $71 \%$ of the participants did not touch any cones, showing a floor effect of the test. Among the participants not using walking aids $12 \%$ touched the cones, among participants using walking aids $56 \%$ touched the cones, and significantly more cones were touched with the back wheels compared to the front wheels $(p=0.02)$. In mean, three (range 1-7) cones were touched among those who touched cones.

Significantly poor correlations were found in the analyses of construct validity between the CEW and TUG $(r \mathrm{~s}=0.45)$, MoCA-S7 $(r \mathrm{~s}=-0.36)$, and the SCT total score $(r \mathrm{~s}=-0.36)$, and a moderate correlation was found to FAC ( $r \mathrm{~s}=-0.67)$, but not to TUG S7. There were significant poor correlations between the number of cones touched on the left side and the number of marked stars on the left $(r \mathrm{~s}=-0.23)$ and right $(r \mathrm{~s}=0.23)$ sides in the SCT. No correlation was seen between the number of cones touched on the right side and the SCT. Among participants with right hemisphere stroke ( $n=79)$, significantly more persons hit cones on the left side $(n=25)$ compared to the right $(\mathrm{n}=8)$, and among persons with left hemisphere stroke $(n=64)$ significantly more persons hit cones on the right side $(n=11)$ compared to the left $(n=3)$.

The linear regression analysis in paper 2 showed a significant poor correlation between the number of cones touched in the CEW and number of falls, which became more robust when only those who touched the cones were included in the analyses (Table 10). Being unable to perform the CEW or having two touches or more on the worst side was associated with an almost doubled risk for early falls in both women and men when analyzed separately in paper 4 , and in the three month followup this limitation more than doubled the risk for early falls for the total cohort. The risk for a high fall incidence was similar in the three- and sixmonth follow-ups for the total cohort (IRR, 1.78-1.79, $\mathrm{p}=0.023-0.034$ ). (Table 10). 


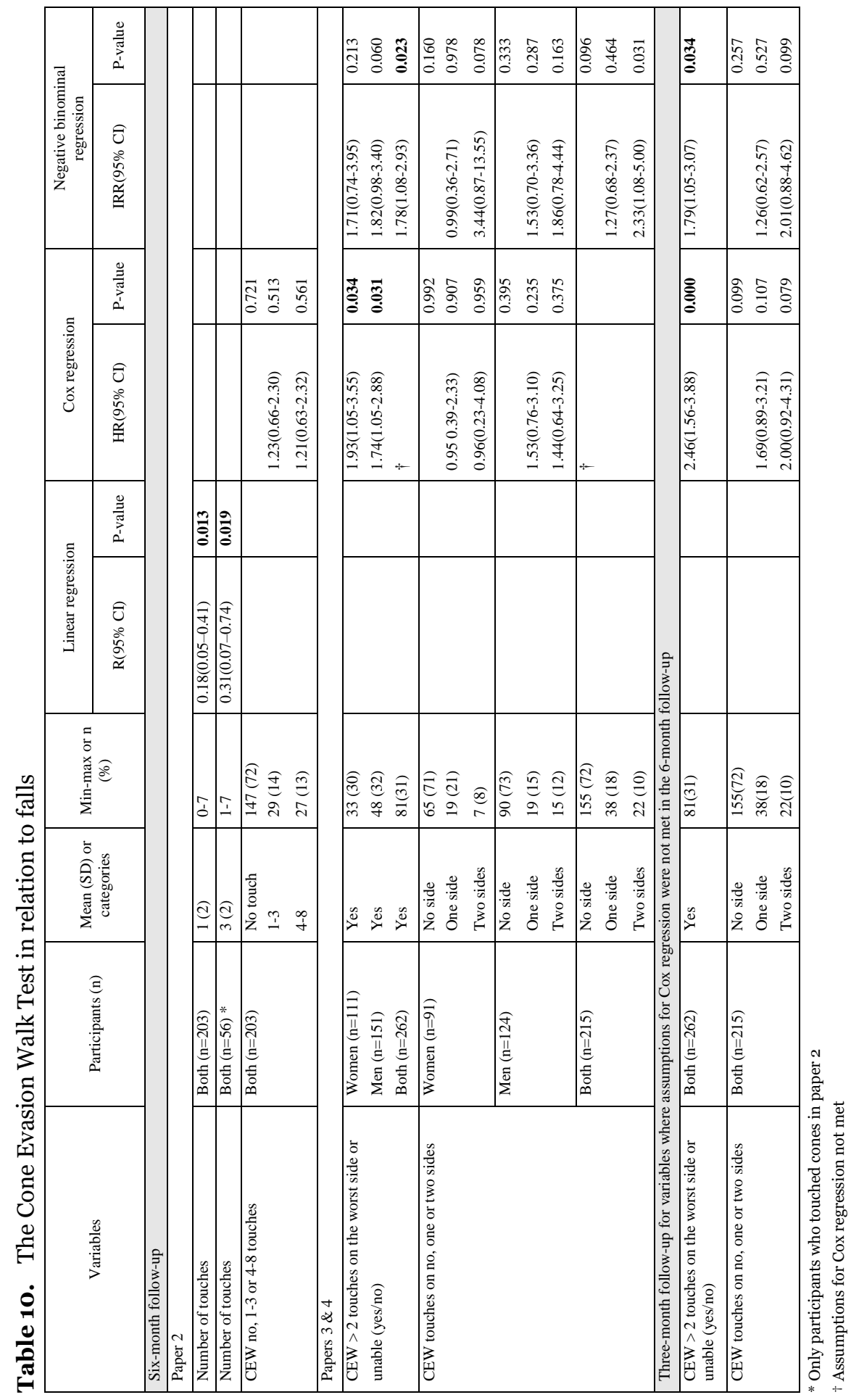




\section{Fall incidence}

During the six months of follow-up after discharge from the stroke units, 118 (42\%) participants fell ( 51 women $67 \mathrm{men}$ ), yielding an incidence rate of 2.22 (95\% CI 1.73-2.86) falls for each person-year, and a monthly incidence rate of 0.178 falls for women and 0.185 falls for men, during the six-month follow-up. For men, the fall incidence during the first month was almost doubled compared to women's (IRR, 1.85 [95\% CI, 1.14-3.02] $\mathrm{p}=0.013$ ) (Figure 2). In median, the female fallers experienced one fall and the male fallers two, (range) (1-18/1-17), and 52/46 (1-177/0-178) days passed from discharge to the first fall. Only $20(7 \%)$ of the participants experienced more than three falls.

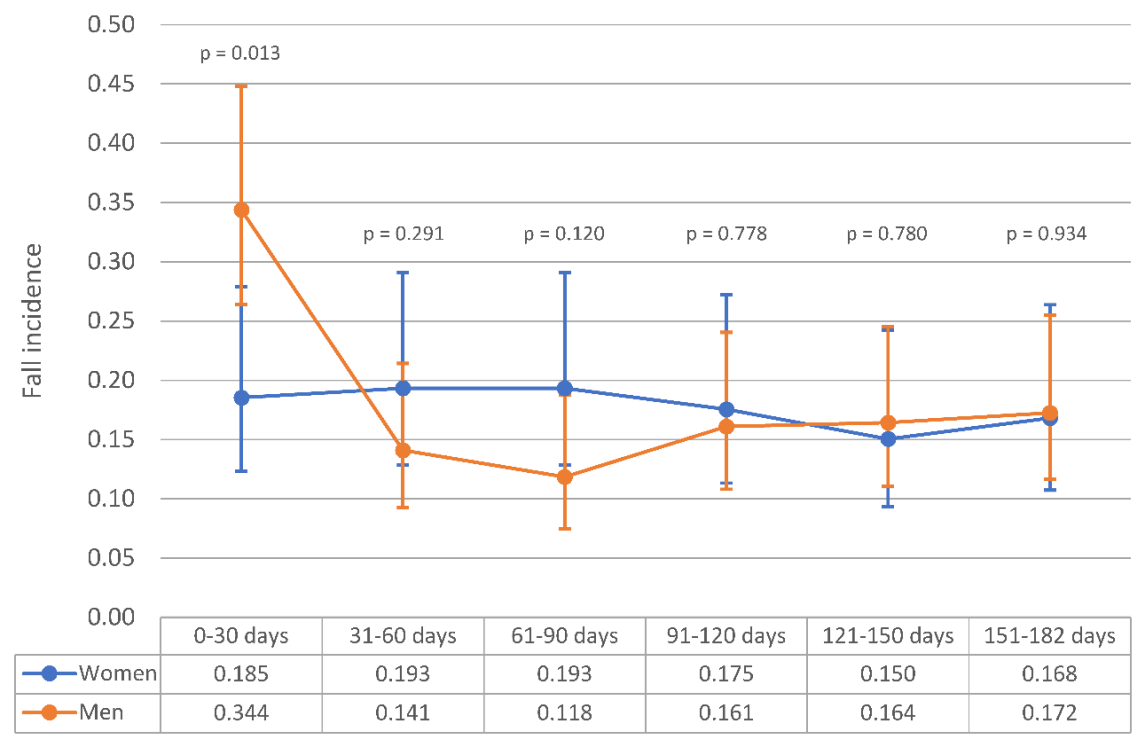

Figure 2. Monthly fall incidence by sex 


\section{Fall risk factors}

In the text below, the most decisive risk factors for falls are presented for the total cohort, and for women and men separately. In men, no variables were significant when the limit $\mathrm{p}<0.0005$ was used, whereas possible risk factors for falls, with $\mathrm{p} \leq 0.01$ are presented. Variables with a $\mathrm{p}$-value of $\leq$ 0.01 in one or both analyses, for both sexes, women, or men, are presented in Tables $9 \&$ 11-15. Please see supplemental material for paper 3 \& 4 for complete results of all variables included in the study.

\section{Participant characteristics}

In the total cohort, intake of more than eight medications was a decisive risk factor for early falls, and the assessors' judgment of the six-month fall risk was particularly well suited for identification of persons at high risk for multiple falls both in the total cohort and in women $(\mathrm{p}<0.0005)$.

For men, intake of a high number of medications, more than 8 medications, antidepressants, and $\geq 5$ medications including No5BA, No5CD, No5CF, or No6A, were possible risk factors for falls $(\mathrm{p} \leq \mathrm{0.01})$ (Table 11).

\section{Functions}

Among the functions assessed in this study the most decisive risk factors for falls were seen among the neuromusculoskeletal and movementrelated functions (ICF code b7). Paresis in the arms, paresis in the legs, and impaired protective reactions while sitting were decisive risk factors for early falls in the total cohort, and paresis in the arms was a risk factor for early falls in women (Table 9). For women, mental functions (ICF code b1) were also seen among the risk factors for falls, including motor restlessness, and visuospatial neglect (assessed by the SCT) $(\mathrm{p}<0.0005)$. (Table 12).

In men, possible risk factors for falls were paresis in the legs, low handgrip strength (Table 9), and impaired attention (assessed by MoCA Attention 3 tasks) $(\mathrm{p} \leq 0.01)$ (Table 12). 


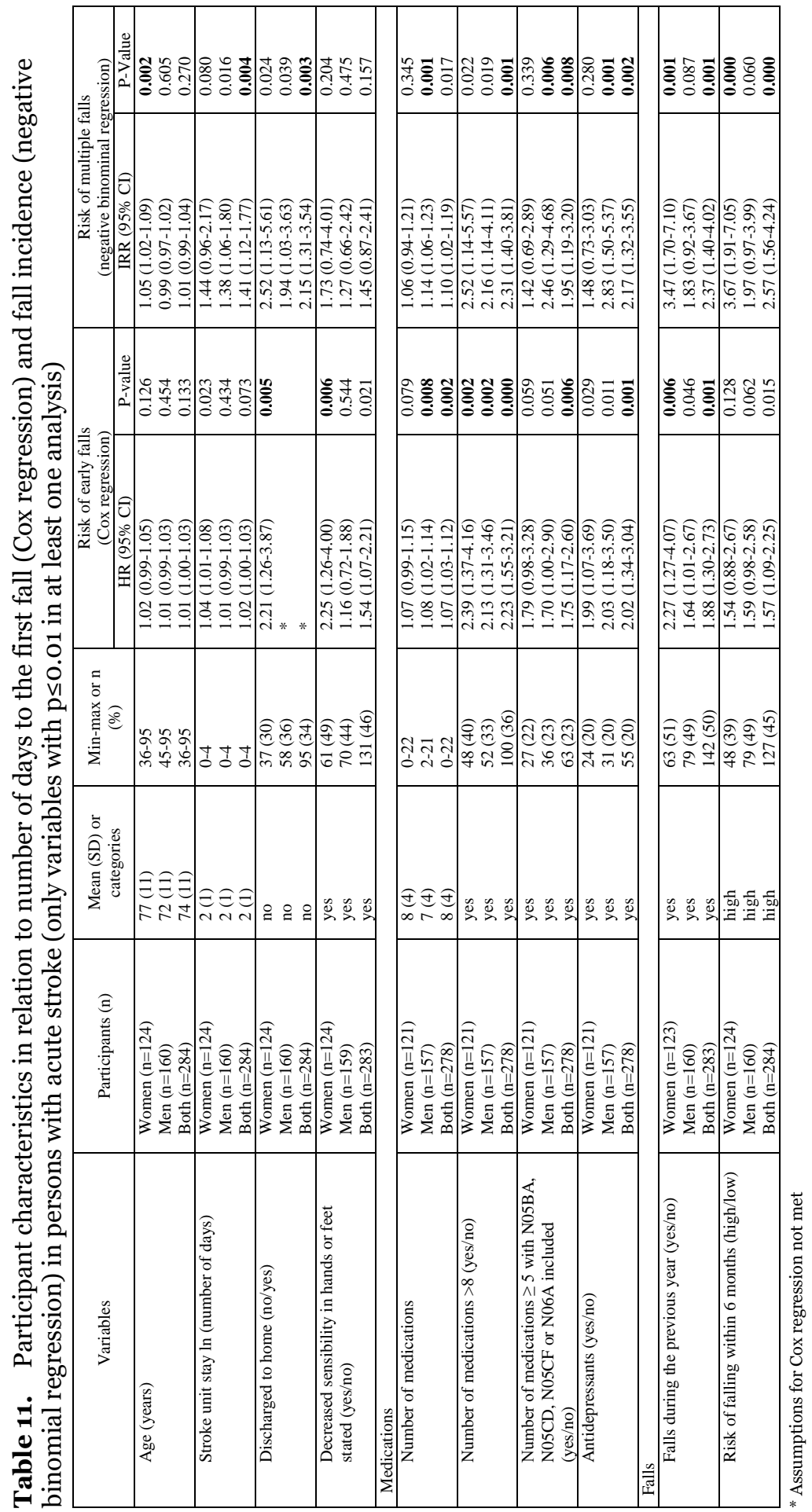




\section{Activities}

Limitations in activities of self-care (ICF code d5) had a higher impact on the risk for early falls than it had on the risk of a high fall incidence. Low Barthel total scores, and the category "dependent" in the separate Barthel items Grooming, and Toilet can be used for identification of persons at risk for early falls (Table 13). Limited ability in changing and maintaining body position (ICF codes d410-d429) had a high impact on the risk for high fall incidence. A low number of repetitions in CST, and low number of steps in ST can be used for identification of persons at high risk for multiple falls $(\mathrm{p}<0.0005)$ (Table 14).

Also in women, limitations in activities of self-care (ICF codes d5) had a high impact on the risk for early falls. A low Barthel total score, the separate items Barthel Grooming (dependent), Bowels (incontinent), and Toilet use (dependent) can be used for identification of women at high risk for early falls. Women categorized in the lowest category in Barthel total score (0-20 scores) had a more than five times doubled risk for multiple falls (Table 13). Limited mobility (ICF code d4) also increased the risk for falls in women. Assessment of the ability to stand without support for 10 seconds (Table 14), and Barthel Mobility (immobile) can be used for identification of women at high risk for early falls (Table 15), and a low number of steps with the most impaired leg in ST (Table 14), long performance time in the TUG, and being categorized in one of the two categories, 14-60 s, or unable, in TUG categories, can be used for identification of women at high risk for multiple falls, the unable category being the one with the highest risk (IRR, 5.56 [95\% CI, 2.38-13.02] $\mathrm{p}<0.0005$ ) (Table 15).

In men, limited mobility (ICF code $\mathrm{d} 4$ ) was a possible risk factor for falls. Long performance time in the TUG (Table 15), the Barthel item Transfers (major help), and a low number of repetitions in the CST can possibly be used for identification of men at high risk for falls $(\mathrm{p} \leq \mathrm{0.01})$ (Table 14). 


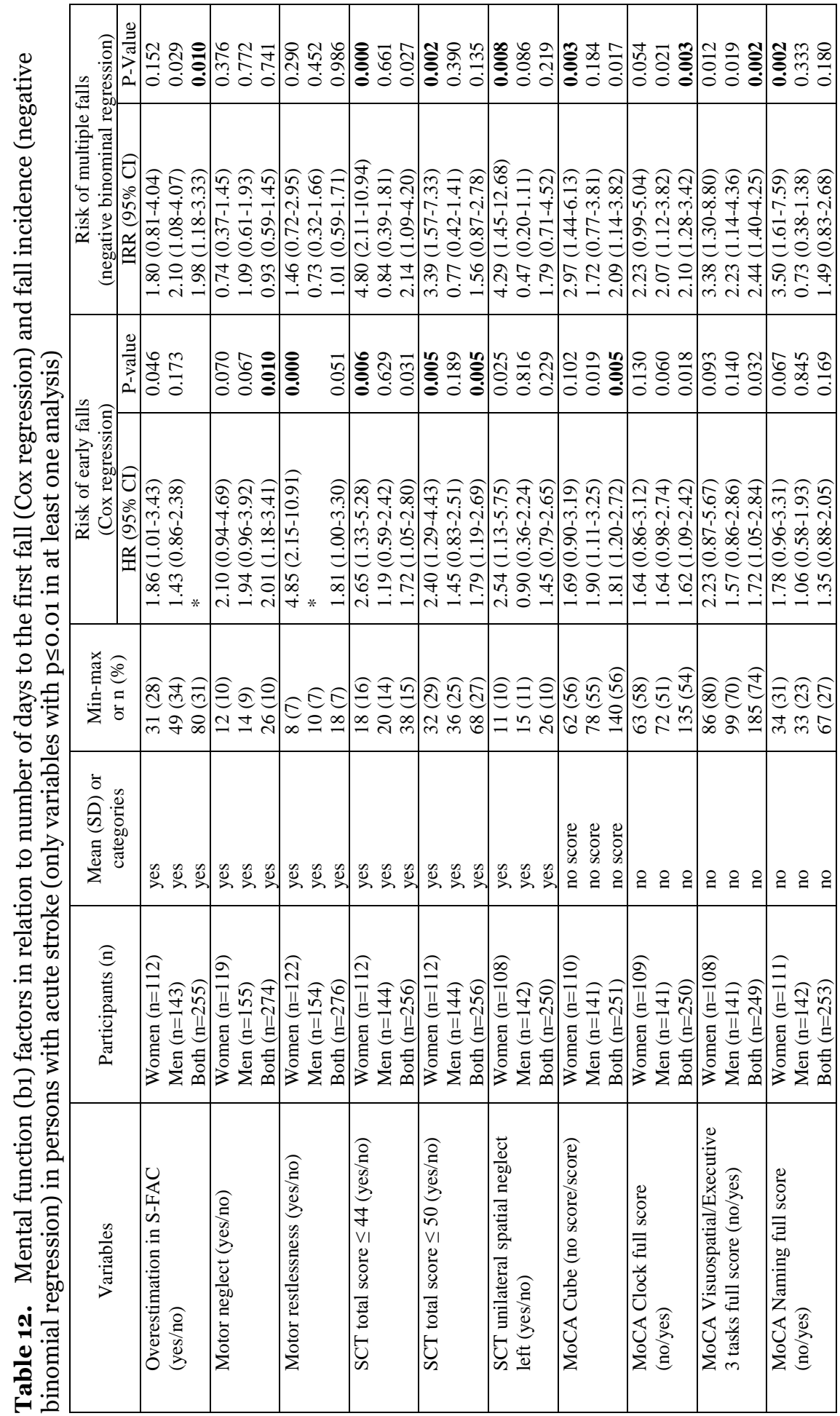




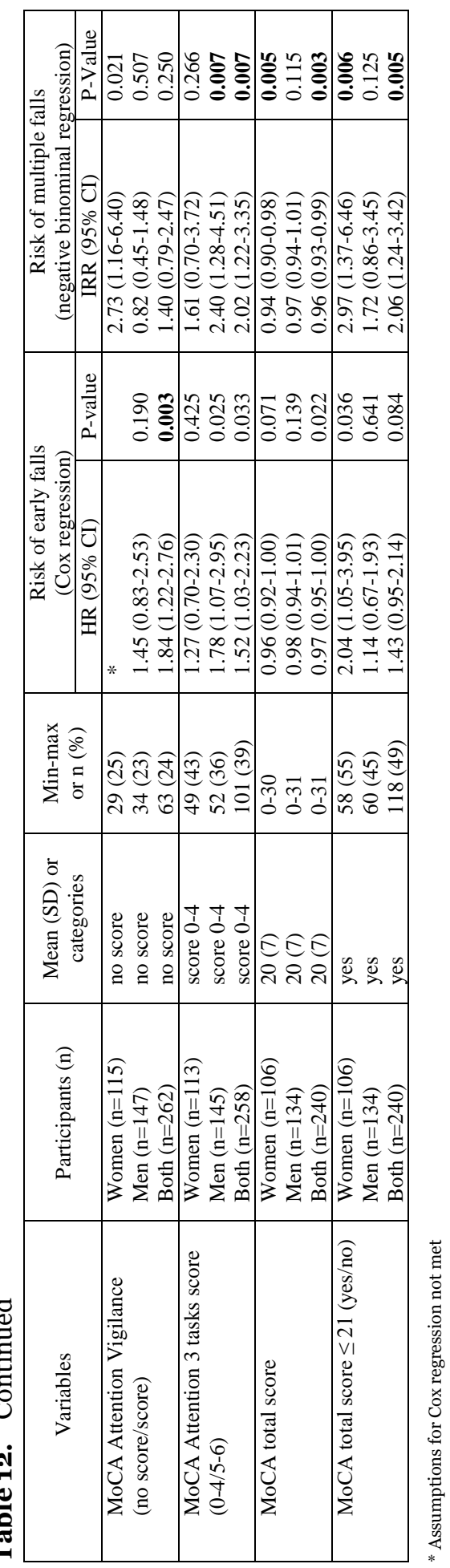




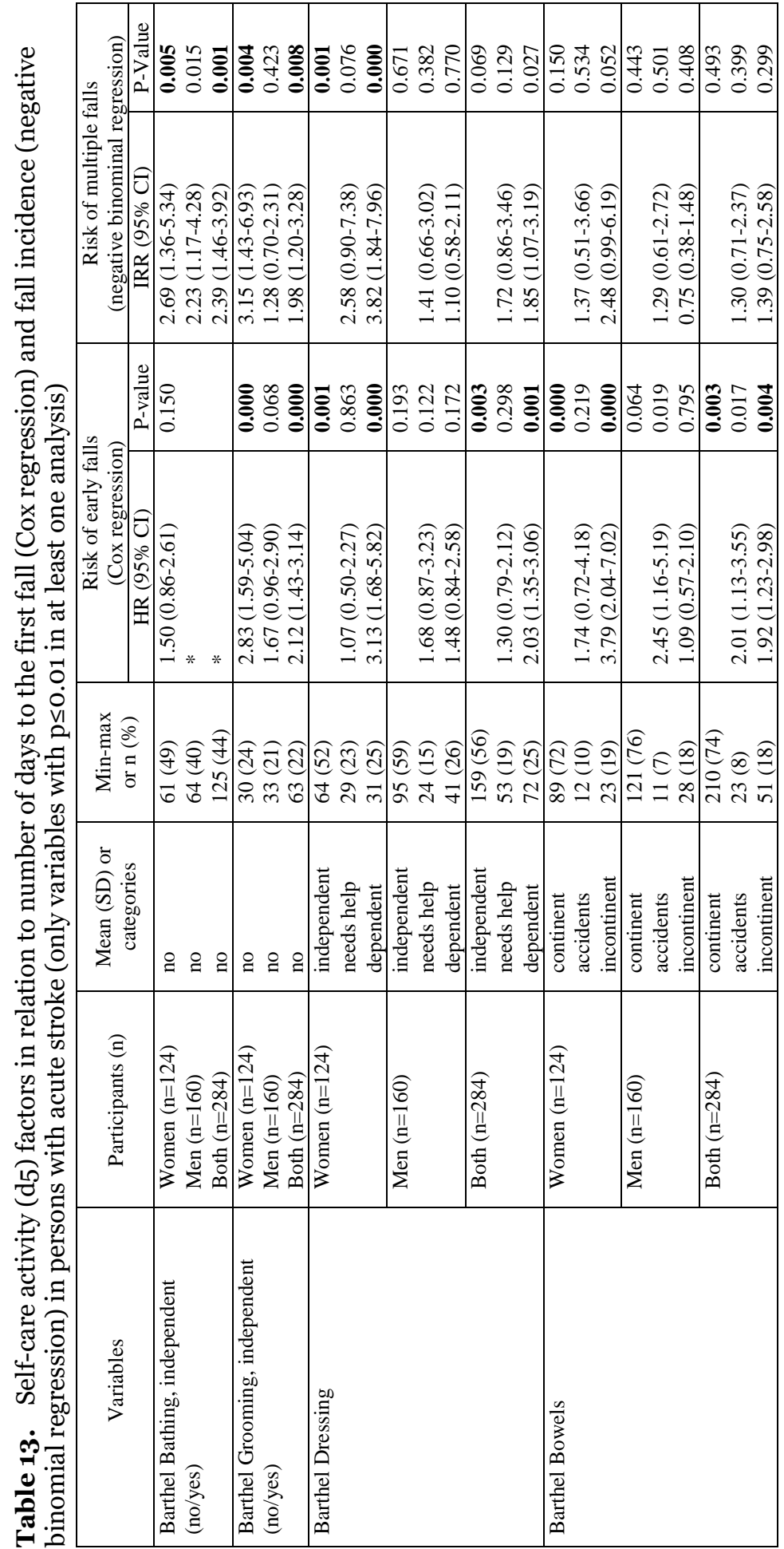




\begin{tabular}{|c|c|c|c|c|c|c|c|c|c|c|}
\hline \multirow{2}{*}{ 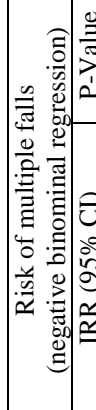 } & $\mid \begin{array}{lll}\infty & \infty & \\
0 & 0 & 0 \\
0 & 0 & 0 \\
0 & 0 & 0 \\
0\end{array}$ & 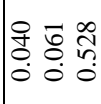 & 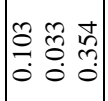 & 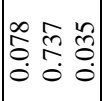 & $\left|\begin{array}{ccc} & 0 & 0 \\
\sigma & 1 & 0 \\
0 & 0 & 0 \\
0 & 0 & 0\end{array}\right|$ & 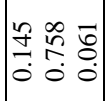 & 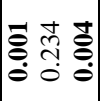 & 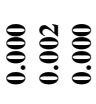 & 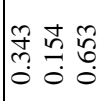 & $\mid \begin{array}{ccc}2 & \bar{a} & \overline{0} \\
0 & 0 & 0 \\
0 & 0 & 0\end{array}$ \\
\hline & 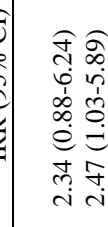 & 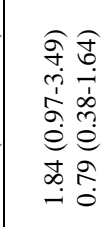 & 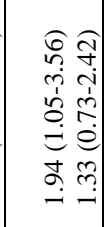 & 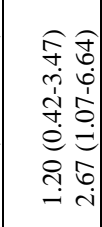 & 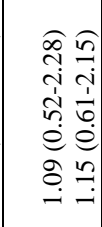 & 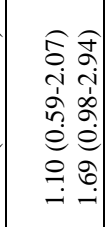 & 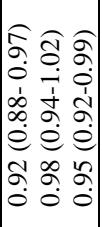 & 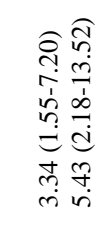 & 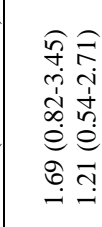 & 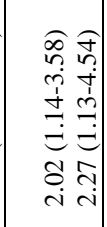 \\
\hline \multirow{2}{*}{ 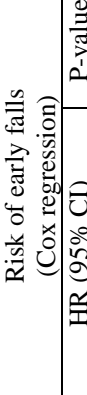 } & 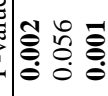 & $\begin{array}{lll}0 & 0 \\
0 & 0 & 0 \\
0 & 0 & 0 \\
0 & 0 & 0 \\
0 & 0\end{array}$ & 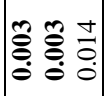 & 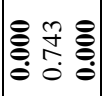 & 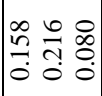 & $\mid \begin{array}{ccc}0 & 0 \\
0 & 0 & 0 \\
0 & 0 & 0 \\
0 & 0 & 0\end{array}$ & 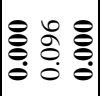 & 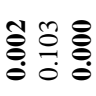 & 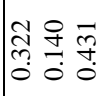 & 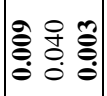 \\
\hline & 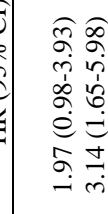 & 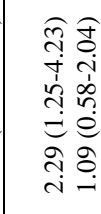 & 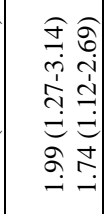 & 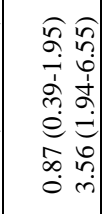 & 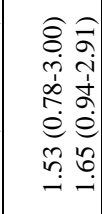 & 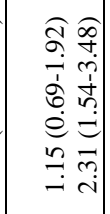 & 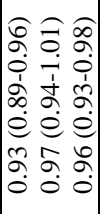 & 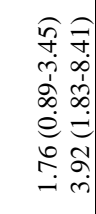 & 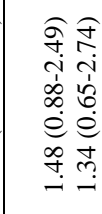 & 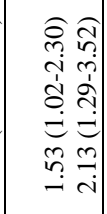 \\
\hline 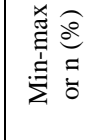 & 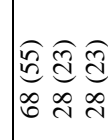 & 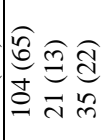 & 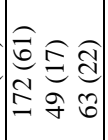 & 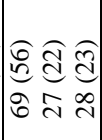 & 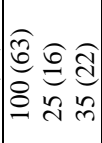 & 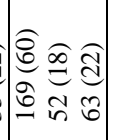 & $\frac{8}{\frac{8}{1}} \frac{8}{1} \frac{8}{1}$ & 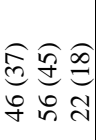 & 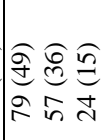 & 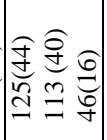 \\
\hline 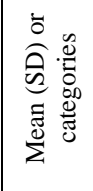 & 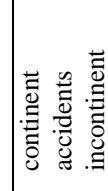 & 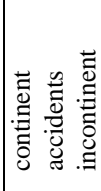 & 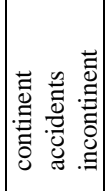 & 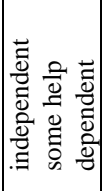 & 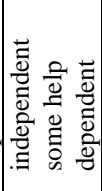 & 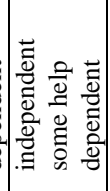 & 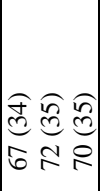 & 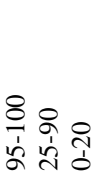 & 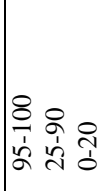 & 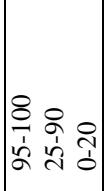 \\
\hline 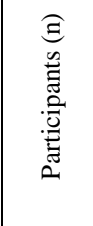 & 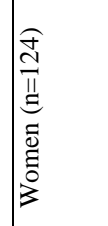 & 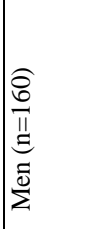 & 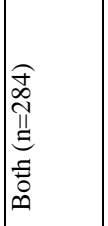 & 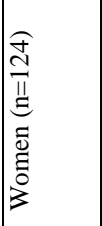 & 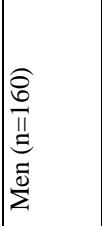 & 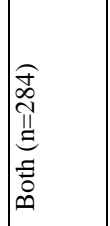 & 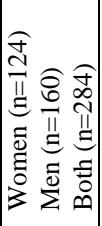 & 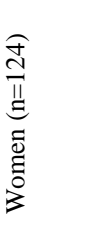 & 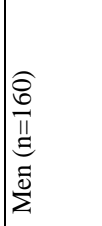 & 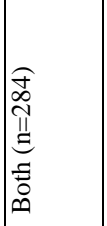 \\
\hline $\begin{array}{l}\frac{3}{0} \\
\frac{0}{0} \\
\frac{\pi}{\pi} \\
\frac{\pi}{7}\end{array}$ & 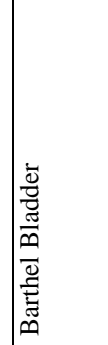 & & & 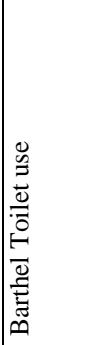 & & & 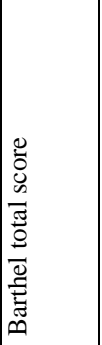 & 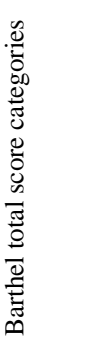 & & \\
\hline
\end{tabular}




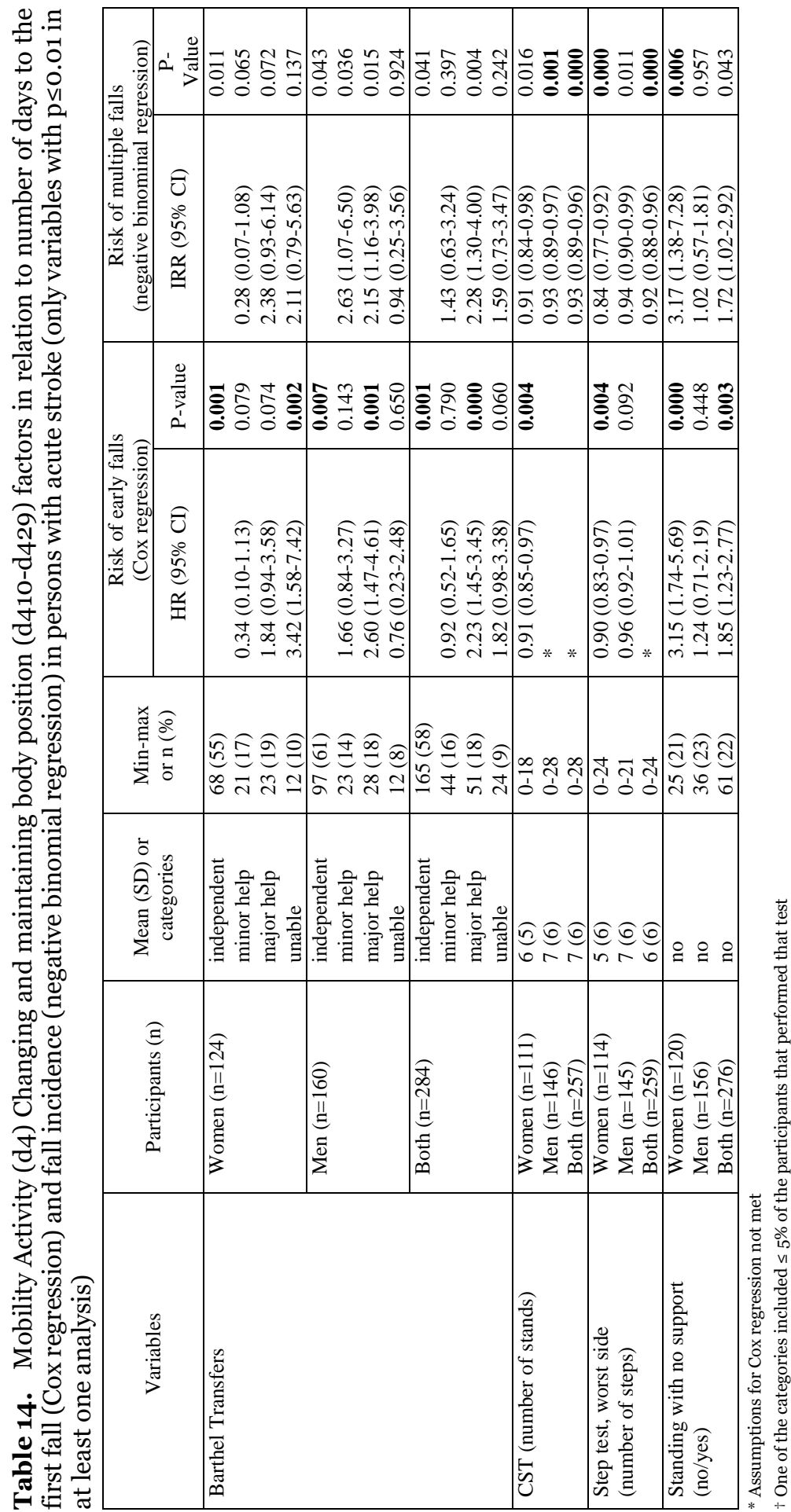




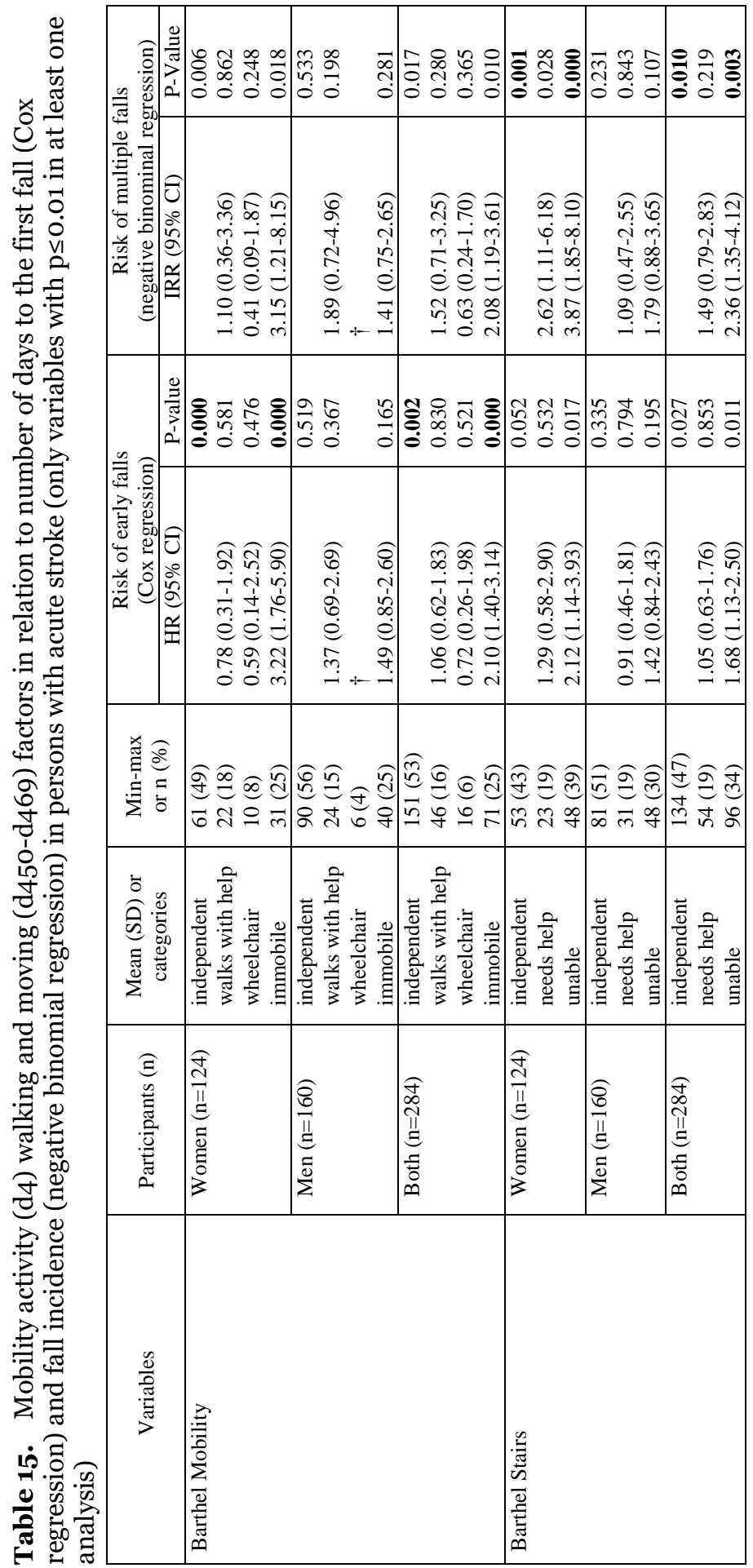




\begin{tabular}{|c|c|c|c|c|c|c|c|c|c|c|}
\hline 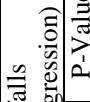 & 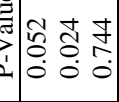 & 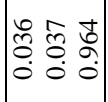 & 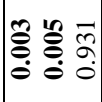 & 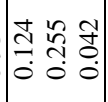 & $\left|\begin{array}{lll}n & 0 & 0 \\
0 & 0 & 0 \\
0 & 0 & 0 \\
0 & 0\end{array}\right|$ & $\begin{array}{lll} & \nexists & \infty \\
0 & 0 & 0 \\
0 & 0 & 0 \\
0\end{array}$ & 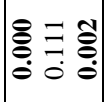 & 查 & 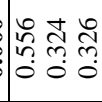 & $\left|\begin{array}{lll}2 & 0 & \overline{0} \\
0 & 0 & 0 \\
0 & 0 & 0 \\
0 & 0 & 0\end{array}\right|$ \\
\hline 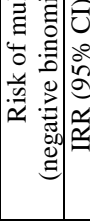 & 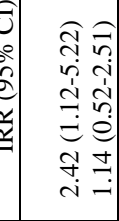 & 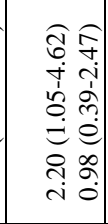 & 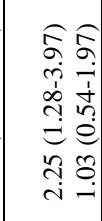 & 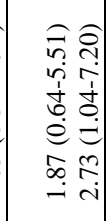 & 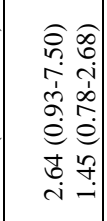 & 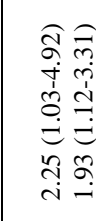 & 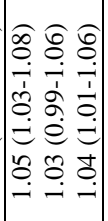 & 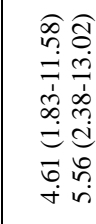 & 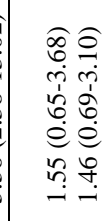 & 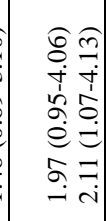 \\
\hline & 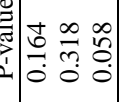 & $\left|\begin{array}{ccc}0 & 0 & m \\
0 & 0 & 0 \\
0 & 0 & 0 \\
0 & 0 & 0\end{array}\right|$ & $\mid \begin{array}{lll}0 & 0 & - \\
0 & 0 & 0 \\
0 & 0 & 0 \\
0 & 0 & 0\end{array}$ & 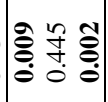 & 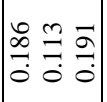 & 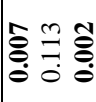 & 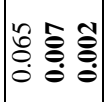 & 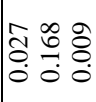 & 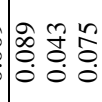 & 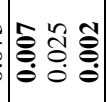 \\
\hline 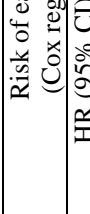 & 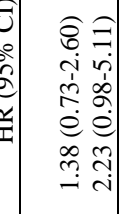 & 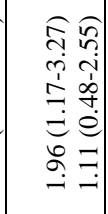 & 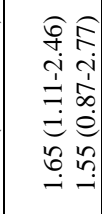 & 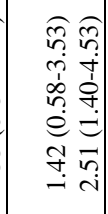 & 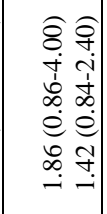 & 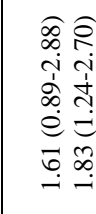 & 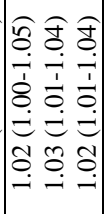 & 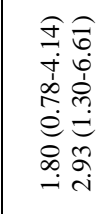 & 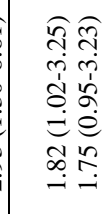 & 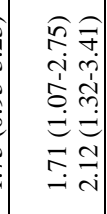 \\
\hline 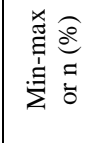 & 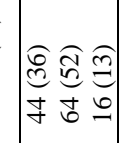 & 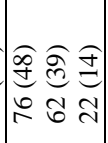 & 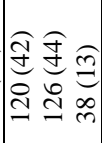 & 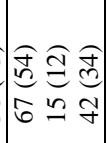 & 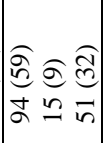 & 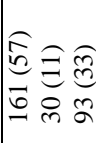 & $\mid \begin{array}{lll}0 & 0 \\
0 & 8 & 0 \\
1 & 1 & 1\end{array}$ & 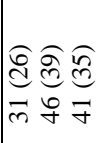 & 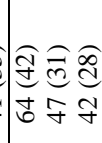 & 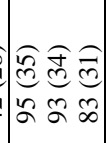 \\
\hline 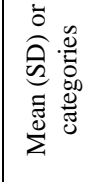 & 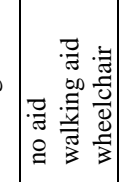 & 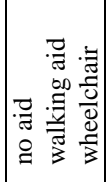 & 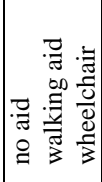 & $\dot{l}+r$ & $\stackrel{p}{i}+\stackrel{?}{i}$ & $\stackrel{\varphi}{n}+r$ & 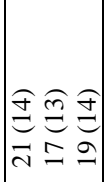 & 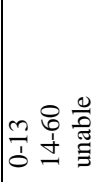 & $\mid$\begin{tabular}{ll}
0 \\
\hdashline
\end{tabular} & 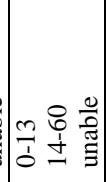 \\
\hline 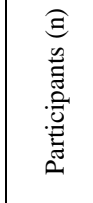 & 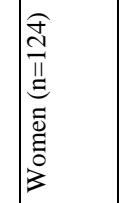 & 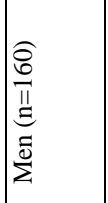 & 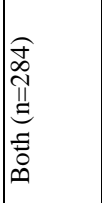 & 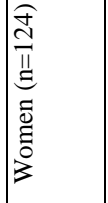 & 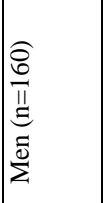 & 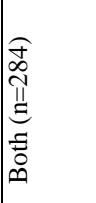 & 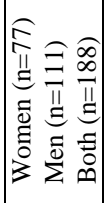 & 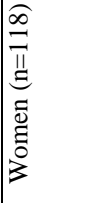 & 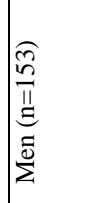 & 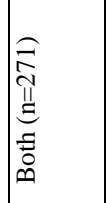 \\
\hline $\begin{array}{l}\frac{0}{\pi} \\
\frac{\pi}{\tilde{\sigma}} \\
> \\
>\end{array}$ & 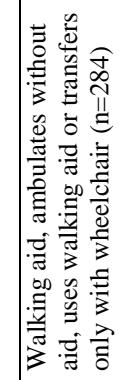 & & & 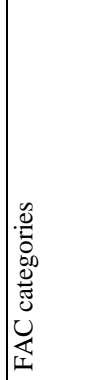 & & & 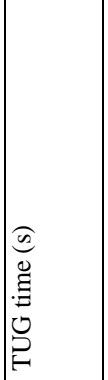 & 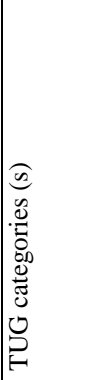 & & \\
\hline
\end{tabular}




\section{Falls during stroke unit stay}

Nineteen (7\%) of the participants fell during their stay at the stroke unit. In median (range) the first fall at the hospital occurred six (1-31) days after stroke onset. Three of the participants fell 2-3 times, resulting in 24 fall incidents in total. Thirteen of the falls occurred in the participants' room, five in the bathroom, and five elsewhere (for one fall incident, data is missing). Nineteen of the fall incidents occurred without staff present, and three with staff present (for two fall incidents this information is missing). In 13 of the fall incidents, participants were not following the recommendations regarding use of walking aids or supervision while transferring, and in 10 they did (for one fall incident this information was missing). Mean length of stay was 11 days. There was no significant difference between the fallers and non-fallers during stroke unit stay, with respect to protective reactions, CEW, or sex (Table 16).

Table 16. Sex, protective reactions, and the Cone Evasion Walk Test in relation to falls during stroke unit stay, in persons with acute stroke

\begin{tabular}{|l|l|l|}
\hline \multicolumn{1}{|c|}{ Variable } & \multicolumn{1}{|c|}{$\begin{array}{c}\text { Risk of } \\
\text { multiple falls }\end{array}$} & \multicolumn{1}{|c|}{$\begin{array}{c}\text { Difference } \\
\text { between fallers } \\
\text { and non-fallers }\end{array}$} \\
\hline Protective reaction, sitting, worst side (score) $(\mathrm{n}=242)$ & $*$ & Ns \\
\hline $\begin{array}{l}\text { Protective reaction, sitting, intact in both, one or no side } \\
(\mathrm{n}=242)\end{array}$ & $*$ & Ns \\
\hline Protective reaction, standing, worst side (score) $(\mathrm{n}=192)$ & $*$ & Ns \\
\hline $\begin{array}{l}\text { Protective reaction, standing, intact in both, one, or no side } \\
(\mathrm{n}=192)\end{array}$ & Ns & Ns \\
\hline $\begin{array}{l}\text { CEW }>2 \text { touches on the worst side or unable (yes/no) } \\
(\mathrm{n}=262)\end{array}$ & $*$ & Ns \\
\hline CEW touches on no, one or two sides $(\mathrm{n}=215)$ & $*$ & Ns \\
\hline Sex (male/female) $(\mathrm{n}=284)$ & $*$ & Ns \\
\hline
\end{tabular}

* SPSS warnings

Ns meaning $\mathrm{p} \geq 0.05$ 


\section{DISCUSSION}

\section{Discussion of results}

This thesis presents psychometric properties for two newly developed assessments; the PRT, containing standardized testing procedures for postural reactions, and the CEW, an assessment of the ability to evade obstacles while walking. The results show that these tests can be reliably used in persons with acute stroke and are valid for assessment of fall risk. The thesis also presents an exploration of test results, and the fall risk impact of a large quantity of rapidly and easily collected data in persons with acute stroke. Study B presented in the thesis, is the first to analyze post-discharge falls both by time to first fall, and fall incidence in relation to data on persons with acute stroke. It is also unique in exploring fall risk factors separately for women and men with acute stroke. Such results are useful for advancing knowledge of clinical instruments and of how they can be used to identify high fall risk individuals and areas for prevention. Valuable information obtained is that the risk factors for falls differ in part when analyzing the time to the first fall and the six-month fall incidence, that a higher number of risk factors were identified in women, that fall incidence during the first month from discharge was significantly higher in men, and that the assessor's judgment of a person's six-month fall risk, was particularly well suited for identification of individuals with high risk for multiple falls, which emphasizes the value of comprehensive risk analysis of a multifactorial phenomenon.

\section{The Postural Reactions Test}

The reliability of the PRT is similar to previously reported reliability results of other tests, including assessments of postural reactions, namely: the Fugl-Meyer Test, the BESTest, and the Birgitta Lindmark assessment. Intra-rater reliability values of $0.89-0.98$ were found for the balance tasks in the Fugl-Meyer Test in persons with chronic stroke (130). For the section on postural responses in the BESTest, an ICC value of 0.92 was found for inter-rater reliability in community-dwelling elderly persons (73), and an ICC value of 0.91 was found in persons with Parkinson's disease (131). For the total score of the Birgitta Lindmark assessment, 96\% agreement was found for inter-rater reliability, and $98 \%$ for intra- 
rater-reliability in persons with acute stroke (132), being the only one of these tests having reliability confirmed in persons with acute stroke similarly to the PRT. Unique for the PRT is that reliability was confirmed for each item separately so that the different postural reactions can be assessed and scored separately or together, depending on what is most relevant in each situation and individual.

Previous studies of persons with acute stroke have shown that impaired postural control is a risk factor for post discharge falls $(50,57,59)$. Visual functions, somatosensory functions, vestibular functions and cognitive functions also contribute to postural control (60), and measurements like PRT, able to adequately detect impairments at a functional level are therefore valuable, contributing knowledge that can be used for guidance of interventions. Instead of time-consuming assessments also including mobility activities for which postural reactions are needed, such as the tests mentioned above, or the gold standard assessment for functional balance, BBS, the results of paper 3 indicate that such a function alone can be used for identification of potential fallers.

Impaired protective reactions while sitting (ICF code b755) was a determinant risk factor for early falls $(\mathrm{p}<0.0005)$, whereas the protective reactions while standing were not (Table 9). Since patients and care givers might be more comfortable pushing the patient to trigger a reaction while sitting than in standing, this is clinically relevant information. However, perturbation-based training has been found to improve stepping responses to balance perturbations (133-135), and to be effective in the prevention of falls (136).

\section{The Cone Evasion Walk Test}

The inter-rater and intra-rater reliability of the CEW total score in persons with acute stroke, was similar to that of the test-retest reliability of the TUG (ICC values of 0.96 in persons with chronic stroke) (123).

The correlations between the CEW and the FAC, TUG, SCT, and the MoCA-S7 show that the CEW assesses many of the same abilities as these tests. The CEW, FAC, and TUG assess the mobility activity (ICF code $\mathrm{d} 4$ ) walking and moving (ICF codes d450-d469), and CEW, SCT, and the MoCA-S7 assesses mental function (ICF code b1) and attention function (ICF code b140) to some extent. However, the poor to moderate correlation coefficients also confirm the novel status of the CEW, and that it does not assess exactly the same abilities as these other tests. The 
results indicated that the CEW assesses both walking and moving, as well as attention, but from a different perspective than the TUG-cog, because the correlation between these two tests was not significant.

The TUG-cog assesses dual task sensitivity in walking, whereas the CEW assesses proactive gait control in response to an environmental challenge, which is common in everyday life. The TUG also assesses gait control in relation to the environment, but a novel aspect of the CEW is that it may provide spatial information about which side is more vulnerable while walking, as both the number and locations of cone touches are noted. The proportion of cancelled stars in the SCT only correlated with the number of cones touched on the left side (not the right side) in the CEW. A possible explanation might be that visuo-spatial neglect is more common following a right hemisphere than a left hemisphere stroke (137).

The CEW has a floor effect in persons with acute stroke, and the proportion of participants touching cones was higher among persons using walking aids compared to those who did not. The former can be expected to have impaired motor control, which might contribute to a tendency to touch cones. It also seems reasonable that it is easier to adapt the gait to evade obstacles when attention must be paid only to the body, rather than the body and something else, like an additional walking aid. This is in line with a previous study where persons who performed the TUG test had better results if they did not simultaneously carry and pay attention to a glass of water (138). There is a lack of instruments assessing the ability to evade objects while walking with walking aids, and the CEW is especially useful in that particular group of persons.

If the test is repeated over time, changes in obstacle avoidance performance regarding the number of touches, and the proportion of touches made by a front or back wheel, can be identified. The results showed that significantly more cones were touched with the back wheels, indicating that it is more difficult to pay attention to those.

The risk for falls is multifactorial, and participants who did not touch any cones might have had other impairments that increased their risk for falls, which may explain the increased correlation between the CEW and falls when their data were excluded (Table 10). It has been shown that physical exercise can improve the ability to negotiate obstacles while walking (139), which has been found to decrease the fall incidence (140). 


\section{Fall incidence}

The fall incidence rate of 2.2 falls each person-year in study B is within the range of 1.3-6.5 falls each person-year, that has previously been reported in persons with stroke with different follow-up times (27). In study B, the monthly fall incidence was 0.2 each month for women, compared to the fall incidence ranging from 0.1-0.3 falls each month in men (Figure 2). Several studies have reported that the fall incidence is highest soon after discharge $(27,50,56)$. The results from study B showed that particularly men contribute to these results, having a significantly higher fall incidence during the first month from discharge compared to women, which is consistent with the findings of previous studies $(55,91$, 141).

\section{Fall risk factors}

When someone is to be discharged from hospital, decisions about whether it is possible to return home must be made. If fall risk is present at this point, supervision and community care might be needed. Also, spontaneous neural recovery after stroke occurs within a time-sensitive window, starting early after stroke and slowly decreasing with time. The duration of this time-window varies across neural systems (16), which also might have an impact on the predictive ability of different fall risk factors at different time points. To meet the need for identification of risk factors for early falls, Cox regression was used for analyses of time to the first fall and fall risk factors collected in the acute stage of stroke. Nbreg was used for analyses of fall incidence as recommended (97), and can be considered as the most relevant analysis for advancing knowledge of identification of high fall risk individuals, since both time and number of falls are taken into account. Sex differences in fall risk factors has a complex nature, and study B was not set up with the ambition to identify underlying explanations, but to describe the actual situation in order to guide clinicians in choices of assessments and interventions to use. Due to the sex differences and heterogeneity of the population, it is valuable to have a wide range of rapidly and easily collected assessments to choose from when assessing the individual person (2). Even if confounding is present in the presented factors, it is valuable to know how well suited commonly used assessments are for identification of persons at high risk for falls. 


\section{Number and character of high impact fall risk factors}

It seems reasonable that women being older, having more frailty (142) suffering from more stroke-related disability, and non-classical stroke symptoms (90) compared to men, also have smaller margins to maintain safe walking, and a larger number of potential fall risk factors including a wider range of functions, and activities performed at a less demanding level, as shown in study B. For women, mainly linear relationships to falls were found. Inability to walk (perform the TUG), inability to stand without support, and total dependency in self-care activities (a total score of 0-20 in Barthel (128)), were decisive fall risk factors for women but not for men. According to the Barthel item Transfer, women unable to transfer were at the highest risk for early falls, but for men the persons in need of major help were at highest risk (Tables 13-15).

Risk-taking behavior is associated with the male sex (94), and fear of falling is associated with the female sex (92). The risk-taking behavior might interact with the explanatory variables to a higher degree for men, resulting in a mixture of U-shaped and linear relationships to falls for men. This might also be a partial reason for the lower number of identified fall risk factors for men in study B, and may partly explain why the assessor's judgment of a person's six-month fall risk, was suited only for identification of women at high risk for falls, not for men, when women and men were analyzed separately.

In study B, the analyses of the total cohort showed that the persons categorized as the most disabled in the two variables of Barthel Transfer and Walking aid were not the ones at the highest risk for falls (Table 14 \& 15). A previous study about impairments in acute stroke found that the participants with the most impairments were less mobile than those with fewer impairments, and not the ones at highest risk for post discharge falls (58). This emphasizes the need to consider U-shaped relations between abilities and risks, and how the sex affect the outcome.

\section{Medications}

In the total cohort, intake of more than eight medications was a decisive risk factor for early falls (Table 11). The variable most likely reflects both general health and adverse effects of medications. When medications were analyzed as separate groups based on ATC codes, antidepressant drugs were the only group of medications associated with risk for falls. In a previous meta-analysis, both depression and intake of sedatives or 
psychotropic medications were associated with falls in community stroke survivors (48). Only three variables had p-values $\leq 0.001$ for men in the six-month follow-up, and intake of a high number of medications, and intake of antidepressants were two of those (Table 11). Depression has previously been shown to be associated with the female sex $(92,93)$. In study B, only self-reported depression prior to stroke was registered (present in 29\% of the women and 31\% of the men), and was not a risk factor for falls in either sex (Supplemental material for paper 4).

\section{Rapid and easily collected data}

As an alternative to time-consuming tests, often assessing more than one function or activity, study B shows that short and specific tests such as the rapid and easily performed fifth and sixth item from the NIHSS (assessing paresis in arms and legs), protective reactions while sitting from the PRT, CST, ST, Barthel (total score), and the Barthel items Grooming, and Toilet use can also be used for identification of persons at high risk for falls.

\section{Level of demands in identified fall risk factors}

The two analyses, Cox regression and nbreg, complement each other, and similar trends in both analyses strengthen the results. The two different methods also provide an opportunity to study differences in fall risk factors for early falls and high fall incidence. Paresis in the arms, protective reactions while sitting (preventing a fall with the arm), dependence in self-care activities (according to the Barthel total score, and specific Barthel items) were decisive risk factors for falls in the analyses with Cox regression, indicating that arm function and disabilities in activities of self-care are important in relation to early falls. The same variables were decisive fall risk factors for women, but not for men when analyzed separately. In the nbreg analysis, mobility activities assessed by tests that require performance on a more demanding level, such as CST, and ST, were seen among the variables related to a high risk for multiple falls ( $\mathrm{p}<0.0005)$, and mobility assessed by CST was one of the most decisive risk factors for falls in men $(\mathrm{p} \leq \mathrm{0.01})$.

\section{Falls during stroke unit stay}

In study B, only $7 \%$ of the participants fell during the stroke unit stay, which is lower than the $13 \%$ previously reported in another Swedish study also with a mean length of stay of 11 days (91), but within the previously reported range of $3 \%$ to $22 \%$ in persons with acute stroke $(143,144)$. During the stroke unit stay, there was no significant difference between 
the fallers and non-fallers with respect to sex, postural reactions in sitting, or postural reactions in standing in study B (Table 16). However, the multivariate analyses by Persson et al. (91) showed that postural control (assessed by the Swedish Postural Assessment Scale for Stroke Patients) (56), and male sex were associated with falling during the hospital stay after acute stroke. Possible explanations for the divergent results might be differences in proportions of fallers, differences in statistical methods, and different outcome measures.

\section{Methodological considerations}

In order to study the prediction of falls in persons with stroke, several methodological issues must be considered. The different phases of stroke (16) need to be taken into account for decisions about inclusion and follow-up time. The heterogeneity (2) of the acute stroke population affects decisions about inclusion criteria but also the choice of outcome measures. To cover the wide spectrum of functional and activity levels in persons with acute stroke, but to avoid floor and ceiling effects in the results, a wide range of assessments are needed. The presence of fatigue and natural repair after stroke (16) affects the data collection and followup time.

\section{Inclusion and exclusion criteria}

In study A, including 36 participants, the exclusion criteria were selected so that stroke would be the primary medical condition of the participants. For example, persons with major orthopedic problems were excluded, and persons with residual symptoms from acute stroke were recruited consecutively, despite use of a walking aid and cognitive impairments.

In study B, including 300 participants, we designed the study to be as representative of the acute stroke population as possible, and the wideranging inclusion criteria were intended to capture the heterogeneity in the population and contribute to high external validity.

A limitation of the studies included in this thesis, which aimed to study persons in acute stroke care, is that some of the participants were included in the study on days 8-14, which were not within the acute phase of stroke. Sometimes the medical diagnosis of stroke is delayed, thus the criteria for participation in both study A and study B were a diagnosis of stroke and onset of symptoms within 14 days. However, this decision 
contributes to the internal validity of the study, since in our experience, participants that receive their diagnosis at a later state generally have more complex medical conditions compared to those who get diagnosed early. The mean (SD) number of days since stroke onset for data collection (four (3) in study A and 5 (3) in study B) is within the acute phase of stroke (days 1-7) (16), and the clinical setting is the most relevant for persons with acute stroke.

Neuroradiological verification was not required for inclusion, since medical imaging by computed tomography does not always identify an infarction if carried out within the first hours from stroke onset (145), and the diagnosis of ischemic stroke can be made accurately on the basis of the clinical presentation without a new computed tomography or magnetic resonance imaging in many persons (12).

\section{Development of the Postural Reactions Test}

The development and standardizations of the PRT aimed to create a test with high reliability, validity, and availability for use in persons with acute stroke. The use of human pushing and resistance instead of technical equipment makes the test easy and rapid to use in clinical practice. However, exact standardization is not possible when humans push or offer resistance, whereas the standardizations were restricted to what was necessary to distinguish between the different scores. For a detailed description of the reasoning regarding the standardizations please see paper 1.

A possible limitation of the assessment of the protective reactions is that the outcome depends on the patients' ability to relax when pushed. Also, there will be no outcome in the assessment of the equilibrium and righting reactions if the patient is totally relaxed in the arms of the assessor instead of trying to keep the balance by themselves.

\section{Development of the Cone Evasion Walk Test}

The development and standardizations of the CEW aimed to create a test with high reliability, validity, and relevance for use in persons with acute stroke. The CEW assesses the ability to evade obstacles at a self-chosen speed and with the person's ordinary walking aid in order to reflect daily life behavior. In most daily life situations, it is possible to choose how fast to walk. Therefore, the test score is not affected by the time needed to complete the test even though that time also reflects the functional performance. Time and touches would also be difficult to combine into 
one score in a relevant way. The distances from the cones to the center line were determined so that the margin was approximately equal regardless of the presence or type of walking aid. When testing activities including attention-demanding tasks, a standardized instruction is essential since repeating or emphasizing the instructions might influence the test results.

\section{Assessment of reliability in persons with acute stroke}

Due to fatigue or improved function, the performance of persons with stroke varies considerably over time. To account for this variability, we assessed intra-observer reliability in study A by videotaping the participants and requesting two separate test scores from separate assessment sessions from the observing physiotherapists, as recommended by Streiner et al. (44). At least two weeks passed between the first and the second physiotherapist assessment in order to reduce the risk that the second outcome would be influenced by the first outcome due to physiotherapists remembering their previous assessments. Streiner et al. (44) recommended one to two weeks. At each meeting, the physiotherapists were given the opportunity to assess the videos twice, since the test can be repeated if it is hard to judge the subject's performance in clinical practice.

\section{Assessment of validity in persons with acute stroke}

The presence of fatigue and the acute phase of stroke were reasons that a five-day span was allowed for test completion in study B. The five-day span might affect the results of the tests since function improves greatly during the first week after stroke (16). Thus, only participants who performed the different tests on the same day were included in the analyses of construct validity. For the analyses of predictive validity in paper 2, the number of days was included in the model, with no effect on the results.

The changeable state of persons with stroke also raises the question of for how long data collected in the acute phase of stroke is valid for prediction of falls. In study B, analyses were performed with a 12-month follow-up period at first, but the risk for falls changed significantly over time in several variables and thus the proportional hazard assumptions were violated. In the presented six-month follow-up, only 12 variables violated the assumptions, and at the three-month follow-up, assumptions were only violated by three of these 12 variables. Minet et al. (54) found that 
among participants with impaired gait and balance after acute stroke the fall risk decreased over time, but in participants with no impaired balance or gait the risk for falls had increased at six years compared to six and 12 months. Possibly, impairments that occur soon after stroke onset contribute to the fall risk, but as the stroke-related impairments decrease, the fall risk also decreases. But in persons with minor balance and gait disabilities after their stroke, other problems will arise and contribute more to the fall risk over time.

\section{Assessment of functions and activities in persons with acute stroke}

A limitation of the studies in this theses, is that some of the functions and activities that we aimed to assess were not assessed optimally, since floor and ceiling effects were present in this heterogeneous population. Also, the validity and reliability were not determined in persons with acute stroke for all outcome measures used. However, high validity is dependent on high reliability, placing an upper limit on the validity (44), meaning that the high predictive values contained in study B also indicate that these assessments can be reliably used in persons with acute stroke.

\section{Data collection of falls}

In study B, falls were reported in $42 \%$ of the participants, during the first six months after discharge. This is higher than the $26-35 \%$ that has been reported in three previous studies in persons with acute stroke and sixmonth follow-ups $(50,51,54)$. Daily recording and monthly reporting has been recommended in studies of falls $(30,96)$, and the results might indicate that a larger proportion of occurred falls is collected by falls diary and monthly follow-ups, since the three other studies collected data at sparser intervals. In a study of persons $>60$ years of age, $13-32 \%$ did not recall a confirmed fall during the previous 3,6 , or 12 months (146).

Another strength of study B, were that an established fall definition was used (30), and that it was provided both orally and written to the participants, families and staff that reported falls. Persons with lower scores in cognitive tests are less likely to report falls (96), so it also is a strength that family members and staff supported the data collection in these cases, and that the falls were complemented with falls registered in the National Quality Registry for Preventative Care. 


\section{Statistical methods}

For both intra- and inter-rater reliability of the PRT, the weighted kappa values were calculated but rejected since the skewed variable distributions generated low kappa values despite high agreement (147). For example, in median 10 out of 10 physiotherapists scored the most common value for the equilibrium reactions on both sides. When testing the right side, 15 of 20 participants were given a score of 1 , which resulted in a kappa value of 0.71. In contrast, when testing the left side, 19 of 20 participants were given a score of 1 , which resulted in a kappa value of 0.31 . Considering the identical medians and quartiles, and the high overall proportion of agreement, and number of physiotherapists scoring the same value, we believe that the test is reliable.

In study B, which included analyses of 95 factors, there are risks of type I errors because of multiple comparisons. However, strict usage of the cutoff $\mathrm{p}<0.0005$ as suggested by the Bonferroni correction increases the risk of type II errors. In Tables $9 \& 11-15$, variables with $\mathrm{p} \leq 0.01$ are presented, and those are possibly also factors contributing to the risk of falls, as well as some of the factors presented only in the supplementary material for paper 3 \& 4. For example, impaired mental functions were not seen among the risk factors for falls with p-values $<0.0005$ for the total cohort, but the SCT, S-FAC, MoCA total score, and MoCA items of attention and visuospatial/executive functions seem to capture components that possibly contribute to the multifactorial risk for falls (Table 12). This is in line with a previous study of persons with acute stroke, where low MoCA results were associated with an increased risk for falls in univariable, but not in multivariable analyses $(50,59)$. It is vital to remember that scientific conclusions should not be based only on whether a p-value passes a specific threshold or not, and that the p-value does not measure the size of the effect or clinical importance (148). Also, it is not possible to compare HR/IRR and 95\% CI between the different variables since dichotomized, categorical, and continuous variables are presented and the risk values are affected by the number of categories. 


\section{Clinical implications}

- The PRT can be used to reliably assess function in persons with acute stroke, and is a complement to the existing assessments for persons with affected postural control.

- The PRT item "protective reactions while sitting", can be used to identify persons with acute stroke, at high risk of falling.

- The CEW test can be used to reliably assess the ability to evade obstacles while walking in persons with acute stroke, and is a complement to the existing assessments for persons with impaired attention and proactive gait control.

- The CEW can be used to identify persons with acute stroke, at high risk of falling.

- Participant characteristics, and functional and activity levels of persons with acute stroke are presented, and several participant characteristics, functions, and activities were identified as risk factors for falls. The knowledge presented can be used for guidance in clinical practice.

- For identification of persons at high risk of early falls, it is particularly useful to note intake of more than eight medications, the fifth and sixth item in the NIHSS (assessing paresis in the arms and legs), the item "protective reactions while sitting" in the PRT, the Barthel index total score, Barthel Grooming, and Barthel Toilet.

- For identification of persons at high risk of multiple falls, the assessor's judgment of a person's six-month fall risk, CST, and ST is particularly useful.

- Assessments of functions and activities performed on a less demanding level might be more suitable for identification of persons at high risk of early falls, and assessments of functions and activities performed on a demanding level might be more suitable for identification of persons at high risk of multiple falls.

- For identification of women at high risk of falling, the assessor's judgment of a person's six-month fall risk, the assessment of motor restlessness, the SCT, the fifth item in NIHSS (assessing paresis in the arms), Barthel total score, Barthel Grooming, Bowel, Toilet, and Mobility, ST, TUG, and assessment of the ability to stand without support are particularly useful.

- For identification of men at high risk for falls, noting the intake of a high number of medications, intake of antidepressants, and CST is particularly useful. 
- Assessments of functions and activities performed on a less demanding level might be more suitable for identification of women at high risk of falls, and assessments of functions and activities performed on a demanding level might be more suitable for identification of men at high risk of falls.

- For men, it is possible that special caution may be needed with those still able to transfer and walk but needing major help, since they seem to be at high risk for falls. For women, mainly the most disabled persons have the highest risk for falls.

- In the planning of fall risk assessments and interventions, an awareness of the sex differences in fall incidence is needed, since the monthly fall incidence was significantly higher in men during the first month, and the fall risk was relatively constant over time for women.

The knowledge presented can be used for identification of individuals at high risk for falls, thereby providing a basis for future interventions. 


\section{Future research}

Further research is needed to evaluate the reliability of the PRT and CEW, including the aspects of physiotherapist performance and patient variability. It would be valuable to assess reliability for the PRT total score, for the four PRT items separately, and separately for each walking aid in the CEW.

Further testing of content, and predictive validity is needed for the total score of PRT, and it would be of value to assess the validity of the CEW for each walking aid separately.

The PRT and CEW might be useful in other groups of patients, and thus their reliability and validity need to be confirmed for those groups.

Also, sensitivity to change needs to be assessed for the PRT and the CEW, and the test results for persons with acute stroke should be compared to those of sex- and age-matched controls.

Future studies are needed to further assess the predictive abilities of potential fall risk factors in different strata of the acute stroke population.

Future studies of U-shaped relationships to falls, as well as sex differences in characteristics, level of functions, and level of activities are needed in persons with acute stroke.

Future studies are needed that investigate for how long assessments performed in the acute stage of stroke can be validly used for the prediction of falls.

Intervention studies of sex-adjusted prevention of falls, based on the results of this thesis, for persons with stroke are needed. 


\section{CONCLUSIONS}

The PRT was reliable in assessing postural reactions in persons with acute stroke. The test complements the existing assessments for persons with affected postural control.

The CEW was reliable and valid in assessing the ability to evade obstacles while walking in persons with acute stroke. The test complements the existing range of assessments for subjects with impaired attention and proactive gait control.

Several easily collected participant characteristics, functions, and activities were identified as risk factors for falls. The findings emphasize the wide range of assessments that can be used for identification of persons at high risk for falls, and different assessments have varying degrees of suitability in different strata of the population. These results will be important when developing multivariate risk models. The risk factors differed in part when analyzing the time to the first fall, and sixmonth fall incidence.

Different fall risk factors were the most decisive when analyzed separately in women and men, and the monthly fall incidence was higher in men during the first month. 


\section{REFERENCES}

1. World Physiotherapy. Description of physical therapy: policy statement [Internet] London: World Confederation for Physical Therapy; 2019 [cited: 2021-01-25]. Available from:

https://world.physio/sites/default/files/2020-07/PS-2019Description-of-physical-therapy.pdf.

2. Mansfield A, Inness EL, McIlroy WE. Stroke. In: Day BL, Lord SR, editors. Balance, Gait and Falls. Amsterdam: Elsevier; 2018. p. 20528.

3. Langhorne P, Stott DJ, Robertson L, MacDonald J, Jones L, McAlpine C, et al. Medical complications after stroke: a multicenter study. Stroke. 2000;31(6):1223-9.

4. Price R, Choy NL. Investigating the relationship of the functional gait assessment to spatiotemporal parameters of gait and quality of life in individuals with stroke. J Geriatr Phys Ther. 2019;42(4):25664.

5. Cott C FE, Gasner D, Yoshida K, Thomas S, Verrier M. The movement continuum theory of physical therapy. Physiotherapy Canada. 1995;47(2):87-95.

6. Krishnamurthi RV, Ikeda T, Feigin VL. Global, regional and country-specific burden of ischaemic stroke, intracerebral haemorrhage and subarachnoid haemorrhage: a systematic analysis of the global burden of disease study 2017. Neuroepidemiology. 2020;54(2):171-9.

7. Strong K, Mathers C, Bonita R. Preventing stroke: saving lives around the world. Lancet Neurol. 2007;6(2):182-7.

8. The World Health Organization MONICA Project (monitoring trends and determinants in cardiovascular disease): a major international collaboration. WHO MONICA Project Principal Investigators. J Clin Epidemiol. 1988;41(2):105-14.

9. Hatano S. Experience from a multicentre stroke register: a preliminary report. Bull World Health Organ. 1976;54(5):541-53. 
10. Abbott AL, Silvestrini M, Topakian R, Golledge J, Brunser AM, de Borst GJ, et al. Optimizing the definitions of stroke, transient ischemic attack, and infarction for research and application in clinical practice. Front Neurol. 2017;8:537.

11. World Health Organization. ICD-10 version for 2010 [Internet]. Geneva: World Health Organization; 2010 [cited: 20210125]. Available from: https://icd.who.int/browse10/2010/en.

12. Powers WJ, Rabinstein AA, Ackerson T, Adeoye OM, Bambakidis NC, Becker K, et al. Guidelines for the early management of patients with acute ischemic stroke: 2019 update to the 2018 guidelines for the early management of acute ischemic stroke: a guideline for healthcare professionals from the American Heart Association/American Stroke Association. Stroke. 2019;50(12):e344-e418.

13. Kairys N, Das J, Garg M. Acute subarachnoid hemorrhage (SAH) [Internet]. Treasure Island (FL): StatPearls Publishing; 2020 [updated 2020-10-13; cited 2021-02-02]. Available from: https://www.statpearls.com/articlelibrary/viewarticle/29606/.

14. Qureshi AI, Mendelow AD, Hanley DF. Intracerebral haemorrhage. Lancet. 2009;373(9675):1632-44.

15. Kunz A, Dirnagl U, Mergenthaler P. Acute pathophysiological processes after ischaemic and traumatic brain injury. Best Pract Res Clin Anaesthesiol. 2010;24(4):495-509.

16. Bernhardt J, Hayward KS, Kwakkel G, Ward NS, Wolf SL, Borschmann K, et al. Agreed definitions and a shared vision for new standards in stroke recovery research: the stroke recovery and rehabilitation roundtable taskforce. Neurorehabil Neural Repair. 2017;31(9):793-9.

17. Riksstroke. Stroke och TIA: Riksstrokes årsrapport för 2019 års data [Internet]. Riksstroke; 2020 [cited: 20210105]. Available from: https://www.riksstroke.org/wpcontent/uploads/2020/09/Riksstroke_Årsrapport2019_slutversionWEB-1.pdf.

18. World Health Organization. ICF browser [Internet]. Geneva: World Health Organization; 2017 [cited: 2021-01-25]. Available from: https://apps.who.int/classifications/icfbrowser/Default.aspx. 
19. Linden T, Skoog I, Fagerberg B, Steen B, Blomstrand C. Cognitive impairment and dementia 20 months after stroke.

Neuroepidemiology. 2004;23(1-2):45-52.

20. Hyndman D, Pickering RM, Ashburn A. The influence of attention deficits on functional recovery post stroke during the first 12 months after discharge from hospital. J Neurol Neurosurg Psychiatry. 2008;79(6):656-63.

21. Tsouli S, Kyritsis AP, Tsagalis G, Virvidaki E, Vemmos KN. Significance of aphasia after first-ever acute stroke: impact on early and late outcomes. Neuroepidemiology. 2009;33(2):96-102.

22. Sullivan JE, Hedman LD. Sensory dysfunction following stroke: incidence, significance, examination, and intervention. Top Stroke Rehabil. 2008;15(3):200-17.

23. Hendricks HT, van Limbeek J, Geurts AC, Zwarts MJ. Motor recovery after stroke: a systematic review of the literature. Arch Phys Med Rehabil. 2002;83(11):1629-37.

24. Peurala SH, Kononen P, Pitkanen K, Sivenius J, Tarkka IM. Postural instability in patients with chronic stroke. Restor Neurol Neurosci. 2007;25(2):101-8.

25. Phan PL, Blennerhassett JM, Lythgo N, Dite W, Morris ME. Overground walking on level and sloped surfaces in people with stroke compared to healthy matched adults. Disabil Rehabil. 2013;35(15):1302-7.

26. Ng SSM, Chan SCL, Chan AKY, Chung HHY, Lee NKW, Ngan ATS, et al. Reliability and concurrent validity of standardized walking obstacle course test in people with stroke. J Rehabil Med. 2017;49(9):705-14.

27. Weerdesteyn V, de Niet M, van Duijnhoven HJ, Geurts AC. Falls in individuals with stroke. J Rehabil Res Dev. 2008;45(8):1195-213.

28. Joo H, Wang G, Yee SL, Zhang P, Sleet D. Economic burden of informal caregiving associated with history of stroke and falls among older adults in the U.S. Am J Prev Med. 2017;53(6s2):S197S204.

29. Zheng JQ, Lai HJ, Zheng CM, Yen YC, Lu KC, Hu CJ, et al. Association of stroke subtypes with risk of hip fracture: a 
population-based study in Taiwan. Arch Osteoporos. 2017;12(1):104.

30. Lamb SE, Jorstad-Stein EC, Hauer K, Becker C. Development of a common outcome data set for fall injury prevention trials: the Prevention of Falls Network Europe consensus. J Am Geriatr Soc. 2005;53(9):1618-22.

31. World Health Organization. Falls [Internet]. Geneva: World Health Organization; 2018 [updated 2018-01-16, cited 2021-02-03]. Available from: https://www.who.int/news-room/factsheets/detail/falls.

32. Sveriges Kommuner och Regioner. Fall och fallskador [Internet]. Stockholm: Sveriges Kommuner och Regioner; 2020 [updated 2020-01-17, cited: 2021-01-30]. Available from: https://skr.se/halsasjukvard/patientsakerhet/riskomraden/falloch fallskador.618.html.

33. Socialstyrelsen. Öppna jämförelser 2020: Kommunal hälso- och sjukvård [Internet]. Stockholm: Socialstyrelsen; 2020 [updated 2020-06-24, cited: 20210105]. Available from: https://www.socialstyrelsen.se/globalassets/sharepointdokument/artikelkatalog/oppna-jamforelser/2020-6-6795.pdf.

34. Gyllensvärd H. Fallolyckor bland äldre: en samhällsekonomisk analys och effektiva preventionsåtgärder. Stockholm: Statens folkhälsoinstitut; 2009.

35. Batchelor FA, Mackintosh SF, Said CM, Hill KD. Falls after stroke. Int J Stroke. 2012;7(6):482-90.

36. Forster A, Young J. Incidence and consequences of falls due to stroke: a systematic inquiry. BMJ. 1995;311(6997):83-6.

37. Gillespie LD, Robertson MC, Gillespie WJ, Sherrington C, Gates S, Clemson LM, et al. Interventions for preventing falls in older people living in the community. Cochrane Database Syst Rev. 2012;9:Cdoo7146.

38. Denissen S, Staring W, Kunkel D, Pickering RM, Lennon S, Geurts $\mathrm{AC}$, et al. Interventions for preventing falls in people after stroke. Cochrane Database Syst Rev. 2019;10(10):Cdoo8728.

39. Downton J. Falls in the elderly. London: Edward Arnold; 1993. 
40. Skog M. Riskbedömning In: Vårdhandboken. [Internet] Stockholm:

Sveriges kommuner och regioner; 2019 [updated 2019-05-29, cited: 2021-01-05]. Available from:

https://www.vardhandboken.se/vard-och-behandling/basal-ochpreventiv-omvardnad/fallprevention/riskbedomning/.

41. Nyberg L, Gustafson Y. Using the Downton index to predict those prone to falls in stroke rehabilitation. Stroke. 1996;27(10):1821-4.

42. Simpson LA, Miller WC, Eng JJ. Effect of stroke on fall rate, location and predictors: a prospective comparison of older adults with and without stroke. PloS One. 2011;6(4):e19431.

43. Nordin E, Lindelof N, Rosendahl E, Jensen J, Lundin-Olsson L. Prognostic validity of the Timed Up-and-Go test, a modified GetUp-and-Go test, staff's global judgement and fall history in evaluating fall risk in residential care facilities. Age Ageing. 2008;37(4):442-8.

44. Streiner DL, Norman GR, Cairney J. Health measurement scales: a practical guide to their development and use. $5^{\text {th }}$ ed. Oxford: Oxford University Press; 2015.

45. Berg K, Wood-Dauphinėe S, Williams JI, Gayton D. Measuring balance in the elderly: preliminary development of an instrument. Physiotherapy Canada. 1989;41(6):304-11.

46. Mossey JM. Social and psychologic factors related to falls among the elderly. Clin Geriatr Med. 1985;1(3):541-53.

47. Frith J, Davison J. Falls. Rev Clin Gerontol. 2013;23(02):101-17.

48. Xu T, Clemson L, O'Loughlin K, Lannin NA, Dean C, Koh G. Risk factors for falls in community stroke survivors: a systematic review and meta-analysis. Arch Phys Med Rehabil. 2018;99(3):563-73 e5.

49. Campbell GB, Matthews JT. An integrative review of factors associated with falls during post-stroke rehabilitation. J Nurs Scholarsh. 2010;42(4):395-404.

50. Samuelsson CM, Hansson PO, Persson CU. Early prediction of falls after stroke: a 12-month follow-up of 490 patients in The Fall Study of Gothenburg (FallsGOT). Clin Rehabil. 2019;33(4):773-83. 
51. Andersson AG, Kamwendo K, Seiger A, Appelros P. How to identify potential fallers in a stroke unit: validity indexes of 4 test methods. J Rehabil Med. 2006;38(3):186-91.

52. Callaly EL, Ni Chroinin D, Hannon N, Sheehan O, Marnane M, Merwick A, et al. Falls and fractures 2 years after acute stroke: the North Dublin Population Stroke Study. Age Ageing. 2015;44(5):882-6.

53. Foster EJ, Barlas RS, Bettencourt-Silva JH, Clark AB, Metcalf AK, Bowles KM, et al. Long-term factors associated with falls and fractures poststroke. Front Neurol. 2018;9:210.

54. Minet LR, Peterson E, von Koch L, Ytterberg C. Occurrence and predictors of falls in people with stroke: six-year prospective study. Stroke. 2015;46(9):2688-90.

55. Nyström A, Hellström K. Fall risk six weeks from onset of stroke and the ability of the Prediction of Falls in Rehabilitation Settings Tool and motor function to predict falls. Clin Rehabil. 2013;27(5):473-9.

56. Persson CU, Hansson PO, Sunnerhagen KS. Clinical tests performed in acute stroke identify the risk of falling during the first year: postural stroke study in Gothenburg (POSTGOT). J Rehabil Med. 2011;43(4):348-53.

57. Pyoria O, Talvitie U, Nyrkko H, Kautiainen H, Pohjolainen T. Validity of the Postural Control and Balance for Stroke test. Physiother Res Int. 2007;12(3):162-74.

58. Yates JS, Lai SM, Duncan PW, Studenski S. Falls in communitydwelling stroke survivors: an accumulated impairments model. J Rehabil Res Dev. 2002;39(3):385-94.

59. Samuelsson CM, Hansson PO, Persson CU. Determinants of recurrent falls poststroke: a 1-year follow-up of the Fall Study of Gothenburg. Arch Phys Med Rehabil. 2020;101(9):1541-8.

6o. Shumway-Cook A, Wollacott MH. Motor control: translating reasearch into clinical practice. $5^{\text {th }}$ ed. Philadelphia: Lippincott Williams \& Wilkins; 2016. 
61. Batra M, Sharma VP, Batra V, Malik GK, Pandey RM. Postural reactions: an elementary unit for development of motor control. Disability, CBR \& Inclusive Development. 2011;22(2): 134-7.

62. Edwards S, editor. Neurological physiotherapy: a problem-solving approach. 2nd ed. Edinburgh: Churchill Livingstone; 2002.

63. Corbeil P, Bloem BR, van Meel M, Maki BE. Arm reactions evoked by the initial exposure to a small balance perturbation: a pilot study. Gait Posture. 2013;37(2):300-3.

64. Lakhani B, Mansfield A, Inness EL, McIlroy WE. Compensatory stepping responses in individuals with stroke: a pilot study. Physiother Theory Pract. 2011;27(4):299-309.

65. Mansfield A, Inness EL, Lakhani B, McIlroy WE. Determinants of limb preference for initiating compensatory stepping poststroke. Arch Phys Med Rehabil. 2012;93(7):1179-84.

66. Inness EL, Mansfield A, Lakhani B, Bayley M, McIlroy WE. Impaired reactive stepping among patients ready for discharge from inpatient stroke rehabilitation. Phys Ther. 2014;94(12):175564.

67. de Kam D, Roelofs JMB, Bruijnes A, Geurts ACH, Weerdesteyn V. The next step in understanding impaired reactive balance control in people with stroke: the role of defective early automatic postural responses. Neurorehabil Neural Repair. 2017;31(8):708-16.

68. Marigold DS, Eng JJ. Altered timing of postural reflexes contributes to falling in persons with chronic stroke. Exp Brain Res. 2006;171(4):459-68.

69. Handelzalts S, Gray G, Steinberg-Henn F, Soroker N, Melzer I. Characteristics of proactive balance and gait performance in subacute stroke patients demonstrating varying reactive balance capacity: a research study. NeuroRehabilitation. 2020;46(4):491500.

70. Bobath K, Bobath B. The facilitation of normal postural reactions and movements in the treatment of cerebral palsy. Physiotherapy. 1964;50:246-62. 
71. Fugl-Meyer AR, Jaasko L, Leyman I, Olsson S, Steglind S. The poststroke hemiplegic patient. 1. a method for evaluation of physical performance. Scand J Rehabil Med. 1975;7(1):13-31.

72. Lindmark B, Hamrin E. Evaluation of functional capacity after stroke as a basis for active intervention. Presentation of a modified chart for motor capacity assessment and its reliability. Scand $J$ Rehabil Med. 1988;20(3):103-9.

73. Horak FB, Wrisley DM, Frank J. The Balance Evaluation Systems Test (BESTest) to differentiate balance deficits. Phys Ther. 2009;89(5):484-98.

74. Sjöholm H, Hägg S, Nyberg L, Kammerlind A-S. Reliability of test procedures for postural reactions in people with acute stroke. Int $\mathrm{J}$ Ther Rehabil. 2018;25(11):576-86.

75. Plummer P, Eskes G, Wallace S, Giuffrida C, Fraas M, Campbell G, et al. Cognitive-motor interference during functional mobility after stroke: state of the science and implications for future research. Arch Phys Med Rehabil. 2013;94(12):2565-74.e6.

76. Yang L, Lam FM, Huang M, He C, Pang MY. Dual-task mobility among individuals with chronic stroke: changes in cognitive-motor interference patterns and relationship to difficulty level of mobility and cognitive tasks. Eur J Phys Rehabil Med. 2018;54(4):526-35.

77. Haggard P, Cockburn J, Cock J, Fordham C, Wade D. Interference between gait and cognitive tasks in a rehabilitating neurological population. J Neurol Neurosurg Psychiatry. 2000;69(4):479-86.

78. Timmermans C, Roerdink M, Janssen TWJ, Meskers CGM, Beek PJ. Dual-task walking in challenging environments in people with stroke: cognitive-motor interference and task prioritization. Stroke Res Treat. 2018;2018:7928597.

79. van Swigchem R, van Duijnhoven HJ, den Boer J, Geurts AC, Weerdesteyn V. Deficits in motor response to avoid sudden obstacles during gait in functional walkers poststroke. Neurorehabil Neural Repair. 2013;27(3):230-9.

8o. Lundin-Olsson L, Nyberg L, Gustafson Y. "Stops walking when talking" as a predictor of falls in elderly people. Lancet. 1997;349(9052):617. 
81. Shumway-Cook A, Brauer S, Woollacott M. Predicting the probability for falls in community-dwelling older adults using the Timed Up \& Go Test. Phys Ther. 2000;80(9):896-903.

82. Beauchet O, Annweiler C, Dubost V, Allali G, Kressig RW, Bridenbaugh $\mathrm{S}$, et al. Stops walking when talking: a predictor of falls in older adults? Eur J Neurol. 2009;16(7):786-95.

83. Hofheinz M, Mibs M. The prognostic validity of the Timed Up and Go Test with a dual task for predicting the risk of falls in the elderly. Gerontol Geriatr Med. 2016;2:2333721416637798.

84. Punt M, Bruijn SM, Wittink H, van de Port IG, Wubbels G, van Dieen JH. Virtual obstacle crossing: reliability and differences in stroke survivors who prospectively experienced falls or no falls. Gait Posture. 2017;58:533-8.

85. Sun W, Watanabe M, Hirota C, Tanimoto Y, Kono R, Takasaki K, et al. Obstacle-negotiating gait and related physical measurement indicators for the community-dwelling elderly in Japan. Arch Gerontol Geriatr. 2010;50(3):e41-5.

86. Taylor MJ, Gunther J. Standardized walking obstacle course: reliability and validity of a functional measurement tool. J Neurol Phys Ther. 1997;21:167.

87. Aravind G, Lamontagne A. Effect of visuospatial neglect on spatial navigation and heading after stroke. Ann Phys Rehabil Med. 2018;61(4):197-206.

88. Sjöholm H, Hägg S, Nyberg L, Rolander B, Kammerlind AS. The Cone Evasion Walk test: reliability and validity in acute stroke. Physiother Res Int. 2019;24(1):e1744.

89. Spychala MS, Honarpisheh P, McCullough LD. Sex differences in neuroinflammation and neuroprotection in ischemic stroke. J Neurosci Res. 2017;95(1-2):462-71.

90. Sohrabji F, Park MJ, Mahnke AH. Sex differences in stroke therapies. J Neurosci Res. 2017;95(1-2):681-91.

91. Persson CU, Kjellberg S, Lernfelt B, Westerlind E, Cruce M, Hansson PO. Risk of falling in a stroke unit after acute stroke: The Fall Study of Gothenburg (FallsGOT). Clin Rehabil. 2018;32(3):398-409. 
92. Larén A, Odqvist A, Hansson PO, Persson CU. Fear of falling in acute stroke: The Fall Study of Gothenburg (FallsGOT). Top Stroke Rehabil. 2018;25(4):256-60.

93. Herrmann N, Black SE, Lawrence J, Szekely C, Szalai JP. The Sunnybrook Stroke Study: a prospective study of depressive symptoms and functional outcome. Stroke. 1998;29(3):618-24.

94. Byrnes J, Miller D, Schafer W. Gender differences in risk taking: a meta-analysis. Psychol Bull. 1999;125:367-83.

95. Rikli RE, Jones CJ. Development and validation of criterionreferenced clinically relevant fitness standards for maintaining physical independence in later years. Gerontologist. 2013;53(2):255-67.

96. Ganz DA, Higashi T, Rubenstein LZ. Monitoring falls in cohort studies of community-dwelling older people: effect of the recall interval. J Am Geriatr Soc. 2005;53(12):2190-4.

97. Robertson MC, Campbell AJ, Herbison P. Statistical analysis of efficacy in falls prevention trials. J Gerontol A Biol Sci Med Sci. 2005;60(4):530-4.

98. Foster EJ, Barlas RS, Wood AD, Bettencourt-Silva JH, Clark AB, Metcalf AK, et al. A history of falls is associated with a significant increase in acute mortality in women after stroke. J Clin Neurol. 2017;13(4):411-21.

99. Riksstroke. Stroke och TIA: Riksstrokes årsrapport 2016 [Internet]. Riksstroke; 2017 [cited 20210105]. Available from: https://www.riksstroke.org/wpcontent/uploads/2017/o7/RiksstrokeÅrsrapport2016_slutversion. pdf.

100. Brott T, Adams HP Jr, Olinger CP, Marler JR, Barsan WG, Biller J, et al. Measurements of acute cerebral infarction: a clinical examination scale. Stroke. 1989;20(7):864-70.

101. Alenazi AM, Alshehri MM, Alothman S, Rucker J, Dunning K, D'Silva LJ, et al. Functional reach, depression scores, and number of medications are associated with number of falls in people with chronic stroke. PM R. 2018;10(8):806-16. 
102. Richardson K, Bennett K, Kenny RA. Polypharmacy including falls risk-increasing medications and subsequent falls in communitydwelling middle-aged and older adults. Age Ageing. 2015;44(1):906.

103. Holden MK, Gill KM, Magliozzi MR. Gait assessment for neurologically impaired patients. Standards for outcome assessment. Phys Ther. 1986;66(10):1530-9.

104. Podsiadlo D, Richardson S. The timed "Up \& Go": a test of basic functional mobility for frail elderly persons. J Am Geriatr Soc. 1991;39(2):142-8.

105. Nasreddine ZS, Phillips NA, Bedirian V, Charbonneau S, Whitehead V, Collin I, et al. The Montreal Cognitive Assessment, MoCA: a brief screening tool for mild cognitive impairment. J Am Geriatr Soc. 2005;53(4):695-9.

106. Wilson B, Cockburn J, Halligan P. Development of a behavioral test of visuospatial neglect. Arch Phys Med Rehabil. 1987;68(2):98-102.

107. Dong Y, Venketasubramanian N, Chan BP, Sharma VK, Slavin MJ, Collinson SL, et al. Brief screening tests during acute admission in patients with mild stroke are predictive of vascular cognitive impairment 3-6 months after stroke. J Neurol Neurosurg Psychiatry. 2012;83(6):580-5.

108. Salvadori E, Pasi M, Poggesi A, Chiti G, Inzitari D, Pantoni L. Predictive value of MoCA in the acute phase of stroke on the diagnosis of mid-term cognitive impairment. J Neurol. 2013;260(9):2220-7.

109. Royall DR, Mahurin RK, Gray KF. Bedside assessment of executive cognitive impairment: the executive interview. J Am Geriatr Soc. 1992;40(12):1221-6.

110. Friedman PJ. The Star Cancellation Test in acute stroke. Clin Rehabil. 1992;6:23-30.

111. Bailey MJ, Riddoch MJ, Crome P. Evaluation of a test battery for hemineglect in elderly stroke patients for use by therapists in clinical practice. NeuroRehabilitation. 2000;14(3):139-50.

112. Bailey MJ, Riddoch MJ, Crome P. Test-retest stability of three tests for unilateral visual neglect in patients with stroke: Star 
Cancellation, Line Bisection, and the Baking Tray Task.

Neuropsychol Rehabil. 2004;14(4):403-19.

113. Baetens T, De Kegel A, Calders P, Vanderstraeten G, Cambier D.

Prediction of falling among stroke patients in rehabilitation. $\mathrm{J}$

Rehabil Med. 2011;43(10):876-83.

114. Innes E. Handgrip strength testing: a review of the literature. Aust Occup Ther J. 1999;46(3):120-40.

115. Bertrand AM, Fournier K, Wick Brasey MG, Kaiser ML, Frischknecht R, Diserens K. Reliability of maximal grip strength measurements and grip strength recovery following a stroke. J Hand Ther. 2015;28(4):356-62; quiz 63.

116. Vermeulen J, Neyens JC, Spreeuwenberg MD, van Rossum E, Hewson DJ, de Witte LP. Measuring grip strength in older adults: comparing the grip-ball with the Jamar dynamometer. J Geriatr Phys Ther. 2015;38(3):148-53.

117. Peters MJ, van Nes SI, Vanhoutte EK, Bakkers M, van Doorn PA, Merkies IS, et al. Revised normative values for grip strength with the Jamar dynamometer. J Peripher Nerv Syst. 2011;16(1):47-50.

118. Jones CJ, Rikli RE, Beam WC. A 30-s chair-stand test as a measure of lower body strength in community-residing older adults. Res Q Exerc Sport. 1999;70(2):113-9.

119. Lyders Johansen K, Derby Stistrup R, Skibdal Schjott C, Madsen J, Vinther A. Absolute and relative reliability of the Timed 'Up \& Go' test and '3osecond Chair-Stand' test in hospitalised patients with stroke. PloS One. 2016;11(10):e0165663.

120. Hill KD, Bernhardt J, McGann AM, Maltese D, Berkovits D. A new test of dynamic standing balance for stroke patients: reliability, validity and comparison with healthy elderly. Physiotherapy Canada. 1996;48(4):257-62.

121. Mackintosh SF, Hill KD, Dodd KJ, Goldie PA, Culham EG. Balance score and a history of falls in hospital predict recurrent falls in the 6 months following stroke rehabilitation. Arch Phys Med Rehabil. 2006;87(12):1583-9.

122. Mehrholz J, Wagner K, Rutte K, Meissner D, Pohl M. Predictive validity and responsiveness of the functional ambulation category 
in hemiparetic patients after stroke. Arch Phys Med Rehabil. 2007;88(10):1314-9.

123. Flansbjer UB, Holmback AM, Downham D, Patten C, Lexell J. Reliability of gait performance tests in men and women with hemiparesis after stroke. J Rehabil Med. 2005;37(2):75-82.

124. Mahoney FI, Barthel DW. Functional evaluation: the Barthel Index. Md State Med J. 1965;14:61-5.

125. Duffy L, Gajree S, Langhorne P, Stott DJ, Quinn TJ. Reliability (inter-rater agreement) of the Barthel Index for assessment of stroke survivors: systematic review and meta-analysis. Stroke. 2013;44(2):462-8.

126. Hsueh IP, Lee MM, Hsieh CL. Psychometric characteristics of the Barthel activities of daily living index in stroke patients. J Formos Med Assoc. 2001;100(8):526-32.

127. Uyttenboogaart M, Stewart RE, Vroomen PC, De Keyser J, Luijckx GJ. Optimizing cutoff scores for the Barthel index and the modified Rankin scale for defining outcome in acute stroke trials. Stroke. 2005;36(9):1984-7.

128. Granger CV, Albrecht GL, Hamilton BB. Outcome of comprehensive medical rehabilitation: measurement by PULSES profile and the Barthel Index. Arch Phys Med Rehabil. 1979;60(4):145-54.

129. Koo TK, Li MY. A guideline of selecting and reporting intraclass correlation coefficients for reliability research. J Chiropr Med. 2016;15(2):155-63.

130. Duncan PW, Propst M, Nelson SG. Reliability of the Fugl-Meyer assessment of sensorimotor recovery following cerebrovascular accident. Phys Ther. 1983;63(10):1606-10.

131. Leddy AL, Crowner BE, Earhart GM. Utility of the Mini-BESTest, BESTest, and BESTest sections for balance assessments in individuals with Parkinson disease. J Neurol Phys Ther. 2011;35(2):90-7.

132. Lindmark B. Evaluation of functional capacity after stroke with special emphasis on motor function and activities of daily living. Scand J Rehabil Med Suppl. 1988;21:1-40. 
133. Pigman J, Reisman DS, Pohlig RT, Jeka JJ, Wright TR, Conner BC, et al. Posterior fall-recovery training applied to individuals with chronic stroke: A single-group intervention study. Clin Biomech (Bristol, Avon). 2020;82:105249.

134. Pigman J, Reisman DS, Pohlig RT, Jeka JJ, Wright TR, Conner BC, et al. Anterior fall-recovery training applied to individuals with chronic stroke. Clin Biomech (Bristol, Avon). 2019;69:205-14.

135. Chayasit P, Hollands K, Hollands M, Boonsinsukh R. Immediate effect of voluntary-induced stepping response training on protective stepping in persons with chronic stroke: a randomized controlled trial. Disabil Rehabil. 2020:1-8.

136. Mansfield A, Wong JS, Bryce J, Knorr S, Patterson KK. Does perturbation-based balance training prevent falls? Systematic review and meta-analysis of preliminary randomized controlled trials. Phys Ther. 2015;95(5):700-9.

137. Li K, Malhotra PA. Spatial neglect. Pract Neurol. 2015;15(5):333-9.

138. Hofheinz M, Schusterschitz C. Dual task interference in estimating the risk of falls and measuring change: a comparative, psychometric study of four measurements. Clin Rehabil. 2010;24(9):831-42.

139. Guadagnin EC, da Rocha ES, Duysens J, Carpes FP. Does physical exercise improve obstacle negotiation in the elderly? A systematic review. Arch Gerontol Geriatr. 2016;64:138-45.

140. Weerdesteyn V, Rijken H, Geurts AC, Smits-Engelsman BC, Mulder $\mathrm{T}$, Duysens J. A five-week exercise program can reduce falls and improve obstacle avoidance in the elderly. Gerontology. 2006;52(3):131-41.

141. Nyberg L, Gustafson Y. Fall prediction index for patients in stroke rehabilitation. Stroke. 1997;28(4):716-21.

142. Hubbard RE. Sex differences in frailty. Interdiscip Top Gerontol Geriatr. 2015;41:41-53.

143. Sinanović O, Raicevic B, Brkic M, Hajdarbegovic E, Zukić S, Kojić B, et al. Falls in hospitalized acute stroke patients. Med Arh. 2012;66(1):33-4. 
144. Davenport RJ, Dennis MS, Wellwood I, Warlow CP. Complications after acute stroke. Stroke. 1996;27(3):415-20.

145. Fiorelli M, Toni D, Bastianello S, Sacchetti ML, Sette G, Falcou A, et al. Computed tomography findings in the first few hours of ischemic stroke: implications for the clinician. J Neurol Sci. 2000;173(1):10-7.

146. Cummings SR, Nevitt MC, Kidd S. Forgetting falls. The limited accuracy of recall of falls in the elderly. J Am Geriatr Soc. 1988;36(7):613-6.

147. Portney LG, Watkins MP. Foundations of clinical research: applications to practise. 3rd ed. Philadelphia, PA.: FA Davis Company; 2015.

148. Wasserstein RL, Lazar NA. The ASA's statement on p-values: context, process, and purpose. Am Stat. 2016;70(2):129-33. 


\section{Papers}

The papers associated with this thesis have been removed for copyright reasons. For more details about these see:

http://urn.kb.se/resolve?urn=urn:nbn:se:liu:diva-173531 
Linköping University Medical Dissertations No. 1770, 2021

Division of Prevention, Rehabilitation and Community Medicine

Department of Health, Medicine and Caring Sciences

Linköping University, Sweden

www.liu.se

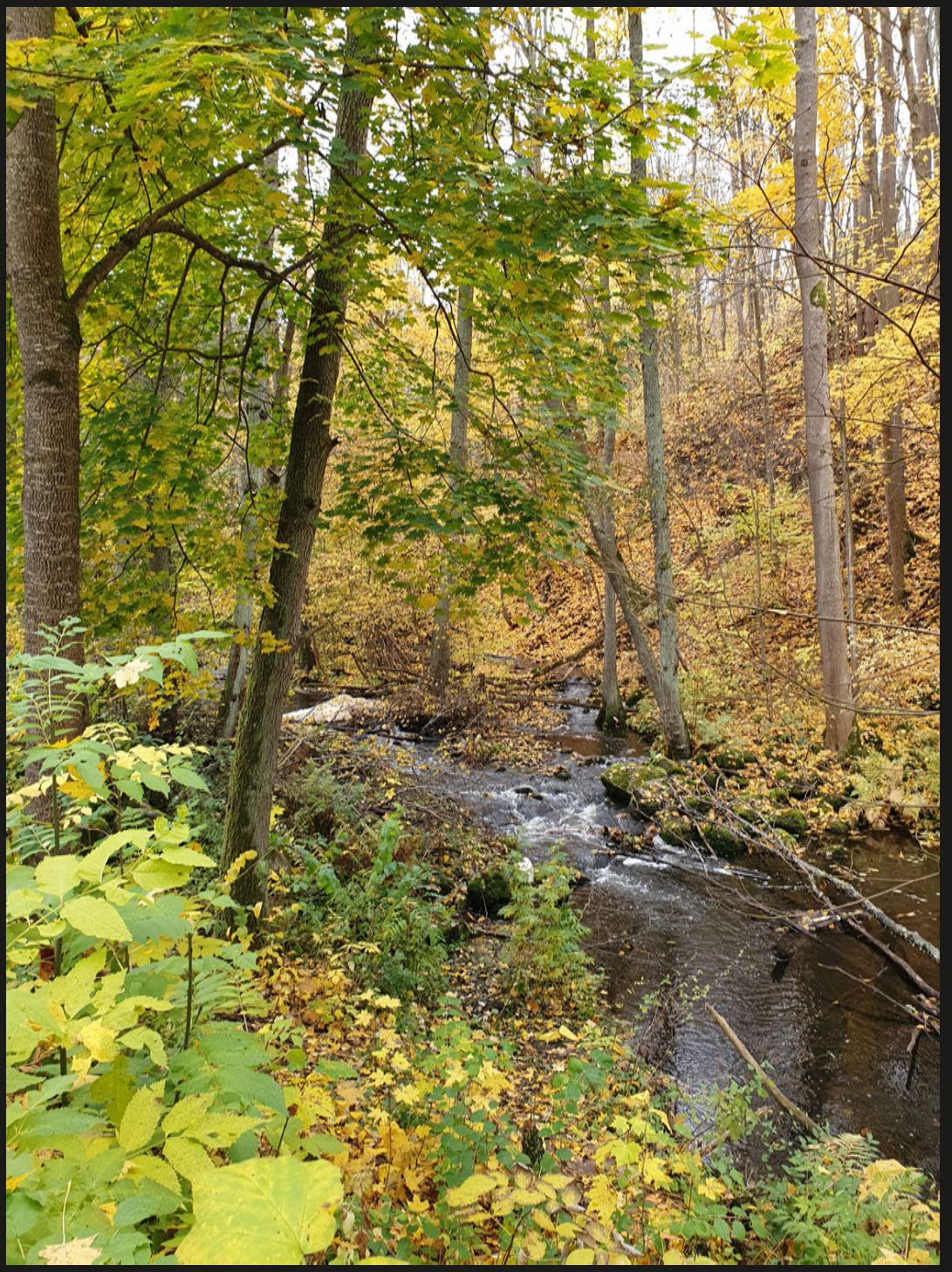

